Portland State University

PDXScholar

1976

\title{
Exploring collaboration: a program evaluation of a mental health intervention in a public elementary school
}

Joy Rhodes

Portland State University

Follow this and additional works at: https://pdxscholar.library.pdx.edu/open_access_etds

Part of the Mental Disorders Commons, and the Student Counseling and Personnel Services Commons

Let us know how access to this document benefits you.

\section{Recommended Citation}

Rhodes, Joy, "Exploring collaboration: a program evaluation of a mental health intervention in a public elementary school" (1976). Dissertations and Theses. Paper 2368.

https://doi.org/10.15760/etd.2365

This Thesis is brought to you for free and open access. It has been accepted for inclusion in Dissertations and Theses by an authorized administrator of PDXScholar. Please contact us if we can make this document more accessible: pdxscholar@pdx.edu. 
AN ABSTRACT OF THE THESIS OF Joy Rhodes for the Master of Social Work presented November 24, 1976.

Title: Exploring Collaboration: A Program Evaluation of a Mental Health Intervention in a Public Elementary School

APPROVED BY MEMBERS OF THE THESIS COMMITTEE:

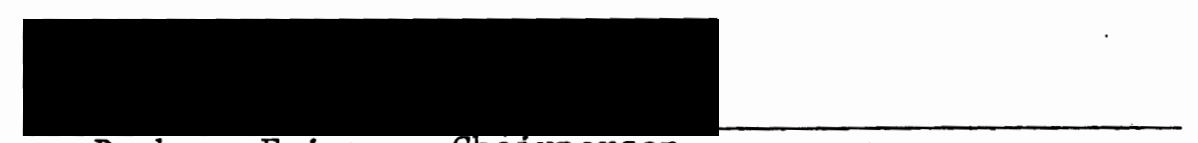

Barbara Friesen, Chairperson

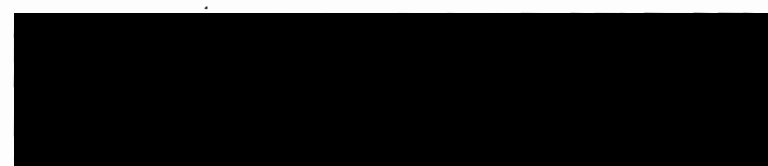

Nancy Kogjloff

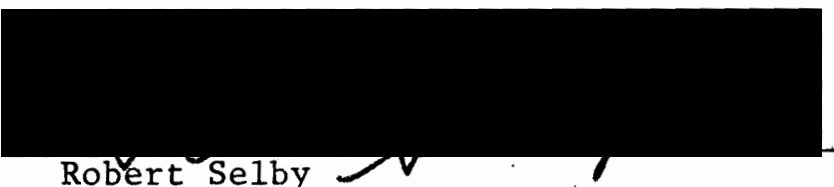

The purpose of this evaluative study was to develop and implement a program evaluation design for a model of early mental health intervention to primary grade level classrooms in a public elementary school. The design reflects a formative evaluation study, providing information for current and future programming and is manageable to implement, thus facilitating longitudinal data collection.

This therapeutic model of classroom intervention stresses the integration of childrens' social, emotional and intellectual development and proposes a collaborative approach between therapist and educator. Levels of intervention for collaborators include (1) children 
identified as requiring therapeutic approaches to social-emotional difficulties experienced in the classroom, (2) all children in the classroom and, (3) the classroom milieu. The overall goal is to promote optimal growth at all levels.

The program evaluation design includes a format for monitoring the service delivery system of the model and to identify procedural and collaborative discrepancies. Information regarding collaborators' perceptions of identified children is collected from written intervention plans, Assessment of the frequency and nature of peer interactions was accomplished in this study through an observational technique in the classrooms. A teacher attitude questionnaire was administered at the end of the school year to obtain information about teacher receptivity of the program and suggestions for future restructuring of service delivery. Additional data was collected from the school's files regarding teachers' rating of children as to their current and anticipated social-emotional and learning difficulties.

The results of the information collected reflect a general awareness, acceptance and support of the collaborative approach on the part of teachers participating in the program. As a direct result of the evaluation process, several issues of programming were raised and proposed for future decision-making. 
EXPLORING COLLABORATION

A Program Evaluation of a Mental Health Intervention

in a Public Elementary School

by

JOY RHODES

A thesis submitted in partial fulfillment of the requirements for the degree of

MASTER OF SOCIAL WORK

Portland State University

1976 
TO THE OFFICE OF GRADUATE STUDIES AND RESEARCH:

The members of the Committee approve the thesis of Joy Rhodes presented November 24, 1976.
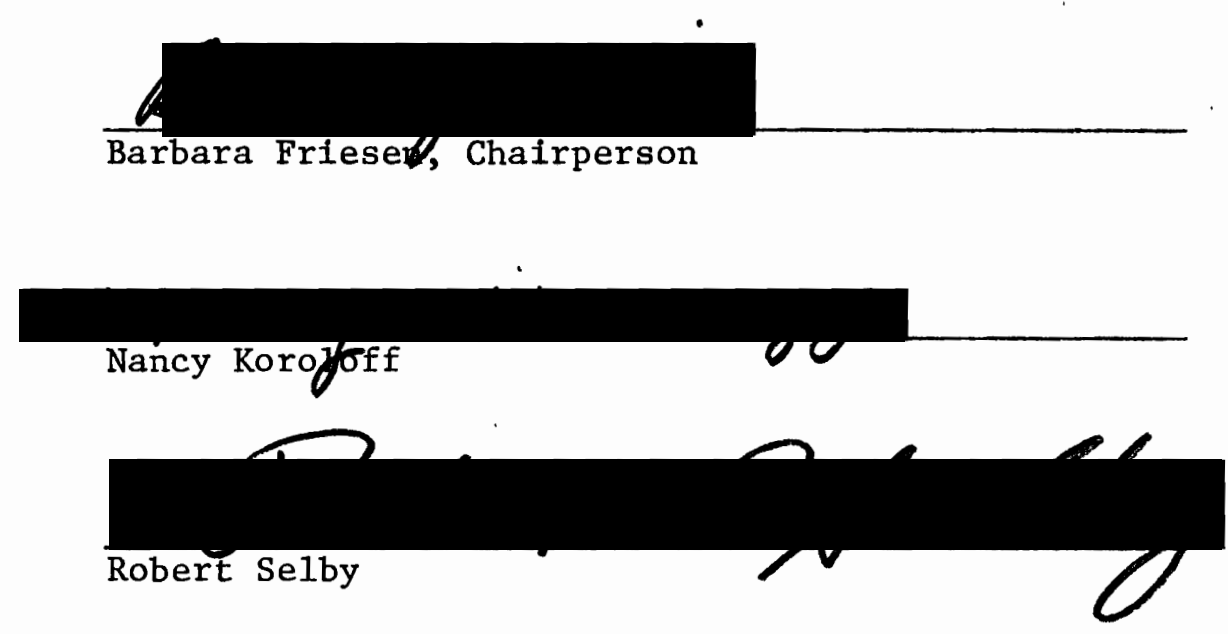

APPROVED :

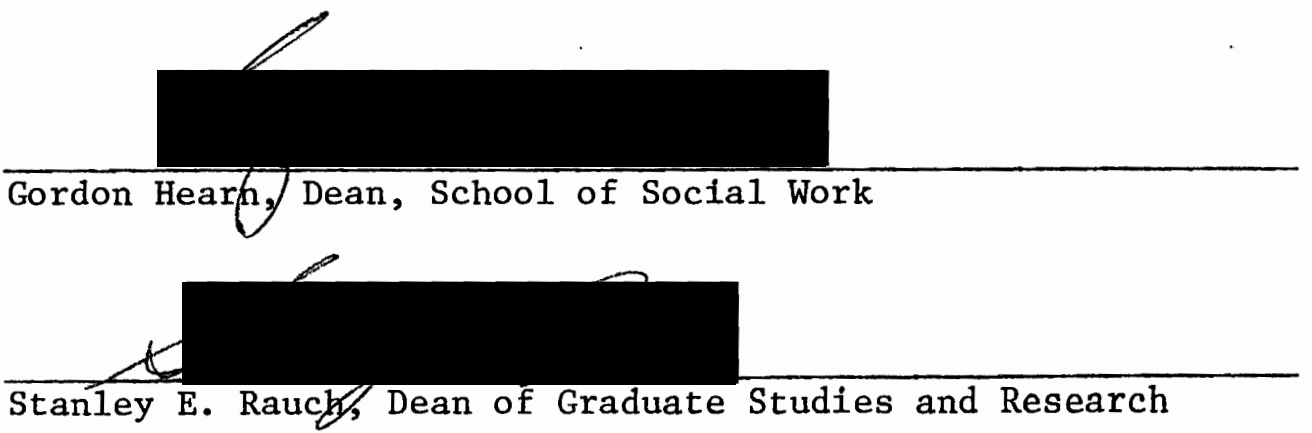




\section{ACKNOWLEDGEMENTS}

There were many participants who were instrumental to this program evaluation--children, teachers, friends, mental health professionals in the community--however, the critical contributions of a few individuals require acknowledgement.

To Barbara Friesen, ACSW, Supervisor of the Community Team and Chairperson of this thesis committee, who gave continual support and insight with clarity, skill and understanding, I wish to express my personal gratitude and sincere appreciation; also to Nancy Koroloff MSW, for her technical assistance and advise and to Robert Selby, Ed.D. for his cooperation and helpfulness.

A special thanks goes to Betty Glantz, who served as co-observer in the classrooms and to Tina Cunningham and Chris Lehl for their technical assistance in the preparation of the document.

This evaluation study was supported by an NIMH training grant made available to the evaluator through the Community Mental Health Project at Portland State University.

The very great resource of time was generously extended to the evaluator by the staff at both Gregory Heights Elementary School and the Children's Psychiatric Day Treatment Center. In addition, the Center provided incalculable support through various resources. These gifts are gratefully acknowledged. 
TABLE OF CONTEN?S

PAGE

ACKNOWLEDGMENTS . . . . . . . . . . . . . . . . . $1 i i$
LIST OF TABLES . . . . . . . . . . . . . . . . . vili
LIST OF FIGURES . . . . . . . . . . . . . . . . . ${ }^{x}$

\section{CHAPTER}

I. INTRODUCTION . . . . . . . . . . . . . . . . . 1

II REVIEW OF THE LITERATURE . . . . . . . . . . . . . . 3

School Mental. Heal th Developments . . . . . . . 3

Early Identification and Prevention

Importance of Classroom Milieu

School. Mental Health Consultation

Program Evaluation . . . . . . . . . . . .

Concept of Program Evaluation

Prevention Evaluation

III

DEVELOPMENT OE PROGRAM EVALUATION DESIGN • • • • • •

History of Model Development . . . . . . . •

Description of Community Team Program

Program Background.

Evaluation of the First Program Phase

Goals and Objectives Development . . . . . . .

Prjoritizing objectives

IV METHODS AND TECHNTQUES . . . . . . . . . . . . . •

Monitocing Instrument". . . . . . . . . . . .

Description of Goal I

Description of the Instrument

Administration of the Instrument 
Description of the Intervention Plans

Description of Collaboration Discrepancy

Inventory

Description of Monitoring Discrepancy

Inventory

Description of Process Development Scale

Peer Interaction Inventory .......... 53

Objective of Observation Technique

Selection of the Instrument

Description of the Instrument

Revisions of the Instrument

Preparation of the Instrument

Description of Administration

Teacher Attitude Questionnaire ........ 63

Development of the Questionnaire

Administration of the Questionnaire

Identified Children Ratings . . . . . . . 65

Description of the Ratings Procedure

Monitoring Report

Number of Identified Children

Community Team Process Development

Information from Intervention Plans

Monitoring Discrepancies

Collaboration Discrepancies

Logistica1 Difficulties

Peer Interaction Inventory

Agreement Rate

Frequency Rates

Percentages

Ratios

Discussion of the Instrument

Teacher Attitude Questionnaire

Awareness of Methods

Most Important Methods

Most Effective Community Team Approach

Conception of Community Team Role

Probe on Collaborative Process

Positive Contributions 


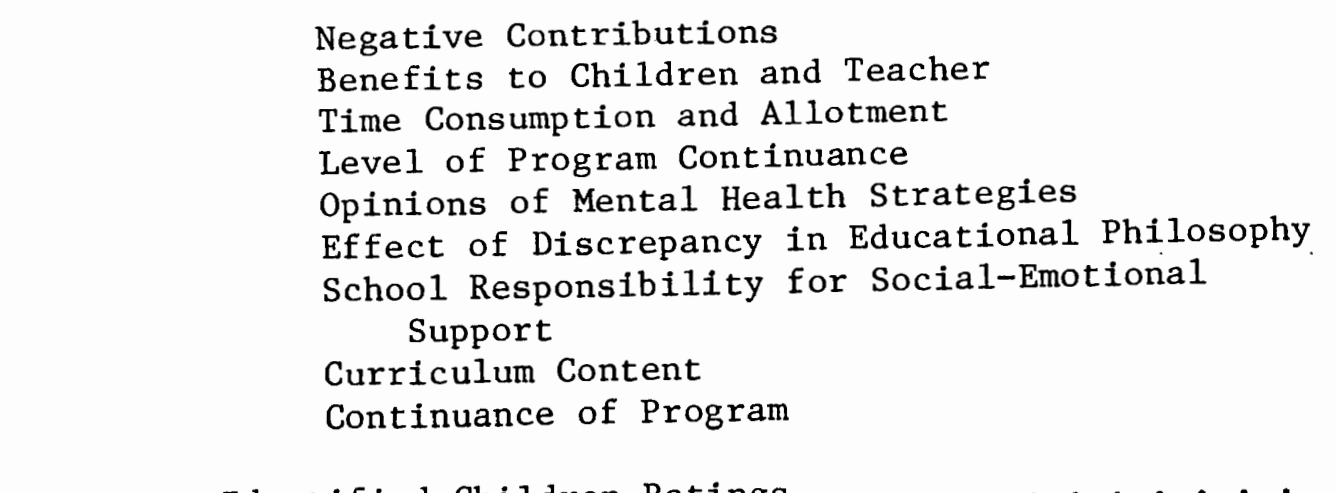

Identified Children Ratings . . . . . . . . 110

VI CONCLUSIONS AND RECOMMENDATIONS . . . . . . . . . . 113

Monitoring . . . . . . . . . . . . 113

Peer Interaction Inventory . . . . . . . . . 114

Teacher Attitude Questionnaire . . . . . . 115

Identified Children Ratings . . . . . . . . 118

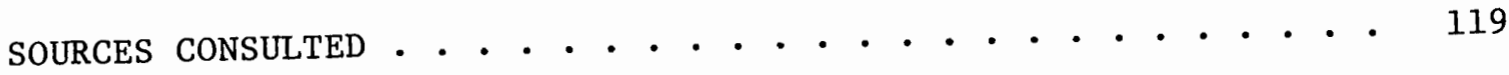

APPENDICES :

APPENDIX A: GOALS AND OBJECTIVES FOR IN-SCHOOL PROGRAM

OF COMMUNITY TEAM . . . . . . . . . 123

APPENDIX B: INTERVENTION PLAN . . . . . . . . . . 126

APPENDIX C: MONITORING INSTRUMENT . . . . . . . . . 128

APPENDIX D: MONITORING DISCREPANCY INVENTORY . . . . . . . 131

APPENDIX E: COLLABORATION DISCREPANCY INVENTORY . • • • 132

APPENDIX F: PROCESS DEVELOPMENT SCALE . . . . . . . . 133

APPENDIX G: INSTRUCTIONS FOR CODING . . . . . . . . . 134

APPENDIX H: PEER INTERACTION INVENTORY . . . . . . . . . 135

APPENDIX I: PEER INTERACTION INVENTORY DEFINITIONS . • • 136 
APPENDTX J: TEACHER ATTITUDE QUESTTONNAIRE . . . . . . . 137

APPENDIX K: GUIDANCE/EXTRA SERVICES SCREENING . . . . . 145

APPENDIX L: IDENTIFIED CHILDREN RATING CHART . . . . . . 146 


\section{LIST OF TABLES}

TABLE

PAGE

I January Instances of Discrepancies Regarding Decision

to Write Intervention Plan.......... 69

II Process Development Scale . . . . . . . . . 71

III Frequency of Monitoring Discrepancies . . . . . . . 74

IV Frequency of Monitoring Discrepancies by Procedure . . 77

V Frequency of Collaboration Discrepancies . . . . . 78

VI Frequency of Community Team Member Under-reporting

Provision of Collaborative Services . . . . . 79

VII Frequency of Observed Interactions . . . . . . . . 82

VIII Percentages of Observed Interactions . . . . . . . . 84

IX Ratio of Interactive: Non Interactive Behaviors . . . 85

X Ratio of Cooperative: Non Interactive Behavior . . . 86

XI Awareness of Intervention Methods . . . . . . . . 94

XII Most Important Methods To Be Continued . . . . . . . 95

XIII Most Effective Approach . . . . . . . . . . . 96

XIV Perceived Community Team Function In C1assroom . . . . 97

XV Teacher Perception of Role in Relation to Community Team - 98

XVI Best Description of Community Team Approach . . . . . 99

XVII How Much Work Required By Community Team . . . . . . 101

XVIII At What Level Should Program Be Continued? . . . . . 104

XIX To What Extent Should Children Remain In Classroom

Provided With Special Support Services . . . . . 105 
TABLE

PAGE

XX To What Extent Is Early Identification Possible? . . 105

XXI To What Extent Can Community Team Methods Effect

Prevention? .................. 106

XXII Can Community Team Member and Teacher With Differing

Philosophies Work Together Effectively? . . . . 107

XXIII Should Social-Emotional Content Be Part of

Curriculum? . . . . . . . . . . . . . 108

XXIV Would Social-Emotional Curriculum Compete With

Academic Program? . . . . . . . . . . . 109

XXV Would Social-Emotional Curriculum Complement

Academic Program? . . . . . . . . . . . 109

XXVI Would Social-Emotional Curriculum Be Integrated with

Academic Program? . . . . . . . . . . 110

XXVII Frequency and Nature of Identified Children Rating

Change During One Year . . . . . . . . . . 111 


\section{LIST OF FIGURES}

FIGURE

PAGE

1 Levels of Intervention. . . . . . . . . . . 36

2 Goals of the Community Team ... . . . . . . . . 40

3 Categories of objectives Under Goal II . . . . . . 43

4 Graphical Representation of the Development of the Process . . . . . . . . . . . 73 
Dedicated to

Jerry and Norm 


\section{CHAPTER I}

\section{INTRODUCTION}

This paper is a description and report of a program evaluation which was developed and conducted for the Community Team program of the Children's Psychiatric Day Treatment Center, University of Oregon Health Sciences Center, Portland, Oregon. The Community Team program is a collaborative project, operated in conjunction with classroom teachers in the primary grade levels at Gregory Heights Elementary School in northeast Portland.

The program began operation at Gregory Heights Elementary School in January 1975. The evaluator was introduced to the staff in the spring of that year, the evaluation study was designed in the summer and fall. The program evaluation was implemented in January 1976.

The assignment for the Community Team program evaluation included three objectives: 1) to develop an evaluation design in cooperation with the members of the Community Team staff, 2) to implement the evaluation and to concurrently-make such revisions and adaptations which were dictated by the process and, 3) to include within the evaluation design outcome information which could be utilized in assessing long term effectiveness, i.e. prevention.

The third objective contained the requirement that the evaluation be designed to be as manageable as possible. To ersure that the data could be collected by existing personnel over a period of several 
years, the evaluator needed to consider the feasibility of techniques applied to the program evaluation process. The manageability of the evaluation design was a perennial guideline in the developmental stages.

In addition to the operational objectives stated above, there were expectations which were shared by the Community Team supervisor and the program evaluator that the experience of an evaluation would have an educational benefit for all those involved in the Community Team program implementation. The hope was that clarification of goals and the systematic communication of objective information would increase program effectiveness and enhance individual participant's understanding of the program's process and purpose.

The following chapters describe the theoretical and design development, the administration and results of implementation and the subsequent conclusions and recommendations of the study. 


\section{CHAPTER II}

\section{REVIEW OF THE LITERATURE}

The literature search in this study focuses on a dual emphasis of research. Not only was a theoretical investigation of the consultation-collaboration spectrum critlcal to an understanding of the program evaluated, but the process of program evaluation warranted at least a descriptive overview of the literature. For this reason, the chapter is divided into two sections. The first section focuses on collaboration as a model and its significance within the perspective of school mental health programming developments. The second section deals with concepts and purposes of program evaluation and some of the principles which underlie its operation.

\section{SCHOOL MENTAL HEALTH DEVELOPMENTS}

The expanded role and need of mental health professionals within the environment of education has received impetus from an increased recognition of the interdependence of the educational and therapeutic systems. Both systems have experienced changes in the last twenty years which suggest and require a common commitment and a redefinition of their traditional roles. One catalyst for change has been legislative decisions guaranteeing an education for every child and expanding the definition of handicap to include the emotionally disturbed child. 
Attempts to provide education for every child despite his handicap have created an expectancy that the school must reach not only the group of normal children but also the exceptional children of all kinds. These goals have provoked greater efforts toward the individualization of classroom practices, increased use of psychological diagnostic tools, and led to a widespread development of special education. (Hollister, 1959.)

The increased use and sophistication of psychological determinations and the emergence of special service classrooms, while providing partial answers for some children have not solved the more comprehensive problem of education for all. These partial solutions have, in themselves, accentuated difficulties connected with labeling, stigmatizing and segregating the exceptional child, causing concern among educators and mental health professionals about the long range effects of these special services. Not only are there potential serious hazards for the children, but a split level delivery system does not integrate the essential skills of the educational and therapeutic systems in directing them toward all children who stand to benefit.

Perhaps the most profound basic trend at work that is affecting mental health programming in the classroom is occurring as a part of a shift of emphasis in the basic assumptions underlying the whole mental health field. Today, more comprehensive mental health programs tend to include and balance the availability of resources for interpersonal therapy with facilities for social rehabilitation or attempts to control the impact of social stresses. This broadening of assumptions is not only creating new concepts of the role of the mental hospital and new patterns in the treatment of mental illness, but, most of all, it is motivating a remarkable expansion of community mental health efforts in prevention, health promotion, treatment and rehabilitation. (Hollister, 1959.)

The greater demands placed on the classroom teacher as a result of legislation widening the educational domain and the broader definition of the therapeutic function evidenced within the community mental health movement have extended the interface between educational and mental health professionals, requiring coordination and collaboration 
in the delivery of services. The demands for services to emerge from this interface center around broadly focused consultation, greater utilization of group work methodologies and increased involvement of parents, community agencies and resources. Additional services include extended teacher training in mental health practices, a wider interest in the evaluation process and increased emphasis on socialemotional curriculum development.

What has become increasingly apparent is that more is required of the classroom teacher and a wider repertoire of resources are being mobilized to assist him.

\section{Early Identification and Prevention}

The recommendations for service priorities reflect the awareness that extended possibilities exist when an interdisciplinary approach is effectively utilized. The emphasis on educational enrichment, involvement of community resources and curriculum policy change indicate a desire to increase preventive functions in school mental health. As the scope of the problem of education for all our children, regardless of their learning handicaps has become more clearly defined through legislative and diagnostic expansion, the importance of prevention can be understood as a strategy as well as a goal.

Studies have indicated that there will never be sufficient mental health professionals to give treatment to the children who need it...Prevention must concern us as one attack on this overwhelming problem. (Berlin, 1967).

"Research shows that a casework orientation dominates the school social work field," (Gottlieb, 1971) one of the helping professions involved in community mental health delivery.

Can it be that frequent preoccupation with the immediacy of the 
problematic situation has tended to render less effective our school's helping professionals whose legacies from the past embrace. a more comprehensive view? (Williams, 1976.)

The need to expand the traditional role of the mental health professional within the school, coupled with the increased demands for mental health competencies placed on our educational systems and in turn on the classroom teacher has resulted in educators and mental health professionals seeking to unite their knowledge and skills in the hopes of preventing serious learning disabilities in school children.

The first requirement in the attempt at preventing the development of serious social-emotional difficulties in school age children is that these children be identified early in their school career. A program involving teachers in identifying first graders indicated that early identification of children in schools can be accomplished. Evaluation of the effects of the program at the third grade level revealed,

rather convincingly that children can be designated at the first grade level as likely to experience later emotional problems and that, in fact, by the time they reach third grade, they are doing significantly less well as compared to others not so designated. The high correlation between the predictions made at first grade and the performance of the children at third grade was impressive. (Trost, 1968.)

While the process of identifying the child may effect the manner in which teachers relate to identified children, contributing to the measured outcome, the teachers' assessment of classroom children is an important indicator to investigate.

Most teachers are capable of early recognition of behavioral disturbances due to emotional factors, or of a child's inability to learn because of maturational lag, socio-cultural deprivation or manifestations of brain dysfunction. Studies of reliability of teachers' concerns and evaluations of a child's functioning in school with later diagnostic studies by mental health professionals have found teachers' observation very trustworthy. Thus, 
the early recognition of a child's problems in school is possible. (Berlin, 1967.)

The element of prevention has been a major theme of the community mental health movement over the past decade. President Kennedy set the tone for this theme of prevention in his message on mental illness and mental retardation, which he delivered to the Congress on February 5, 1963. This message intiated the legislative process which resulted in the passage of the Community Mental Health Act, nine months later. Speaking about the prevention of mental illness, the President stated that:

we must seek out the causes of mental illness and mental retardation and eradicate them. . For prevention is far more desireable for all concerned. It is far more economical and it is far more likely to be successful. Prevention will require both selected specific programs directed especially at known causes, and the general strengthening of our fundamental community, social welfare, and educational programs which can do much to eliminate or correct the harsh environmental conditions which often are associated with mental retardation and mental iliness.

There are three levels or types of prevention cited in the

literature: primary, secondary and tertiary prevention.

Primary prevention is focused on reducing the incidence of new cases in the population; secondary prevention is focused on reducing the number of existing cases in the population; and tertiary prevention is focused on reducing the duration or severity of long-term negative consequences or disabilities following treatment. (Broskowski and Baker, 1974.)

Mental health programming in schools has tended to focus on secondary prevention strategies, employing individual casework and consultation methodologies.

\section{Importance of Classroom Milieu}

The classroom milieu is one setting for mental health intervention, which provides opportunities for integrating methods of primary, 
secondary and tertiary prevention. A primary prevention approach within the classroom environment would seek to identify debilitating elements existing with the milieu, to systematically attempt to eliminate these factors and to systematically improve the climate for socialemotional and intellectual development. The focus of secondary preventive practice in the classroom would focus on treatment planning and direct service provision to identified children in the classroom with the goal being to ameliorate their learning disabilities and social-emotional difficulties. Tertiary preventive measures in the classroom would seek to sustain gains made in the treatment of identified children and to facilitate reintegration from special into regular classrooms. This preventive approach requires a epidemiological view of the problem.

The epidemiological or ecological model views the mental health system of an individual, of an organization or of a community as one system among many systems impacting upon the organism. These systems are interrelated and dynamic forces, continually effecting each other and containing overlapping properties. To effectuate the prevention of problems which emerge within an environment an understanding of the multiplicity of elements must be developed. It is not enough to gain a comprehension of a problem as it is manifested within an individual although this is one important aspect. The broader perspective of environmental influences must also be considered in order to understand and successfully intervene in the ecological context.

The environment or milieu, which includes the interaction between the child and the physical space, the equipment, materials, and the other people within that space, is both the arena and the process through which growth-producing change occurs. (Kling and Lohman, 1976.) 
If the classroom milieu is to be growth-producing in a positive way for the child the first dynamic to be understood by teacher and therapist interacting with the child is the effect which the classroom environment exercises on individual children and on the social interactions of all elements involved.

One of the two most important and influential environments for the child is the classroom in which he lives during a part of each day. Each child finds he has a position, or several positions, in this socio-emotional structure. This social structure becomes a dominant aspect of his total environment and of his total life situation. His position in this structure becomes a very important determinant of his personal mental health situation, and of his motivation and ability to participate in classroom interaction. (Lippitt and Gold, 1959.)

As the primary adult within the classroom environment, the authority and major decision-maker, the teacher exercises the most control over what occurs within the milieu.

The problem of mental hygiene in the classroom appears to be establishing a proper balance between (a) the intellectual requirements of classroom functioning versus the social-emotional requirements, and (b) between restricted freedom of action for students versus greater freedom of action. It is clear that the teacher sets the tone of mental hygiene in the classroom. The need for increased attention to the social-emotional aspects of classroom functioning is equally clear. (Flanders, 1959.)

\section{School Mental Health Consultation}

The practice of mental health consultation to teachers has been the primary method utilized by community mental health professional for the provision of social-emotional expertise to the public school. system. The model presented in this study departs from the traditional community mental health consultation model, although there are many similarities between consultation and collaboration. Definitions of both approaches are presented here, as well as their overlapping and unique properties. 
Consultation is used to denote a process of interaction between two professional persons-the consultant, who is a specialist, and the consultee, who invokes the consultants' help in regard to a current work problem with which he is having some difficulty and which he has decided is within the other's area of specialized competence. The work problem involves the management or treatment of one or more clients of the consultee, or the planning or implementation of a program to cater to such clients. (Caplan, 1970.)

Important elements of consultation include an interactional process between two professionals, the request for consultation on the part of the consultee, the existance of difficulty in case or program management from the perspective of the consultee and the transference of expertise from consultant to consultee, who maintains primary responsibility for client management. In a collaboration model the significant differences exist within the nature of the interactional process between professionals and the sharing of responsibility for the client (s).

Collaboration designates the functioning of a specialist who is called in by another professional worker to help deal with a specialized problem arising in the condition of the latter's client. The specialist is invited not merely to enlarge his colleague's understanding of the case and to advise on action but also to take part in implementing the action plan. The responsibility for the client is shared between the two colleagues, each of whom is expected by the other and by the client to carry out the treatment procedures that are appropriate to his professional role. (Caplan, 1970.)

The similarities between the two functions include the invitiation of the specialist (consultant) the definition of a problem existing in the management of clients and the elements of professional advising.

The discrepancies in terminology between the two approaches in referring to participants in the professional relationship should be noted. In the consultation relationship, the professional requesting assistance is referred to as the consultee and in the collaboration 
relationship the recipient of the specialist's services is termed a colleague. The latter term denotes an equal relationship between peers while the former suggests a relationship between an expert and a subordinate. The manner in which the partner is considered within the professional interaction will have a major influence on the nature of the relationship and the way the information is used.

The Oxford Dictionary provides more concise definitions of the two functions:

Consultation - the action of consulting or taking counsel together; deliberation, conference

Collaboration - to work in conjunction with another or others, to cooperate

These definitions delineate the distinction between deliberation within the consultation function and the implementation with collaboration. Collaboration refers to cooperative labor while consultation denotes discussion and planning.

In collaboration, unlike consultation, both parties are considered to be specialists, possessing expert knowledge which is critical to the other. The sharing of information regarding the work problem needs to be reciprocal in collaboration since both professionals carry direct service responsibilities and are held accountable for their respective functions by the client(s). Unlike the consultant, the collaborator has a direct professional relationship with the client(s). In a school mental health collaboration it is not only the educator who requires social-emotional information from the therapist. The therapist is equally dependent upon the educator for information regarding the child's intellectual functioning and development.

The definition of consultation utilized by the Children's Psychi- 
atric Day Treatment Center encompasses the focus of the milieu of the designated client (s).

Consultation A contract directed toward providing mental health consultation, coordination and planning services to other professionals agencies and interested persons. Services are directed toward improving the milieu of a specific client.

This definition is an interesting expansion of focus for it implies that the "client" of the consultee is not only a particular individual but includes the important elements and people interacting within the individual client's milieu. Within the collaborative relationship between a milieu therapist and a teacher where the therapist's skills are directed toward improving the milieu of an identified child, the teacher reflects a double identity, that of a colleague within the collaboration and that of "client" as an important participant in the environment of the identified child.

Goals and Methods of Mental Health Consultation: The consultant's task is to help consultees in one or more of the following ways:

1. To understand the mental health dimensions of their program and problems. This includes their own and other people's intra-psychic and interpersonal reactions and the appreciation of appropriate mental health alternatives for action, both in specific and general work situations.

2. To resolve interpersonal conflicts and program crisis on the job.

3. To acquire and improve skills in dealing with the mental health dimensions of their-work.

4. To research, plan, develop and evaluate programs related to mental health. (MacLennan, 1975.)

The goals of collaboration and consultation are essentially the same. The differences lie in the application of method. 
Perhaps the most important guideline is that the process is designed to promote collaboration with the goal of helping the (teacher) to do a better job with students who have mental health problems. (Ber1in, 1967)

The methodology employed to accomplish this simply stated goal can be explained in several steps which the consultant-collaborator performs in the process of providing services.

The first step is entry into the program and organization which has requested service and advice. The mental health specialist in the school needs to become familiar with the structure and problems of schools and teachers in general and to become sensitive to the idiosyncracies of the spectal milieu in which he will work.

The second step is for the mental health specialist to establish rapport with the teacher as a partner by getting to know the teacher as an individual.

The educator should experience the mental health consultant as a fellow human being whose task is to engage him as a collaborator, not in any way, as a patient or client. The consultant's projection of empathy with, and acceptance of, the teacher's feelings as both human and understandable should lead to collaboration in the service of the student. (Berlin, 1967)

The third step involves empathy with the difficulties of the teacher's role and a mutual sharing of concerns and frustrations. The mental health consultation needs to alloy feelings of anxiety and insecurities experienced by the teacher in attempts to work with disturbed children. Unless the educator's self-blame, tension, and feeling that he should be able to handle such problems without help are dealt with, he is not able to listen to and consider alternative courses of action. If the initiating steps are accomplished successfully, an open communication between the two professionals has been established. At this point the mental health specialist can begin to provide specific 
data about children and the classroom milieu which will help the teacher see the problem from an objective perspective. This communication should be a process of give and take and will continue indefinitely or until the collaboration is formally terminated.

The fifth step involves the planning, and implementing of alternative courses of action to be taken in the classroom. This process can and should involve experimentation and decision-making equally shared by therapist and educator.

Finally, Interest, concern and support for the teacher must be sustained throughout the duration of the plan and collaboration.

Inherent in all of these phases of consultation is the probability that much of the effect of the process results from the identification of the educator with the consultant, his attitudes, and his methods of interaction. The consultant's attitudes which are based on respect for the teacher as a potentially effective collaborator who can learn to use teaching and learning as a means of helping disturbed students, are of ten adopted by the teacher. Very clearly, teachers often act toward their difficult students as consultant's have acted toward them. (Berlin; 1967)

A crucial element common to both 'consultation and collaboration, vital to any cooperative relationship, is the process of renegotiation, clarifying each other's role and continually communicating information, ideas and concerns. Roles will change over time and new decisions will need to be made regarding the planned intervention and the nature of the working relationship. This interactional process between two professionals and between two human beings is a dynamic force, constantly in flux.

Communication will be necessary to develop and maintain professional consensus and congruence regarding the goals and methods of collaboration. This communication can be effective only if it is based on each profession's autonomous and realistic assessment of its own competence. (Granich, 1967) 
The ground rules and procedures for successful mental health consultation-collaboration abound within the literature. Ultimately, the effectiveness of the approach must be evaluated within the context of individual settings.

I cannot believe that any one approach is best. Because you deal with different people you have to use different approaches; you must choose the approach that is best for each individual person. And the only way you can discover what is the best approach is to get to know the person--child, parent or teacher. This demands, among other things, commitment, intuition and patience. In schools, as everwhere else, the human being supercedes any theory. (Abramson, 1974)

What has been described in this paper as the professional process of consultation and collaboration is not only common to both of these methodologies, it is a generic description of a problem-solving approach, employed by all helping professionals in all levels of service provision, be they, direct or indirect interventions. The process of problem identification and need assessment, data collection and analysis, treatment planning and implementation and evaluation is common to all service providers: therapists, educators, community organizers, planners and program evaluators. Crucial to the successful development and outcome of any professional intervention is the perception, flexibilfty and skill demonstrated by the individual practitioners involved in helping.

Some of the distinctions drawn between consultation and collaboration become artificial when viewed within the dynamic of experience. Within the exception of shared responsibility for direct service in collaboration almost all of the characteristics of consultation described in the literature apply equaliy to a collaborative approach. Many times within the literature the two terms are used interchangeably. 
Collaboration appears to be particularly appropriate to the educational setting, at least at this point when the demands placed in classroom teachers have been recently expanded to include social-emotional development. Teachers are required to perform innumerable tasks and quite simply require basic assistance. Collaboration enables mental health professionals to provide the additional service support educators request, as well as performing consultative functions.

The relationship between two professionals requires a delicate balance but the finesse and sensitivity necessary to develop successful collaboration is integral to any helping relationship. The initiation of effective communication involves congruence and empathy. Meeting the client where he is is a precept of community mental health practice. However, as with all precepts, the operationalizing of intent becomes complicated when the needs of individuals are considered situationally.

\section{PROGRAM EVALUATION}

Program evaluation, as conceptualized and practiced in this study, can be described by the generic problem-solving methodology. The same procedures which the collaborator or consultant must accomplish in establishing communication, planning strategies and providing services, may also be employed by the program evaluator in the performance of effective evaluation.

The program itself and the program staff are the evaluator's "clients" and meeting the client's needs for program information is the program evaluator's responsibility. To, meet the client where he is is not only a precept of clinical practice but is also crucial to 
the evaluation process if the information is to be collected and utilized in a meaningful way. The description of the development of the evaluation design in Chapter III will relate some of the experiences of evaluation practice. The concept program evaluation will be explored in this section.

\section{Concept of Program Evaluation}

Program evaluation and evaluative research in general has received recent interest in response to the need for accountability on the part of all social institutions or subsystems, to the society. which supports and perpetuates their existence. During the 1960's the domestic policies of Presidents Kennedy and Johnson spearheaded the proliferation of new programmatic approaches to social problems in a societal atmosphere of domestic turbulence and economic expansion. In the ensuing 1970 's social scientists and human resource practitioners are being called upon to justify the need for resource allocation within a socio-political climate of reassessment and economic restriction.

The current desire to judge the worthwhileness of (social) programs is but one aspect of modern society's belief that many of its social problems can be met most effectively through planned action based upon existing knowledge, including the design of even better solutions in step with advancing knowledge. (Suchman, 1974)

In defining evaluation, what is invariably encountered is a description of method as opposed to a generic conceptual expression which can encompass the theory and application of a common and widespread practice. At this time there is no theoretical framework for the practice of evaluation research upon which all involved in the field can agree. What is implied in the literature is that there is a need 
for the development of evaluation theory. The field of evaluation appears to be involved in a search for a definitive paradigm, that is,

a theoretical structure which is sufficiently unprecedented to attract an enduring group of adherents away from competing modes of scientific activity and simultaneously is sufficiently openended to leave all sorts of problems for the redefined group of practitioners to resolve. (Kuhn, 1970)

A theory of evaluation should:

(1) offer a conceptual scheme by which evaluation areas or problems are classified; (2) define the strategies including kinds of data, and means of analysis and reporting appropriate to each of the areas of the conceptual scheme; (3) provide systems of generalizations about the use of various evaluation procedures and techniques and their appropriateness to evaluation areas or problems. (Alkin, 1969)

The American Public Health Association defines evaluation as,

the process of determining the value or amount of success in achieving a predetermined objective. It includes at least the following steps: Formulation of the objective, identification of the proper criteria to be used in measuring success, determination and explanation of the degree of success, recommendations for further program activity.

This operational definition of the term "evaluation" designates

four distinct procedures which are sequential and interdependent. The first two procedures of formulating program objectives and identifying appropriate criteria of measurement describe the development of an evaluation design. The implementation of the research design is implied but not shared in the above definition. The determination of success and the recommendations for programming refer to the synthesis and analysis of data which essentially comprise the program evaluation report.

A formalized methodology of feedback, that is, the systematic collection and communication of information requested and in turn, received by a program, agency or system, has become a recognized need 
and institutionalized procedure in many human service delivery systems.

Program evaluation studies are basically of two types: evaluation of process and evaluation of outcome. The former study seeks to ascertain whether the planned program has been produced at the quality sought, has been delivered, and has been used. (Kahn, 1969)

The latter evaluative approach attempts to determine the value or efectiveness of aspects of the program or the program as a whole. IdealIy the request for information evolves from a knowledge of purpose and the results of a study are utilized in improvement and enhancement of program objectives.

Consideration of the decision-making function is as important to the evaluation study as the specific problem under investigation. The relationship of evaluation to policy-making is amplified in the following definition, preferred by the Center for the Study of Evaluation at the University of California at Los Angeles:

Evaluation is the process of ascertaining the decision areas of concern, selecting appropriate information, and collecting and analyzing information in order to report summary data useful to decision-makers in selecting among alternatives. (Alkin, 1969)

"Another useful distinction to understanding the purposes of evaluation is the difference between 'formative' and 'summative' evaluation." (Scriven, 1967) "Formative evaluation is designed to aid in the development of a program in its early phases. Sumative evaluation, on the other hand, judges the worth of a program after it has been in operation." (Weiss, 1972) The program evaluation reported in this paper can be considered primarily as an example of formative evaluation. The primary method used to collect formative information in this design was monitoring.

Monitoring consists of a process which allows for systematic collection of information about the program in accordance with the plan of action. The basic steps in the monitoring process are: 
1. Sequencing all key tasks by completion date (to this point a set of tasks were associated with a particular objective.)

2. Designating the strategic tasks which represent crucial decision points regarding the development and implementation of a program.

3. Identifying information inputs/outputs and routing for each program designated with a responsibility for accomplishing part or all of the task.

4. Creating and maintaining graphs and/or charts that show actual progress against planned progress.

(Koroloff, 1974)

Once collected, this information is communicated back to program managers and staff to be used in program decision-making.

\section{Prevention Evaluation}

Much has been written on the difficulties of evaluating primary prevention. Major obstacles have been stated succinctly by Bloom:

In a word, we are generally asked to evaluate the outcome of an undefined program having unspecified objectives on an often vaguely delineated recipient group whose level or variety of pathology is virtually impossible to assess, either before or after their exposure to the program. (Bloom, 1968)

What is particularly distressing about the limitations of prevention evaluation is the lack of sophisticated research methodologies to measure effectiveness of preventive programs which often possess multiple goals and complex organization. Another drawback within mental health is the prevalence of negative definitions of behavior, stated in terms of illness or deviance. Even when measureable behaviors are stated in positive terms, such as increased problem-solving skills, the difficulty of assessment extends to non-specified levels of desired attainment.

What might constitute improvement are positive definitions of the 'quality of 1ife' that are even more general than 'mental health' and may lend themselves to broad measurement and evaluation of program performance. In any case, we must begin to specify what evidence we will accept that the 'better 1 ife' is indeed in the process of becoming. (Broskowski and Baker, 1974) 
This 1iterature review has interwoven several themes of theory and related to various methods of community mental health service provision with a concentration on consultation-collaboration and program evaluation. The content of the evaluation study is an exploration of collaboration model. The form of exploration is evaluative research. The continuum connecting form and content is a generic problem-solving approach, utilized by Community Team members in their service delivery and by the Community Team program evaluator in design development and implementation. An important tension exists between the process and the product which can form a base from which to move toward integration. The appropriate and desireable synthesis is that the ends are contained and exemplified within the means. 
CHAPTER III

DEVELOPMENT OF PROGRAM EVALUATION DESIGN

The first step in constructing a program evaluation design is the formulation of program goals and objectives. When the evaluator was first introduced to the program, the Community Team had a sense of direction and some experience with the first phase of program operation. There was no formal goals and objectives statement at this time. To understand the context from which the formal statement evolved, it is first necessary to explain the development of the Community Team and the background of the program implementation.

\section{HISTORY OF MODEL DEVELOPMENT}

The Community Team collaboration model of in-classroom service provision evolved from the request from educators in the public school system for support services from mental health specialists to deal with school children identified as requiring therapeutic intervention. This request for therapeutic services grew out of increased demands placed on classroom teachers to provide education for all children, including the emotionally handicapped child. These increased demands on the educational system have occurred as a result of legislative decisions which have expanded the domain of the school's responsibility to include social-emotional development. Another concurrent factor, which has effected the enlargement of the defined population of mentally and emotionally disturbed children, is the increased sophistication of psycho- 
logical assessment technologies.

Acting in concert, legislative policy-making and psychological evaluations have extended the responsibility of our educational system, while neglecting to provide adequate resources and professional development services to regular classroom teachers who eventually experience the full burden of responsibility. The axiom that policy dictates practice is 1llustrated in this occurrence and the educational field of practice is currently struggling to fill the gap between the goal and the common reality. The practical difficulties involved in the process of bringing the reality closer to the ideal are intensified in light of limited existing resources.

Several approaches have been attempted by educators to meet the increased need. These approaches include special education classrooms, individual counseling and mental health consultation. All of these approaches were carefully considered in the development of the Community Team model. The advantages and disadvantages of these alternative models were explored and utilized as guidelines in creating a collaboration approach. The Community Team model of service delivery to identify children and classroom teachers sought to combine the best elements of the other models, while hopefully alleviating some of the problems which have been encountered in the past.

The proliferation of special education classrooms removes emotionally handicapped children from the regular classroom resulting in the reduction of stress in the regular classroom and the concentration of special services on the exceptional child. This model of intervention has been developed and implemented within the educational system and does not depend on professional mental health resources. In the special 
education approach the location of the problem has been shifted from one location, the regular classroom, to another, the special classroom. The shifting of location and responsibility to the special classroom, while temporarily relieving tension for the regular classroom teacher, provides him/her with no mental health resources for dealing with children remaining in the classroom. Another liability found in the spectal classroom approach is the problem of re-integrating the exceptional child back into the normal classroom.

The approach utilizing individual counseling usually involves the services of the mental health professional and shifts the location of responsibility outside of the educational system and places it with the therapeutic system. This process includes diagnosis of the child as emotionally disturbed and may imply that the child is inappropriate for the educational setting. An effect of psychological diagnosis may be the assumption that the "problem" is located within the individual child which may exclude the consideration of developing and improving the classroom milieu.

The practice of mental health consultation maintains the responsibility for the child with the educational system while providing the classroom teacher with advice and expertise. Successful consultation can be an extremely effective and efficient approach to problem-solving, however, in practice difficulties with this methodology have been identified. Teachers receiving mental health consultation have often felt the absence of active support since the consultant assumes no direct service responsibility for identified children. The advice offered by the mental health. specialist will frequently be interpreted by the teacher as prescriptive intervention strategy from an outsider who 
possesses no real understanding of the educational structure and requirements.

In developing a collaboration model, the Community Team proposal began by defining an approach to children within public school classrooms, who had been identified by teachers and mental health professionals as requiring therapeutic intervention. The identified child was selected as the primary level of intervention because this level was relatively easy to define and was in direct response to the educator's request for services. A difficulty which was articulated in this direct service approach was the complication of educational and therapeutic competition.

Competition between teacher and therapist for the child's time and attention was defined as a potential by-product of a direct therapeutic approach which did not integrate social-emotional development with the intellectual development of the child. Community Team members wanted to avold competing with the classroom teacher for the reponsibility, and the credit for the outcome of intervention. Believing that social-emotional growth is interrelated with intellectual development, developers of the Community Team model proposed that therapeutic intervention needed to occur within the classroom milieu and to shift mental health responsibility solely to the therapist would be disintegrative.

Collaboration was determined to be the most desireable method for Community Team members, as mental health professionals, to utilize in working with classroom teachers. By sharing responsibility for the children in the classroom the teachers would experience the active support of the therapist. At the same time the mental health professional could provide supportive therapeutic resources to the educator which 
could enhance the teacher's efforts in dealing with all children in the classroom. The objective of the Community Team member working with the teacher was to combine professional efforts and skills for the direct benefit of the child.

This approach required that Commity Team members, while sharing the responsibility for direct service provision, would not receive the ultimate credit for successful outcome. Because the teacher is the primary adult in the child's school experience the eventual goal of the therapist is for the responsibility to finally reside with the educator. The collaborative method is useful in that it provides needed assistance to the teacher, whose responsibility for the integration of the child's social, emotional and intellectual development is a large and difficult task.

\section{Description of Community Team Project}

The following description is taken from the Children's Psychiatric Day Treatment Center Policy Manual and describes the Community Team program as it was operated from January to June of 1975.

\section{Description of Current Consultation Commitment: The Community}

Team is collaborating with Gregory Heights Elementary School to provide mental health services to children kindergarten through third grade.

The objectives of the project are:

1. provision of therapeutic services in the classroom to identified children.

2. intervention in the physical and social milieu to promote optimal growth for all children. 
3. increased teacher sensitivity to needs of children, widening the range of problem solving skills and responses available.

4. increased awareness and support for these activities at the administrative level of the school system.

The Community Team staff engaged in the project are two clinical associates, one of whom is also a registered nurse. Both of these staff members have experience and training in child development and treatment of emotionally disturbed children and have served as members of a treatment team in the Children's Psychiatric Day Treatment Center program. Also involved in the project are two second year graduate social work students.

This group is supervised in their work by the Community Team supervisor, who is a master's level social worker.

Each team member has primary contact with one or more specified elementary school classrooms, six hours. weekly and is available to the classroom teacher on a regular basis for conference.

Planning for individual children and work with groups of children or with the classroom milieu as a whole is discussed in the weekly team meeting. The supervisor is also available to Community Team staff and students for individual supervision.

In addition to the professional services on the Center staff which provide support and consultation to the Community Team, a child psychiatrist on the faculty of the Medical School is available for consultation to the Community Team to do diagnostic assessments of children and families when requested and to meet with school personnel upon request. Communication with the principal of the school on a regular basis is the responsibility of the Community Team supervisor. Together, they. 
work out policies relating to the operations of the project and confer with teachers and Community Team members.

Records of classroom observations, conferences with teachers and contacts with individual children are kept by each Community Team member. These same records are not kept by the school. When a child is identified by a teacher as having problems that warrant a psychiatric examination, a family assessment, or any testing that might be done by Center staff, parental permission is obtained in writing on a Day Treatment form and resulting records are kept at the Center. Information relating to children and families obtained in confidence is not shared with school personnel without specific parental permission, and sharing of this information is on an "as needed" basis.

\section{Program Background}

The Community Team began its program intervention at Gregory Heights Elementary School in the winter of 1975. The mental health services of the Community Team were made avallable to the public elementary school under the auspices of the Children's Psychiatric Day Treatment Center, University of Oregon Health Sciences Center, Portland, Oregon. The Center is a day treatment program for emotionally disturbed children. One of the professional functions of the Community Team, as outlined in the Center's policy is to provide consultation to schools and other community agencles upon request. The project at Gregory Heights Elementary school had been negotiated between the principal of the school and the supervisor of the Community Team.

\section{Proposal for Community Team Service To Gregory Heights School:}

Overall Goal: Behavior change in children identified as having diffi- 
culty in school. These may be academic, social, emotional or other problems identified by school personnel

\section{A. Identification and Evaluation Phase}

1. Identification of children who need some special approaches or service in order to have a more positive school/life experience.

a. Community Team member receives referral from school person-. nel for individual child.

b. Community Team member formulates a description of the problem from Information obtained from teacher and/or parent and/or child and/or peers.

This description should include a summary of special servIces provided to the child by members of the PREP team, such as the diagnostic-counselor, or other specialists, and a description of interventions and approaches employed by the teacher and the child's response to them.

c. Community Team member observes the child in classroom. $\mathrm{Ob}-$ servations will be conducted on two or more different days and will probably require a minimum of four hours. Observations during. Iunch and recess will be scheduled as indicated.

d. If child appears to warrant further evaluation or contact from Community Team member, parental permission will be obtained, and further information and parent's perspective will be obtained from parents. Evaluation, referral or invention possibilities will be shared with parents at this time.

e. If indicated, child will be seen individually by Community Team mẹber. 
f. If Indicated, the child will be further evaluated in physical, psychological, psychiatric and educational areas. Services available to the school through area employees or existing contracts will be utilized first. The Community Team also have resources for psychiatric, psychological and other special evaluations which may be arranged on behalf of the child.

2. Developmental evaluation of child and description of classroom environment as it relates to the child.
a. evaluation of physical health
b. evaluation of intellectual functioning
c. evaluation of social behavior
d. evaluation of impulse control
e. evaluation of emotional functioning
f. evaluation of motor functioning
g. evaluation of self-concept
h. evaluation of family functioning

3. The teacher and Community Team member will define the problem or issues the child is presently dealing with. This information and possible approaches will be shared with child's parents.

4. Teacher, school personnel and Community Team member will explore existing resources or services available to the school for the child, such as the diagnostic-counselor, other specialists from the PREP Team, or reading and math specialists available within the school.

In the event that the child appears to have problems which cannot be appropriately approached in the school setting, the Community 
Team member can assist in arranging referral to other agencies which might include the Children's Psychiatric Day Treatment Center program.

If it appears reasonable to develop in-school, in-classroom approaches to the child's difficulties, school personnel and the Community Team member may proceed with the "Intervention Phase" (see 2 below). Preference will be given to developing plans and approaches which do not identify child as problem to his peers, which can be carried out in his regular classroom by his teacher with the assistance of the Community Team member and does not require his removal from school.

The plan for a child may also include referral to special services, as well as the development of in-classroom intervention approaches, according to the child's needs.

\section{B. Intervention Phase}

To be employed when in-classroom intervention is chosen as appropriate approach.

1. The teacher and Community Team member will delineate possible approaches to the defined problem or issue.

a. An intervention plan will be developed by teacher and the Community Team member to implement behavior change in identified children and/or classroom population.

b. Plan will include end goal statements--desired results, and measurable objectives.

1) Behavioral objectives will be stated in a positive way to reflect change in child's behavior. 
Example: Billy will form a peer relationship with one child in classroom.

2) Approaches related to each objective will be stated as methods to achieve behavior change.

Example: Small group activity with Billy. Adult to model appropriate interaction for Billy.

2. The Community Team member will contract with the teacher and the parent to implement the intervention plan.

3. Implementation of the intervention plan.

a. Documentation of the intervention, methods used and evaluation reflected in daily notation and final written review.

b. Documentation of the impact on the individual child and reflected behavior change using daily notation and completion of benchmark dates on intervention plan.

\section{Evaluation of the First Program Phase}

At the end of the school year 1975, the program evaluator was introduced to the current Community Team members during an all day evaluation meeting. Present during the evaluation were the two clinical associates from the Children's Psychiatric Day Treatment Center, the two second year graduate social work students and the Community Team supervisor. The evaluator's purpose in attending this evaluation meeting was to gain an understanding of the Community Team program, how it was being operated and any experienced and/or potential difficulties in programming. The discussion during the evaluation session centered around several elements relevant to the evaluator's interests.

Goals of the-Community Team Program: Members of the Community 
Team had a sense of both their long and short range goals. The immediate goal appeared to be to promote positive change in identified children. The manner of actualizing this short range goal would be based on the available strength and abilities of the teachers and Community Team members. The long range goal would be an integrative approach toward enhancing social-emotional development and intellectual achievement of children in the public schools.

\section{Obstacles to Goal Attainment: Possible detractors from achieving} long and/or short range goals that were mentioned included competition between teachers and mental health professionals, teacher insecurity about adequacy to meet expectations and pressure within school systems for academic achievement. The confusion or lack of philosophical commitment exhibited by the school system regarding the treatment of children experiencing social-emotional difficulties was also mentioned as a program obstacle.

- Community Team Methodology: The espoused method to be employed by the Community Team members to meet their goals was collaboration with the classroom teacher. They saw themselves more as facilitators of a process than as direct service providers.

Rationale for Collaboration: There were several artjculated reasons given in support of the collaborative methodology utilized by the Community Team. These reasons included recognition of the greater potential of the classroom milieu versus individual psychotherapy with children to affect change in school children. Community Team members noted that the majority of a child's time during the day is spent in the classroom, relating to the teacher. In order to avoid conflicting with the teacher's goals, Community Team members felt a partnership should be 
created where control was shared.

Need for Role Clarification: A couple of cautionary points were cited regarding the collaboration relationship. Both members of the collaboration needed to define their respective skills and areas of expertise, and realistic expectations for the collaboration needed to be established.

Levels of Intervention: Several levels of intervention were identified. These levels included, 1) the individual child, 2) peer groups, dyads, small groups, etc., 3) the classroom milieu, including the teacher, 4) the teacher, 5) the child's family and 6) the school administration. Members of the Community Team viewed these levels within the framework of a holistic system, where all levels continually interfaced and overlapped; each level containing within it elements of all the other levels.

General evaluative comments made by the Community Team members referred to an increase in the observable behavior of the classroom teachers. Community Team members felt that at the end of the school year, teachers manifested more collaborating with Community Team members, increased integration of social-emotional concerns with concern for intellectual development, greater expression of their own feelings, more empathizing with children's experienced difficulties and an increased responsiveness to Community Team member's suggestions.

\section{GOALS AND OBJECTIVES DEVELOPMENT}

In the summer of 1975 , a series of meetings began which extended into the fall and resulted in the Community Team's formal statement of Goals and objectives. The evaluator functioned as a group facilitator in 
the meeting with Community Team program staff. The final statement of Community Team Goals and Objectives was essentially developed and written by the staff of the Community Team.

Although the evaluator had a superficial knowledge of the Community Team's purpose and function, what was required in the development of goals and objectives was an in-depth discussion of values and intent. In requesting that the Community Team clarify issues and explain their methodologies, the evaluator encouraged members of the Community Team to become more clear in their own minds about what their goals actually were. The insistence upon specifying and operationalizing values and intentions resulted in an important group process of learning for all involved.

The first meeting was a general discussion of the Community Team's espoused values: Community Team members saw themselves as supportive of classroom teachers and desiring that all persons functioning within the classroom milieu children, teachers and others become more aware of the interpersonal processes occurring and utilize their heightened awareness to function more effectively within the milieu.

Levels of intervention were discussed and narrowed to three for the purposes of evaluation. The three levels on which the Community Team agreed to focus for their goals and objectives statement were: 1) identified children, 2) all children in the classroom and, 3) the teacher. These levels were viewed as interrelated parts of a whole system, as in concentric circles with the first level of intervention being present throughout the other two levels. It would be possible to intervene with an identified child and not be effecting the other levels, however, to intervene at the level of the teacher would be to effect the level of 


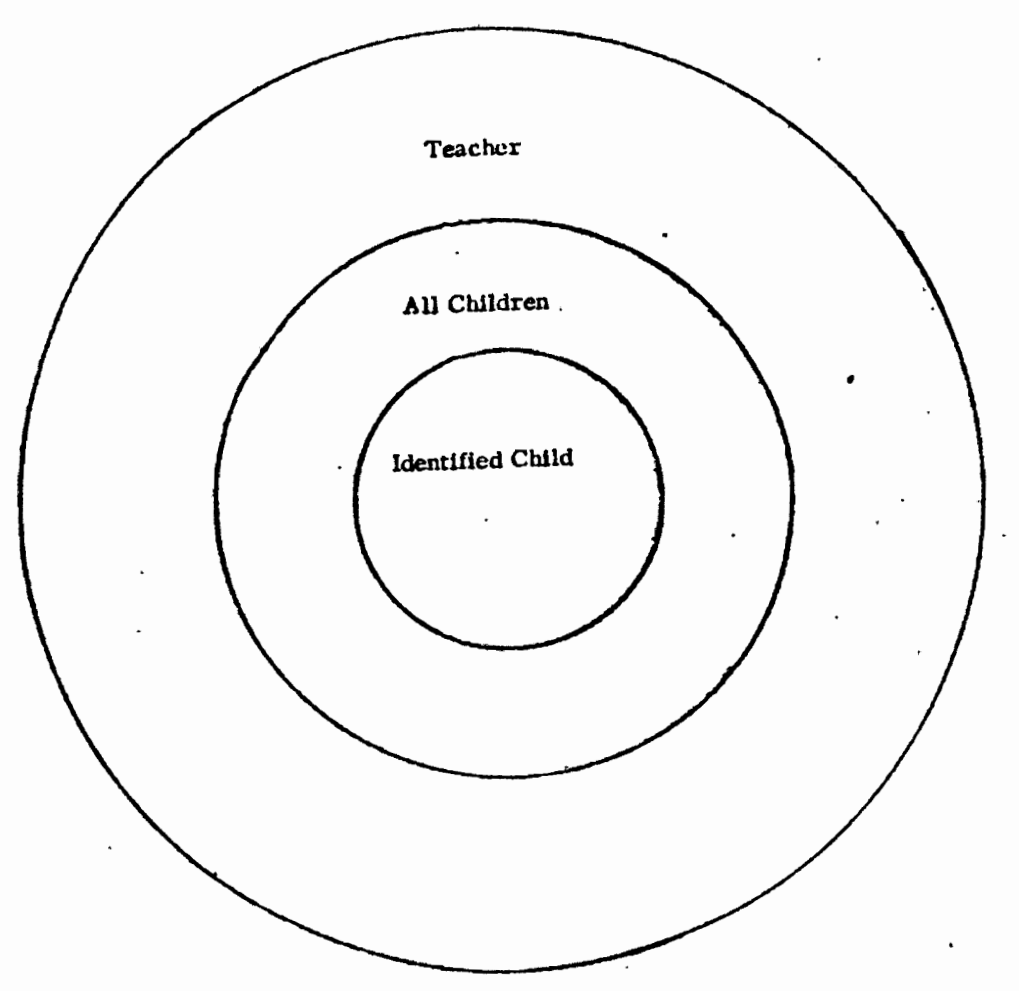

Figure 1. Levels of Intervention

all classroom children inclusive of identified children.

The levels of intervention corresponded to the goals of the program. Once the goals were organized into the three distinctions, it was then possible to proceed in a systematic fashion to an intensive investigation of each goal. The following meeting centered around Goal I which related to the identified child intervention. For discussion purposes, the Community Team supervisor prepared a draft of the goal, objectives and methods designed to meet the stated objectives.

Goal I was to plan for and support positive change in identified children. There were two objectives outlined under the goal: 1) to collaborate with the teacher in defining the "problem" in a mutually acceptable way that is not detrimental to the child and 2) to develop an 
intervention plan with the teacher that specifies objectives and methods to be used. Under each objective several methods were listed. The methods were very specific and when arranged and understood in a chronological progression accurately described the Community Team program intervention in operationalized terms. After several drafts and much discussion, these operational methods became objective statements reflecting the Community Team's intended approach to meeting the goal.

Two important discussions evolved around Goal I, that of defining an identified child and the problem statement written in non-stigmatizing terminology. It was agreed that children would be considered identified if they appeared on a classroom teacher's 1ist, according to the rating and screening procedure conducted by the school. If these children were considered to need therapeutic intervention by both the teacher and the Community Team member, the child would then be defined as an identified child.

Writing the problem statement in a way which was both mutually acceptable to teacher and Community. Team member, and not detrimental to the child, touched on two values held by Community Team members. The importance of having the problem statement be mutually acceptable was a cornerstone of the collaboration. If two professionals were to collaborate in assisting an individual child it was felt to be critical that they viewed the problem from a similar perspective. Community Team members, as a program staff, however, would not be willing to accept a perspective of the problem being inherent within the child himself, as in a "bad" child. Rather children must be viewed as experiencing problems in the classroom, not as being problem children.

In approaching the second goal, confusion was encountered as to 
who was included in the second level of intervention. The first written draft of Goal II was to provide in classroom assistance to identified children and the teacher. Clarification of the second level of intervention indicated that the focus was intended to be all children in the classroom, with the third level directed toward the teacher. The second draft of the goal statement became Goal II, to promote optimal socIal and emotional growth for all the children in the classroom.

- Several examples of desireable activities in the classroom were cited under the goal. Through a process of operationalizing these statements, the objectives for actualizing Goal II were developed. The objectives reflected the Comminity Team's hope that children would become increasingly able to define and solve their own problems.

The process of operationalizing objectives involves changing a statement of intention into an action statement which can be measured. Often this can be easily accomplished by merely adding an infinitive which denotes a degree of change. For example, one of the intentions stated on the original draft was to encourage expression of feelings from children and teacher. By changing "encourage" to "increase", the objective was operationalized and became measurable.

The third level of intervention was then considered and a draft of the Community Team's goals and objectives in effecting the teacher was circulated among team members. When a written statement of intention to effect change in classroom teacher's mental health skills was made available for them to see, Conmunity Team members began to feel uncomfortable about selecting the teacher as a focal point of intervention. Lengthy discussions about team members attitudes towards teachers resulted in an increased empathy for the difficulties and demands of the teacher's role. 
It was felt that great caution needed to be exercised, especially during this early stage in the program's development, in avoiding any tactic which might threaten the classroom teacher's position. The first priority in working with teachers was to establish a collaboration relationship. To focus on the teacher as necessitating change would be more characteristic of a consultative relationship which was seen as incompatible with the Community Team's strategy at this time.

A decision was reached that the teacher be excluded as a direct objective of intervention. The classroom milieu was selected as the third level of intervention which encompassed elements of the physical and social environment. The teacher, as a participant in the classroom milieu, would be a major consideration at this level of intervention but the focus would be broadened to emphasize enhancement of the entire milieu.

The term "milieu" was considered esoteric to those outside the therapeutic system but was very familiar to Community Team members because it is the primary therapeutic modality employed at the Children's Psychiatric Day Treatment Center. The Community Team members were all experienced milieu therapists and the Community Team model essentially proposed translating a modality utilized within a psychiatric setting in the treatment of emotionally disturbed children to the educational setting. An introduction to Goal III, describing the term "milieu" in relation to the school classroom was added as a critical section to the statement of Goals and objectives. Goal III was to promote the development of a physical and social milieu in the classroom that supports growth of social, emotional and intellectual areas. The expanded dimension of the third level is more consistent with the concept of concentric 
circles of intervention which characterizes the systematic perspective of service delivery articulated by Community Team members.

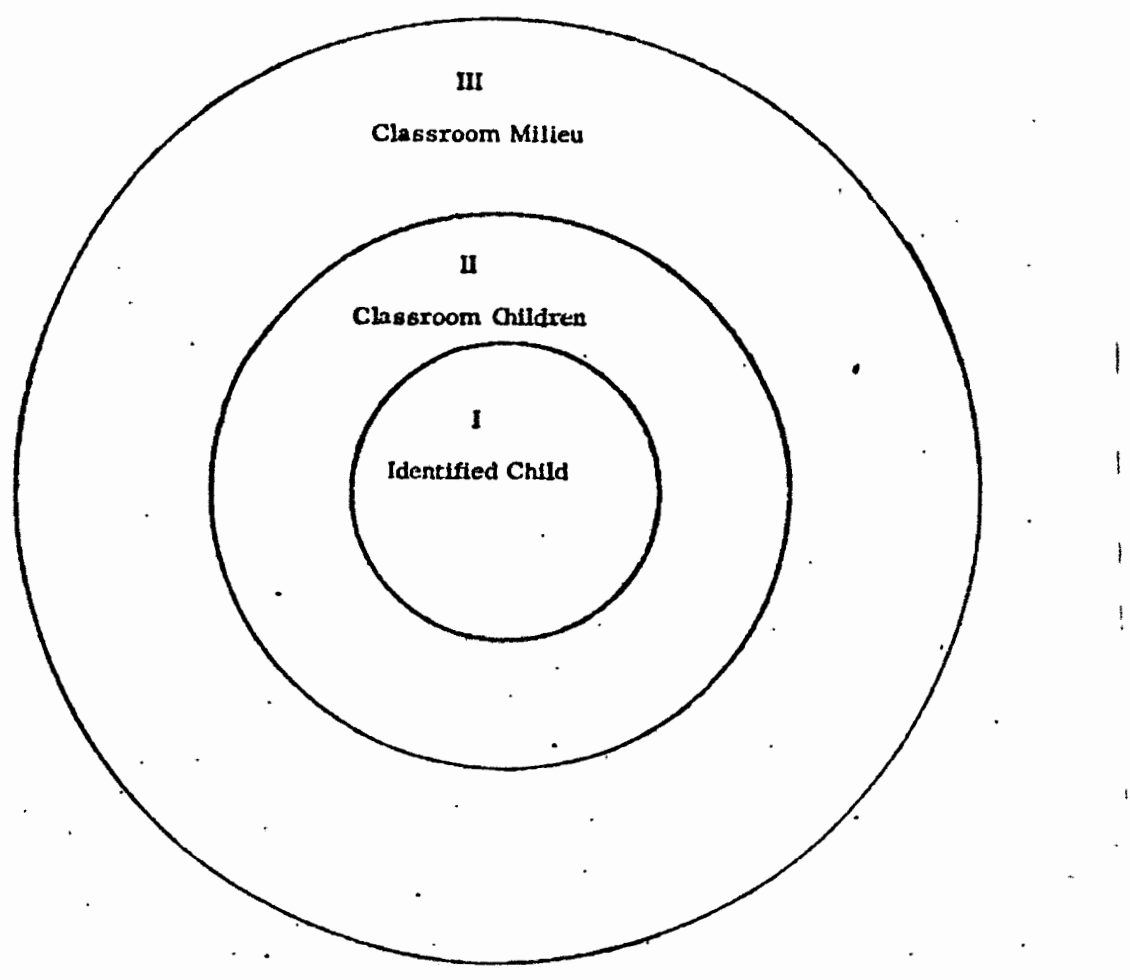

Figure 2. Goals of the Community Team

The request by the Community Team for a program evaluation to be conducted made it necessary for staff members to develop a statement of Goals and objectives. This process was time consuming, taking about two months to complete, and was often painful. Community Team members were forced to examine their values and attitudes and reflect on the implications of their objectives and methods. As a result of this self-examination, changes occurred both at an indịvidual staff member and a program level. These changes were not dictated to staff by the evaluator but evolved from collective awareness which the requirements of evaluation initiated. In this particular instance, the fact of evaluation 
served as a catalyst for clarification, always useful in program development, and as an ever present yardstick, against which program decisions could be tested and measured. When the Goals and objectives were completed and available for circulation, the Community Team staff felt confident that their statement was accurate and comprehensive. There was nothing stated in their Goals and objectives which they could not explain or defend, nor did their statement imply any approach or procedure which made them feel uncomfortable or evasive.

\section{Prioritizing Objectives}

Throughout the development of the Goals and Objectives, the evaluator considered instruments and techniques which might be appropriate measurements for evaluation. There were many factors to be considered in the selection of instruments, but one of the continual constraints was the limitations of time and money. The manageability of the program evaluation was one of the evaluator's goals for the eventual design.

It was not feasible to measure all of the objectives stated on the Goals and Objectives. For this reason, the evaluator asked the Community Team members to select one objective under Goal II as their top priority and two objectives under Goal III. The objectives under Goal I were determined to be process objectives, were a chronological description of the Community Team's strategy of intervention and were appropriate for monitoring to ascertain the level of service provision which was achieved. In discussing priority objectives under Goal III, the Community Team selected two objectives which were added to the process objectives under Goal $I$ and included in the monitoring instrument. These two objectives described the manner in which Community Team members agreed 
to collaborate with the classroom teacher in a combined effort to enhance the classroom milieu. These two objectives are: 1) to share with the teacher methods and techniques for dealing with social and emotional situations which arise in the classroom and 2) to share observations and perceptions of effect of physical and social milieu on identified children and classroom.

Selecting the top priority objective under Goal II proved to be a very difficult assignment. The Community Team members were resistant to the prioritizing requirements because they considered the objectives to be of equal importance and to be interrelated. At one point, they insisted that, like the objectives under Goal I, the Goal II objectives were chronological and described the maturational process of child development, signifying that none of the objectives could be assessed exclusively, but that the entire process should be evaluated as a whole. Since this measure was prohibitive, further negotiation was required. One device employed by Community. Team members during this period of negotiating was to create a new objective which all Team members agreed was the most important. This objective described the milieu threapy approach in the classroom and was a means of encompassing the ultimate intent of all of the specific, operationalized objectives listed. Further discussion resulted in a recognition and acceptance of the fact that this manuever was a ploy to avoid difficult decision-making and so the staff dismissed the new objective and returned to priority consideration.

To facilitate the decision-making, the evaluator reviewed the objectives listed under Goal II, organized them into categories and arranged these categories in a developmental sequence. What emerged from 
this categorization were three distinct levels of social-emotional maturation. The first level of development centered around the child's self-esteem and sense of autonomy. The second level dealt with the child's increasing ability to express and resolve emotional conflicts and the third level emphasized an increased ability to consider the feelings of others, to accept these feelings and to cooperate. These three levels can be considered in the same systematic framework as the levels of intervention with the third level containing elements of all. the other levels: In this sense the third level, or the cooperative level is the broadest level and corresponds to the widest circle within the interlocking concentric circles in the framework.

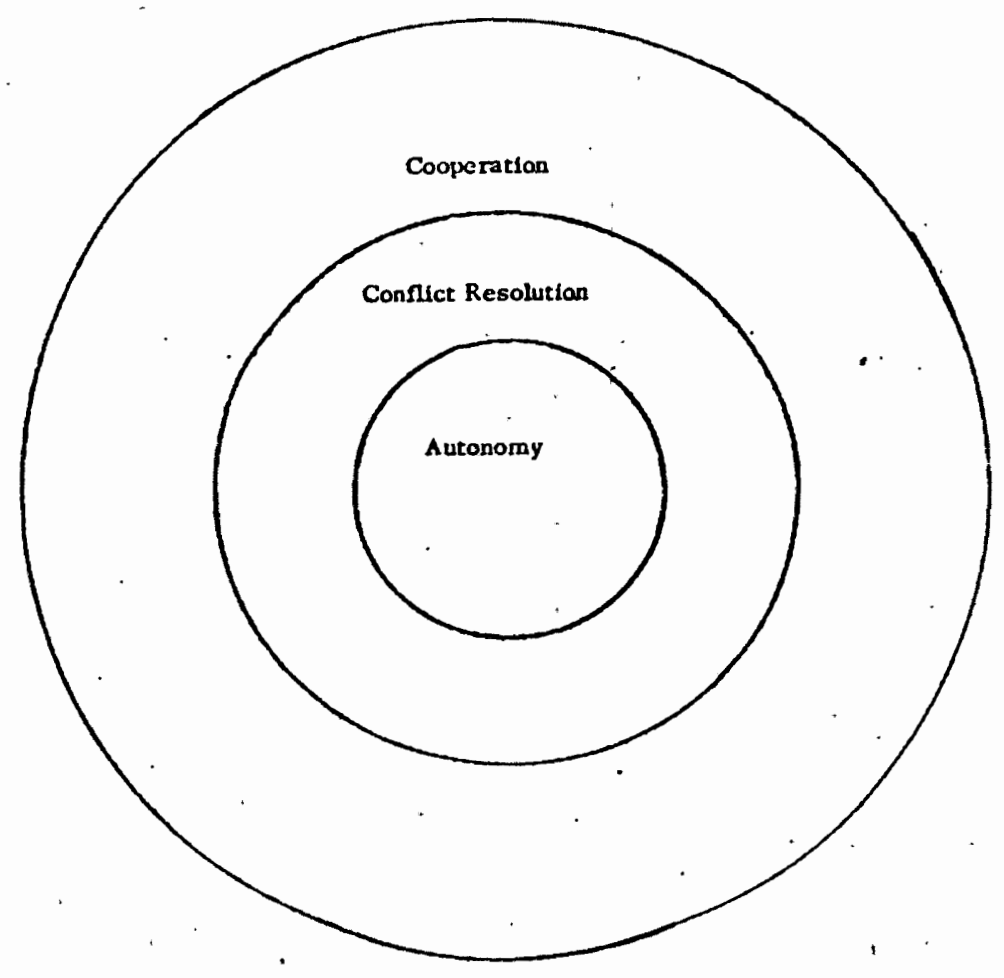

Figure 3. Categories of Objectives Under Goal II

When Community Team members finally selected their top priority objective 
it was reflective of the third layer, or the inclusive level of cooperation. The objective selected was objective 3 , to encourage and promote cooperative activities among children. Although the Community Team had selected one objective it was prioritized with some expectation that cooperation encompassed and symbolized a more global concept of their purpose in promoting optimal growth for all children in the classroom. This global consideration of cooperation was clarified at the time the objective was selected as the top priority; however, the process of operationalizing cooperation substantially changed and narrowed its meaning. At the time this change in definition occurred it was not recognized by the Community Team members or the evaluator and created confusion in the later stages of data analysis. This problem will be discussed in more detail in the following chapters. 
CHAPTER IV

METHODS AND TECHNIQUES

This chapter deals with the selection, development and administration of the instruments which were designed to collect information indicated by the Community Team's Goals and Objectives.

\section{MONITORING INSTRUMENT}

The objective of this technique was to record the provision of services outlined under Goal I of the Goals and Objectives. Further objectives of this method were to identify gaps in the service delivery and to detect discrepancies in the development of collaboration. Discrepancy refers to areas of disagreement or disparity in the responses between a teacher and a Community Team member when questioned about the same service area.

\section{Description of Goal I}

As described in the goals and objectives development section, the first goal of the Community Team's statement focuses on the first level of the program intervention, the identified children. Identified children are defined as those individual children who both the teacher and the Community Team member consider need therapeutic approaches to social and emotional problems experienced in the classroom. The goal states that the intention is to develop, plan for, and support positive change for these children which, in broad terms, describes the system of service 
delivery which is the Community Team model. The six objectives outlined below the goal explain the process and detail specific procedures. These process objectives do not imply any specific outcome, but pose a hypothesis that if these procedures are accomplished, positive changes in identified children will result.

\section{Description of the Instrument}

The first step of the evaluation design was to establish a means to monitor the process objectives. Before any outcome measure could be determined, verification of the provision of Community Team services was required. In addition to monitoring procedural steps, the instrument needed to ascertain whether or not Community Team members were progressing through their proposed model of intervention in collaboration with the classroom teacher. Thus, the purpose of the monitoring was twofold: 1) to provide the evaluator with information about the extent to which the services outlined under Goal I of the Community Team's goals and objectives statement were actually being delivered, and 2) to collect information about discrepancies in perceptions between teacher and Community Team member. This information could be communicated back to the Community Team and could be used to aid Community Team members in improving their service delivery and developing effective collaborative relationships with their respective teacher-partner.

The monitoring instrument was developed systematically from the objective statements listed under. Goal I. Since monitoring the processual development of the collaboration relationships was part of the purpose of the insturment, Objectives 6 and 8 under Goal III were added. Goal III refers to promoting the development of a physical and social 
milieu in the classroom which supports growth of social, emotional and intellectual areas. Objectives 6 and 8 have to do with the Community Team members' sharing techniques and strategies and sharing concerns about classroom milieu with the teacher.

The monitoring instrument begins with the first objective listed under Goal I and asks straight forward questions as to the completion of all procedures stated within the objective. Objective 1 is "to make observations in the classroom, to meet with the classroom teacher and to conduct any additional information-gathering activities." The first three questions on the monitoring instrument refer to the three procedures outlined in the objective:

1. Has the Community Team member observed the child in the classroom?

2. Has the Community Team member met with the teacher to share observations of the child?

3. Has the Community Team member conducted additional information-gathering activities?

The instrument continues in this manner, questioning every procedure which is outlined and/or implied within the objectives.

As to procedures implied by the objectives, an example would be a transitional procedure between objective 1 and 2 . The first procedure stated under objective 2 is the writing of a problem statement. After the observations and additional information-gathering were completed, if the Community Team member and the teacher decided that a child was not appropriate for identification they would decide not to write a plan. The fourth monitoring question asked, therefore, if a decision had been made to write an intervention plan. If the decision was no, this was 
noted on the form and a brief description of the rationale for the decision was written down on the instrument by the evaluator.

Responses to each question include a "Yes", "No" and "Don't Know". An additional column was added for collaboration from the file. For example, when a problem statement was written, it would be included on the intervention plan-form, a copy of which would be kept in the program evaluation file. If problem statements reportedly had been written, the evaluator could then go to the file and check to see if the report could be verified on the intervention plan. This corroboration strengthens the information reported. (See Appendix C for Monitoring Instrument Form.)

\section{Administration of the Instrument}

The first monitoring occurred in January 1976. Community Team members had been involved in the school for several months, observing in all primary grade level classrooms, going through a process of mutual selection of the teacher-partner with whom they would work for the remainder of the school year. Classroom observations to determine which children were in need of therapeutic intervention had begun.

When the monitoring instrument was ready, the evaluator was scheduled to make a presentation at one of the weekly primary grade teacher meetings at the school. The evaluator was introduced to the faculty by the Community Team supervisor who prefaced the evaluator's remarks by offering a brief history of the Community Team program at Gregory Heights Elementary School. The evaluator explained to the teachers, the concept behind evaluative research stressing program accountability, measurement of outcome effectiveness and improvement of service delivery. The 
Community Team's goals and objectives statement was made available to all the teachers, as were copies of the monitoring instruments. The evaluator explained how the monitoring instrument was directly related to the program goals and objectives. A formal request was made of participating teachers to assist in the monitoring procedure by being interviewed periodically by the evaluator. The first monitoring interviews were scheduled at this meeting. Subsequently interviews were scheduled at the school, with the teachers individually.

The monitoring instrument was administered by the evaluator to both teacher and Community Team member, in separate interviews. The monitoring questions were asked about each identified child so the interview took more or less time, depending on how many identified children there were in each classroom.

The evaluator began with the first question and continued through the procedural steps until a "No" response was reported. This would indicate the stage of the process which was currently being negotiated. At the next monitoring. Interview, questioning would resume at the point where it left off during the previous interview. Thus, duplication of questioning was avoided.

Three questions were asked during every monitoring interview. These questions refer to the provision of services and the development of the collaborative relationship in terms of the classroom milieu.

\section{Description of Intervention Plans}

At the time the monitoring was initiated there was one intervention plan in the file. No standardized form existed and the process of monitoring itself identified the need for plans to be on file. A very 
simple two-page format was designed to be easily written and easily read. The design of the intervention plan was dictated by elements contained within the process objectives.

The first page includes the name of the identified child, the Community Team member and the teacher. Appropriate space is provided for the recording of observations, additional information-gathering activities and the problem statement. The second page has two major components. Objectives are listed with corresponding benchmarks and the methods are 1isted, with the respective responsible person, either the teacher or the Community Team member, or both stated. Additional second pages can easily be added so that as benchmarks are met, if new ones are established, anyone reviewing the plan can assess progress over time. (See Appendix B for intervention plan forms.)

The use of standardized intervention plans can serve additional purposes besides facilitating recordkeeping for program staff and the evaluator. They provide material for reporting the number of children identified and for at least a subjective assessment of the second part of objective 2. This objective is "to write a problem statement in collaboration with the teacher from the perspective of issues with which the child is currently dealing". The concern on the part of Community Team members which underlies the writing of this objective is that children are often labeled and in diagnostically negative terms. The Community Team wanted to avoid children being labeled as "bad" or as "problems" but to be viewed and described as children who are experiencing social and emotional difficulties.

By perusing the written problem statement, recorded on the intervention plan, the evaluator can review the statement and check the 
perspective of the description. If there is any question that children are being diagnostically labeled in stigmatizing terms, these questions can be directed to the documentation in the intervention plans and discussed at the appropriate staff level.

\section{Description of Collaboration Discrepancy Inventory}

In making periodic reports to the Community Team, from information gained in the monitoring, three critical areas were selected and a format was designed to condense the data and facilitate reporting. The focus of the information was on the collaborative process and the areas selected were 1) the questions on the monitoring instrument which asked if services were being provided and a description of services provided by the Community Team member and by the teacher, 2) the question which reflects Objective 6 under Goal III, "Has the Community Team member shared with the teacher, techniques and methods for dealing with social and emotional situations in the classroom?" and 3) the question which reflects Objective 8 under Goal III, "Has the Community Team member shared with the teacher observations/perceptions of the effect of physical and social environment on the classroom?"

These questions deal particularly with the collaborative style and it was felt that an indication of any discrepancies between teacher and Community Team member perception in these areas would be helpful in redefining and restructuring collaboration development. The form which resulted from this process was the Collaboration Discrepancy Inventory. (See form in Appendix E.)

The Collaboration Discrepancy Inventory would be filled out by the evaluator after each monitoring and included along with the monitoring 
forms in each Community Team member's file. If a Community Team member wanted to consult the file he or she could glance quickly at the Collaboration Discrepancy Inventory and note any checks made in the discrepancy column and then read across the page to find out in which area there was agreement, note their response as opposed to the classroom teacher's and, In the case of the service provision question, read, after the name of the identified child, the notes the evaluator had made concerning the nature of the differences in describing services.

\section{Description of Monitoring Discrepancy Inventory}

The collaborative discrepancies were the only areas of monitoring which were collected in a systematic way for periodic reporting. For the final report, however, a similar mechanism was devised for the reporting of all questions which are found on the monitoring instrument. This form is the Monitoring Discrepancy Inventory. (See Appendix D for form.)

The form includes names of identified children, the procedural step completed for each identified child, a column for checking discrepancies, a space to record the procedural step about which there is a disagreement and then the three columns for the various responses, "Yes", "No" and "Don't Know". Data can be compiled for the overall program and/ or by individual Community Team member and can be utilized in much the same way as the Collaboration Discrepancy Inventory is used; to provide another indicator of collaboration effectiveness and to identify areas where more explicit communication is required between teacher and Community Team member. In addition to assessing collaboration development, the Monitoring Discrepancy Inventory shows the procedural step achieved in the intervention process and illustrates where the process has become 
stalled.

\section{Description of Process Development Scale}

The information collected and recorded on the Monitoring Discrepancy Inventory which relates to the development of the intervention procedure can then be transmitted to the Process Development Scale. (See Appendix $F$ for form.) The Process Development Scale lists all the procedural steps which are questioned by the monitoring instrument under the corresponding objective. For example, under objective 1 are listed three procedures: 1) make observations, 2) meet with teacher, and 3) gather additional information.

After each monitoring is completed, the number of interventions which are currently involved in the stated procedures, can be counted and recorded on the Process Development Scale. By checking the scale, determinations can be readily made about how many plans have reached a certain stage in the procedure. Over time, the Process Development Scale can provide an assessment of the progression of the overall program. This information can be also be collected for a. Community Team member on an individual basis.

\section{PEER INTERACTION INVENTORY}

The objective of this observation instrument was to provide information about the frequency of classroom interactions related to Goal II of the Community Team's Goals and Objectives statement.

\section{Objective of Observational Technique}

The objective of the classroom observation was to measure the frequency of cooperative activities among children in the classroom. 
Although the observational instrument was not administered as a pre-test post-test measurement it could be used in this manner if an observation could be accomplished before the in-classtroom program was initiated.

Because the observation measure was related to Goal II, the promotion of optimal social and emotional growth for all children in the classroom, a measurement was required which focused on peer classroom milieu, including the teacher and not individualizing identified children.

\section{Selection of the Instrument}

There were three major guidelines or constraints which dictated the selection of an observational technique. The first consideration was that of finding an instrument which operationalized and measured cooperation. The second guideline was that of measuring interaction at the level of classroom environment, but not measuring teacher performance or the performance of identified children in comparison to all children in the class. Thirdly, consideration needed to be given to the manageability of instrument administration.

Operationalized "Cooperation": In a review of the educational observation literature and in questioning local mental health professionals it was ascertained that very few appropriate instruments existed, which exclusively measured classroom cooperative behavior. Several instruments included cooperation as one category of observation and the majority of techniques included the teacher in the measurement strategy. The format which was eventually selected operationalizes cooperation, at the level of peer interaction, as equal participation in an activity or conversation. This operational definition of cooperative behavior among children was acceptable to members of the Community Team although, in terms of an 
instrument selection it comprised a compromise since cooperative was only one of several categories 1 isted and was not originally determined to be the focus of the observation.

At this stage in the process, the functional definition of cooperation was changed substantially from the previous conceptual definition which the Community Team had prioritized.

As discussed in the previous chapter, this conceptual definition of cooperation encompassed a more global sense of cooperation as a symbolic reflection of one of the values of Community Team members. The functional definition of equal participation in an activity or conversation does not describe this symbolic conception of cooperation. This fact was not recognized during the process of selecting and revising the observational technique but became evident much later in the period of interpreting the findings of the observation. It is doubtful whether an awareness of this occurrence would have resulted in members of the Community Team rejecting this observation technique since they had an opportunity to discuss the appropriateness of all definitions and revised and added several categories and definitions of terms.

Exclusion of Teacher from Measurement: The exclusion of the teacher from the observation measure eliminated many standardized instruments for assessing classroom climate. As noted in Chapter II, the classroom climate instruments emphasize the teacher as the single most influential agent in the classroom milieu.

The view that the teacher is the greatest influence on classroom milieu is shared by members of the Community Team. The decision to exclude the teacher from measurement was made purposefully by the staff, although they were aware that this decision narrowed the selection of 
observation instruments and the information which would result. The importance of establishing collaborative relationships with teachers took precedence at this stage of the Community Team's program formulation and it was considered detrimental to the collaborative process, at least during this program year, to attempt a measurement of teacher performance in the classroom.

Manageability of Administration: As stated in the description of the program evaluation goals, one of the major considerations throughout the design process was to keep the evaluative functions to manageable time and technical resource proportions. At the present time the Community Team program of the Children's Psychiatric Day Treatment Center does not have the financial resources to insure perpetuation of a longitudinal evaluation design. If this goal was to be accomplished, evaluation procedures needed to be structured in such a way so as to make it feasible for Children's Psychiatric Day Treatment Center staff to continue the process over an extended period of time without requiring additional personnel. Since the Center is a setting for trainees from several local educational institutions, one possibility for future implementation of the evaluation is to utilize the services of education and mental health student-trainees who are interested in learning evaluative research methodology.

\section{Description of the Instrument: Peer Interaction Inventory}

The observational technique which was eventually developed, The Peer Interaction Inventory, was taken from an interactional observation form which was designed by graduate psychology trainees at the Child Development and Rehabilitation Center at the University of Oregon Health 
Sciences Center, Portland, Oregon. The original form included observation at levels of interaction and behavior additional to peer interaction and was used in counting behaviors in a special classroom for hyperactive youngsters. Levels of interaction included in the original form were with an authority, and amongst peers, isolation, hyperactivity and crying.

This observation design was selected, partially because it presented very few technical or logistical requirements. The requirements of the very small program at Gregory Heights eliminated several possible instruments which were designed for administration across a large sample involving many schools in several school districts and required technical resources which were not at the disposal of the Community Team program.

One requirement of an observation is the need to establish reliability or a rate of agreement between two or more observers. To meet this requirement, the services of a second observer were required, to aid the evaluator in the administration of the observational instrument. At the time the observation format was chosen, it was felt that another observer could be found either at the Child Development and Rehabilitation Center or at Gregory Heights Elementary School.

The most difficult problem connected with the observation, proved to be the need for a second observer. No one at Gregory Heights School or the Center was either available or appropriate to serve as the second observer so a volunteer was sought. A part-time psychology student from Portland State University volunteered to participate in the observation which took 12 - 15 hours to complete. This time included a limited training session, which, had resources been available, could have been more extensive and perhaps have eliminated some of the confusion encountered in the recording of observed behaviors. 
Revisions of the Instrument

The Instrument was changed from the original form utilized in the hyperactivity study and adapted to the needs of the Community Team program evaluation in three basic ways, the selection of only the peer interaction level for observation, the adding of two categories: Interactive and Non-Interactive and the redefining of Aggression.

Selection of Peer Interaction: Although the original observational technique was designed to measure both peer interaction and interaction between children and an authority, since the Community Team had decided not to measure the latter interaction, that category was eliminated, as were the categories pertaining to isolation, hyperactivity and crying. The peer interaction definitions were extracted from the original form and used as the basis for the Peer Interaction Instrument.

Additional Categories: In order to account for the interactions eliminated, two non-specific categories were added to the Peer Interaction Instrument, Interactive and Non-Interactive.

The Interactive category was to include all other peer interactions which did not apply to the specific categories listed and defined on the instrument: positive and negative, physical and verbal aggression, cooperation, dominance, submission, no response and competing response. (See Peer Interaction Instrument Definitions in Appendix I.) The Interactive category was also to include all interactions between children and the teacher or any other authority in the classroom. There was no distinction made within the Interactive category, in order to assess how much of the recorded behavior was additional peer interaction and how much was interaction with an authority. Caution was maintained as to excluding any teacher measurement. 
The Non-Interactive category was added by the Community Team in order to gauge in some way, the extent of isolated activity as compared to the incidence of interaction in the classroom.

These two categories served as generalized catch-alls to capture the information in a non-specific manner, which was included on the original form in operationalized terms. In revising the form this way, the ability of the technique to collect important information about the nature of observable interactions was largely decreased. Considering the guideline of not assessing the teacher, this effect was unavoidable.

Redefinition of Aggression: The third revision of the original form was a redefinition or a clarification of the term aggression. In the original form, used in observing hyperactive children, aggressive denoted a negative behavior and was characterized by such things as expressions of revenge, threats, spitting and wrestling. In discussing the implied negativism of aggression, members of the Community Team began to cite examples of situations where expressions of revenge, for example, would be considered appropriately assertive. Aggression could be considered as hostility when viewed from a negative perspective of unacceptability and undesireable behavior. Appropriate expressions of anger or assertiveness, on the other hand, as in one child confronting another with a legitimate opinion or response could be considered positive or desireable behavior.

What emerged from this discussion were two operating definitions of aggression, one positive and one negative. The general guideline for determining which definition applied to an observable situation was the consideration of what was fair within a particular setting. If a child responded to a non-provoked physical assault by another child defending 
his or her position, either physically or verbally, this would be considered aggressive-positive. If a child, for no apparent reason, went over and yanked someone's pigtails, this act would be considered aggressive-negative.

\section{Preparation of the Instrument}

Before the Peer Interaction Inventory was administered in the classrooms, two preparatory procedures were completed. The first was to validate the appropriateness of the instrument to measure what the Community Team wanted and the second step was a pilot test of the mechanics of administering the observation.

Validity Test: A session was arranged for Cormunity Team members to experiment with the observation form and discuss its appropriateness from a clinical perspective to a practice setting with which they were familiar. Videotapes of children in classroom situations were provided by staff psychologists at the Child Development and Rehabilitation Center. Community Team members observed children on video, scored behaviors for several intervals, then stopped the tape, compared and discussed their responses to the same observed interaction.

There were two issues which emerged out of this session which were later discussed at a meeting of the Community Team. One question was whether or not cooperative should take precedence over dominantsubmissive. There was some difference of opinion during the videotape session about whether or not a child's behavior was dominating or equal participation in an activity. In situations which were not overtly dominating, especially considering the inability to hear clear verbal exchanges, it was decided that cooperative would take precedence. 
The other question which resulted from the run through with the videotapes was whether to score the last scoreable response or the most dominant behavior observed during any given second interval. In the interests of keeping the procedure as regular as possible and with consideration for the problems associated with having to make quick decisions, record a behavior and return to observing, all in a manner of seconds, it was determined that the last scoreable response would be the behavior recorded. The last scoreable response meant a behavior which had begun and was understandable as a completed behavior. The behavior could not be scored as an interaction if the child was walking towards another child, presumably to engage in an interaction. At the end of fifteen seconds, if the child was still walking, the last scoreable response would be non-interactive.

Pilot Test: A practice session was arranged before going into the rooms where the Community Team members were working. One morning was spent in a fourth grade classroom, practicing synchronizing the tapes and clarifying confusion centering around the definitions and coding instructions.

During this pilot test in the fourth grade classroom, the observers recoginzed another situation, common to all classrooms, which required further clarification of coding procedures. When chlldren were sitting quietly at their seats, assumedly listening to the teacher who was addressing the class, they were seemingly interacting with an authority and their behavior should therefore be scored as Interactive. The observers determined, however, that unless there was an observable behavioral response exhibited by the child, as in opening the book and beginning to work, in direct response to instructions, their non-behav- 
ioral assumed 1istening could not be interpreted as an interaction and must therefore be scored Non-Interactive. The rule of thumb became, at that point, in any case involving doubt, Non-Interactive takes precedence.

\section{Description of Administration}

The observation instrument was administered in three classrooms at Gregory Heights Elementary School in which the Community Team members worked. A random sample of eight children was selected from class lists in each room. Each child was observed for a ten minute period, recording a behavior in the appropriate category after a fifteen second interval. After scoring, observers would pause for five seconds and then the next fifteen second interval began. Three counts were made each minute for a total of 30 interactions scored for every child observed.

Each observer had a portable tape recorder which could be carried in a purse or briefcase. The second intervals were recorded on the tapes with the number of the interaction spoken at the end of each fifteen second interval. When observers scored a behavior it was recorded as the third or the twentieth behavior as opposed to a running tally.

The second of the two tapes was recorded off the original so that the recordings were synchronized as long as they were started simultaneously. One of the observers would start both of the tapes at the beginning of each observation. This meant that the two observers needed to sit relatively close together. Earphones were used so that children working in a quiet classroon would not be distracted. The only audible sound was the clicking of buttons when the tape recorders were started or stopped. 
At the beginning of each observation of a child, observers would write the child's name, their name, the time of the observation and a description of the setting at the time of the observation, 1.e. reading period, free play, class discussion. Any change in activity or any unusual or distracting incident which occurred during the ten minute observation was noted on the score sheet.

Observers found that four children could be tracked at one sitting and then a break was required before coming back and completing the observations for each classroom. Observations were made in the morning between 9:00 and 11:30 a.m. and required three separate days, one day per classroom. It was necessary to come to the classroom early on the day of the observation and be with the teacher while children were arriving in order to go over the sample list and identify the children to be observed. Distinguishing characteristics and descriptions of each child were jotted down so that observers could remember which children to observe.

\section{TEACHER ATTITUDE QUESTIONNAIRE}

The objective of the questionnaire was to collect information from the staff at Gregory Helghts Elementary School which would be helpful to the Community Team in improving their service delivery, revising their program in the future and assessing the impact their program has made on the teachers and principal at the school.

\section{Development of the Questionnaire}

Unlike the other developmental processes which resulted in the goals and objectives statement, the monitoring and observation instruments, 
the members of the Community Team were not deeply involved in the design of the Teacher Attitude Questionnaire. The evaluator prepared the first draft of the questionnaire and circulated copies to all members of the Community Team. Then the evaluator and supervisor of the Community Team went over the first draft and discussed the format and intent of each question, deleting, rearranging and adding sections. Members of the team expressed some concern about the length of the questionnaire, but supported the idea of administering it in the form of an interview, as intended.

A rough draft was submitted to the principal of the school for approval and interviews were scheduled. The design and approval process took less than two weeks.

\section{Administration of the Questionnaire}

The questionnaire was administered by the evaluator in an interview. All respondents were insured of confidentiality. The general goals of the program evaluation were reviewed, as were the goals and objectives of the Community Team program. A copy of the Community Team goals and objectives statement was made available to any respondent wishing to have one, as was a copy of the questionnaire for them to keep. The objectives of the questionnaire were stated by the evaluator before beginning the interview.

The Teacher Attitude Questionnaire was administered to all the primary grade teachers and the principal at Gregory Heights Elementary School. There were eight respondents to the questionnaire, including four teachers who had participated in the Community Team program for the major portion of the school year, three teachers who had either not 
worked with the Community Team at all or who had only had a Community Team emmber in their classroom for a relatively short time or involved in fairly limited service provision, and the principal. All the teachers who were appropriate to the interview schedule responded, including the principal.

The questionnaire surveyed teacher's opinions and suggestions concerning their awareness of Community Team methodologies and the relative effectiveness of various approaches, positive and/or negative effects of Community Team intervention, the amount and allotment of time consumed by Community Team program and philosophical issues of educational and mental health intervention. There were also several questions designed to measure awareness of, and receptivity to, the collaborative approach. (See Appendix $J$ for Teacher Attitude Questionnaire.)

\section{IDENTIFIED CHILDREN RATINGS}

The objective of collecting information about particular identified children was to provide some means of assessing the degree and nature of change over a period of several years. This purpose relates to Goal I, supporting positive change in children, identified as needing therapeutic approaches in the classroom and receiving services from the Community Team. The information provided in the Identified Children Ratings can assist the Community Team program in evaluating the effectiveness of early identification and subsequent service provision, in preventing children from experiencing social and emotional difficulties in their later school years. 
Description of the Rating Procedure

The information which was used in the rating process was taken from files at Gregory Heights Elementary School. Several times during the school year, the principal requested that teachers conduct a screening of students in their classrooms and rate each child on a one to four scale. A one on the scale would indicate that the teacher anticipated that the child would experience no particular difficulties during his or her academic career. A rating of two indicated some uncertainty, on the teacher's part, regarding the student's academic future. A three signified that the child was experiencing or, that the teacher anticipated that the child would experience, future learning difficulties, and a four indicated that a child was talented or gifted in particular areas: (See Guidance/Extra Service Screening Form, Appendix K.)

The Community Team program was especially concerned about children who received a two or three rating. Under a rating of three there were four specific categories of learning difficulties:

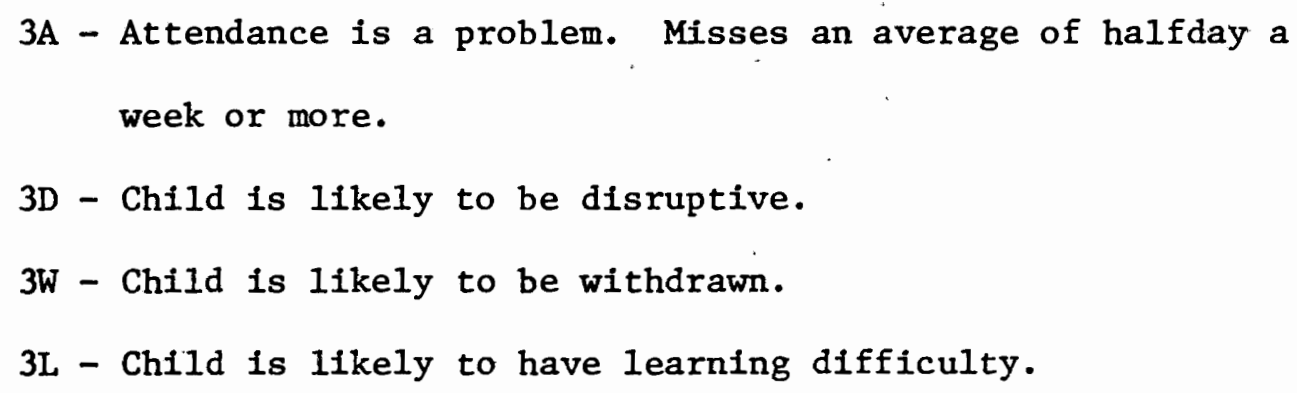
rating of a child and provide additional information about what problems the child experienced in the classroom.

During this school year, ratings took place at three different intervals, once in October, again in December and finally in June.

At the end of the year, the program evaluator made a list of all 
Identified children remaining in the Community Team program. Then the school files were consulted as to how many of the Community Team program's identified children had received ratings of two and three, if there was any change in the ratings they received and if there was a change, what was the difference in the rating. 


\section{CHAPTER V}

RESULTS

In this chapter, the findings of the data collection techniques utilized in this program evaluation are presented and discussed.

\section{MONITORING REPORT}

The results of the monitoring provide information about the extent of the service provision and the development of the collaborative relationships.

\section{Number of Identified Children}

At the time of the first monitoring there were 33 children reported, either by the Community Team member or the teacher, or both, as being in need of special services. Since there was only one writen intervention plan in the file at this time, there is no evidence to corroborate this figure. There were, however, discrepancies, which appear on the Monitoring Discrepancy Inventory, between teachers and Community Team members about the decision to write plans for individual children.

There was one instance where the teacher reported that a decision had been made to not write a plan and the Community Team member responded "Don't Know". This was not counted as a discrepancy instance, especially because of the particular confusion surrounding plans for the child in question. 
TABLE I

JANUARY INSTANCES OF DISCREPANCIES REGARDING DECISION TO WRITE INTERVENTION PLAN*

\begin{tabular}{|c|c|c|}
\hline $\begin{array}{l}\text { Community Team - Yes } \\
\text { Teacher - No }\end{array}$ & $\begin{array}{l}\text { Community Ieam - No } \\
\text { Teacher-.Yes }\end{array}$ & $\begin{array}{c}\text { Community Team - Yes } \\
\text { Teacher - Don't Know }\end{array}$ \\
\hline 3 & -4 & 5 \\
\hline
\end{tabular}

Total $=12$

*Taken from Monitoring .Discrepancy.Inventory

As can be seen from Table I there was a difference of opinion between teacher and Community Team member in thirteen cases, about whether or not an intervention plan was to be written. By the time the next monitoring occured, in March, there were only two reported cases of disagreement. In both of these cases the Community Team member reported that a decision had been made to write a plan, while the teacher, in one case didn't know and in the other case the teacher reported that a decision had not been reached.

At this point, intervention plans were in the file and plans had been written for both of the cases in question, corroborating the Community Team member's affirmative report. Discrepancy, in this instance, could be due to a time lag between Community Team member and teacher meetings where information is shared, and the administration of the second monitoring.

Partially due to this time lag, it is difficult to say how many clearly identified children there were at any fixed point in time during the first three months of monitoring but by March there were twenty five and at the end of the school year, as reported in the final monitoring, there were twenty two identified children. 
There were eleven children who became non-identified during the first few months of monitoring. Of these cases, the reasons given for deciding not to write an intervention plan or terminating the intervention plan were in three areas. It was determined that seven children were not a critical problem, i.e. not appropriate for therapeutic intervention, three children moved away and for one child, alternative arrangements from classroom intervention were planned and accomplished.

\section{Community Team Process Development}

One of the things that monitoring can provide is tracking of the procedural objectives as they are developed. By transfering this information to the Process Development scale, assessment can readily be made of the overall program status. As can be seen from Table II the overall process generally appears to have developed steadily and consistently, with a few notable exceptions.

One point to be noted is that while fourteen of the final twenty two identified cases reached the last process objective, no plan went through the last procedure of establishing new benchmarks.

At the time of the first monitoring in January, three of the thirty three cases had completed plan evaluations and five more had reached that step. By March, the majority of the cases, fifteen, had been evaluated. At the time of the final monitoring twenty of the twenty two cases had been evaluated by teacher and Community Team member. Of the two remaining cases one reported having developed an intervention plan and that plan was at the stage to be evaluated. of the twenty two identified children reported during the final 


\section{PROGRAM EVALUATION OF COMMUNITY TEAM \\ IN-CLASSROOM SCHOOL PROGRAM \\ PROCESS DEVELOPMENT SCALE}

\begin{tabular}{|c|c|c|c|c|}
\hline \multirow{3}{*}{$\begin{array}{l}\begin{array}{l}\text { Process } \\
\text { Objective }\end{array} \\
1\end{array}$} & \multirow[t]{2}{*}{ Corresponding Procedures } & Date:Jan & Date:Mar & Date: May \\
\hline & & \multicolumn{3}{|c|}{ Number of Cases ${ }^{*}$} \\
\hline & $\begin{array}{l}\text { 1: Make observations. } \\
\text { 2: Meet with teacher. } \\
\text { 3: Gather additional information. }\end{array}$ & $\begin{array}{l}3 \\
2\end{array}$ & T & \\
\hline 2 & $\begin{array}{l}\text { 4: Decision to write plan. } \\
\text { 5: Write problem statement. } \\
\text { 6: Write statement with teacher. }\end{array}$ & 20 & 1 & 1 \\
\hline . & $\begin{array}{l}\text { 7: Develop plan. } \\
\text { 8: Use problem statement as base for plan } \\
\text { development. } \\
\text { 9: Develop plan with teacher. } \\
10 \text { a: State objectives in the plan. } \\
\text { b: State methods in the plan. } \\
\text { c: State benchmark in the plan. } \\
\text { d: State delineated responsibility in the plan. }\end{array}$ & $\cdot$ & & $\because$ \\
\hline 4 & $\begin{array}{l}\text { 11: Provide services to children. } \\
\text { 12: Provision of service by Community Team. } \\
\text { 13: Provision of services by teacher. }\end{array}$ & 5 & 4 & 1 \\
\hline 5 & 14: Meet with teacher to evaluate plan. & 2 & 15 & 6 \\
\hline 6 & $\begin{array}{l}14 \text { a: Review benchmarks with teacher. } \\
\text { b: Establish new benchmarks. } \\
\text { c: Establish new benchmarks with the teacher. }\end{array}$ & 1 & & 14 \\
\hline
\end{tabular}

*The numbers recorded indicate the number of cases which have reached the designated procedure. 
monitoring session seventeen had intervention plans in the file. of the five cases which did not have intervention plans only one had not reached the procedural stage of writing an intervention plan. The other four reported being in stages of plan evaluation. Both teacher and Community Team member reported that a plan had been developed in these four cases but in two of the four cases there were discrepancies in perceptions between teacher and Community Team member regarding whether or not a plan had been accomplished.

The graph following, shows how the process progressed in stages over the five month monitoring period. At each month illustrated, the majority of the cases are clustered around particular stages in the process with a few cases scattered throughout the process. By the end of the monitoring activities in all cases but one, have clustered around the plan evaluation functions.

The graph would indicate that reviewing of benchmarks did not occur as frequently as bi-monthly. Note that in January, one case had reached procedure 14a, the reviewing of benchmarks with the teacher, however in March, there were no cases which had completed this procedure. In the final monitoring, fifteen cases were reported to have achieved the procedure of reviewing benchmarks. Because of the difficulties associated with a time lag between interviews, it is possible that benchmarks were reviewed an additional time, in late March, after the second monitoring and again, before the final monitoring. The monitoring instrument does not however, quantify the occurrences of any procedure, only the provision of designated services, and as monitored, the benchmarks were not reviewed, for any of the cases, in March. 


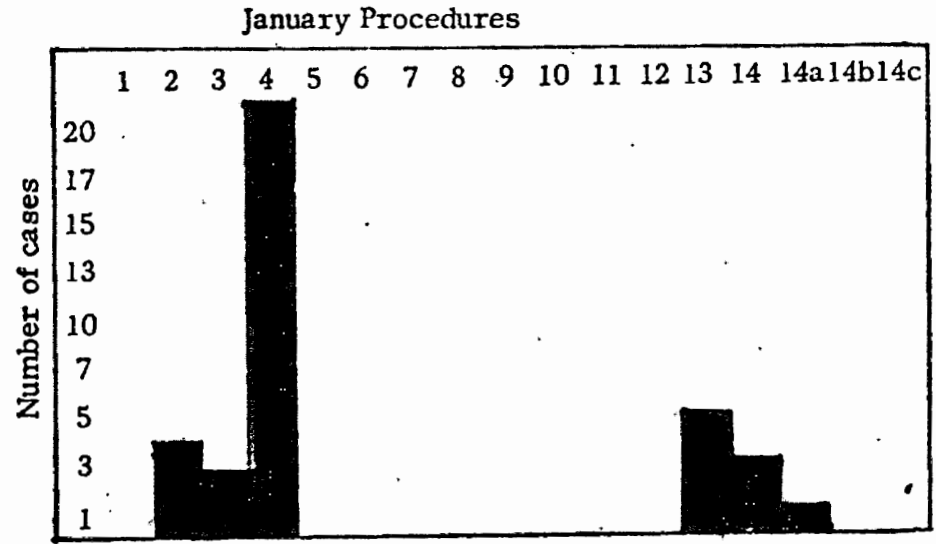

March Procedures

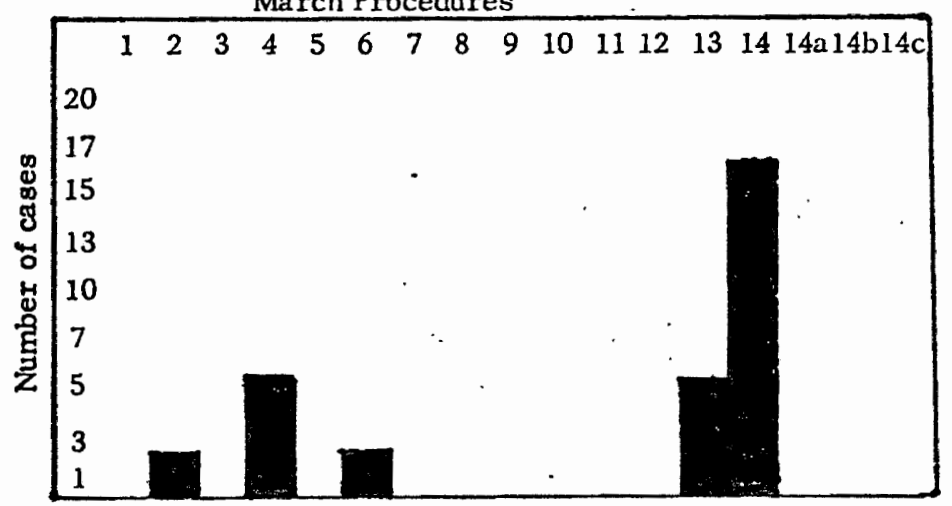

May Procedures

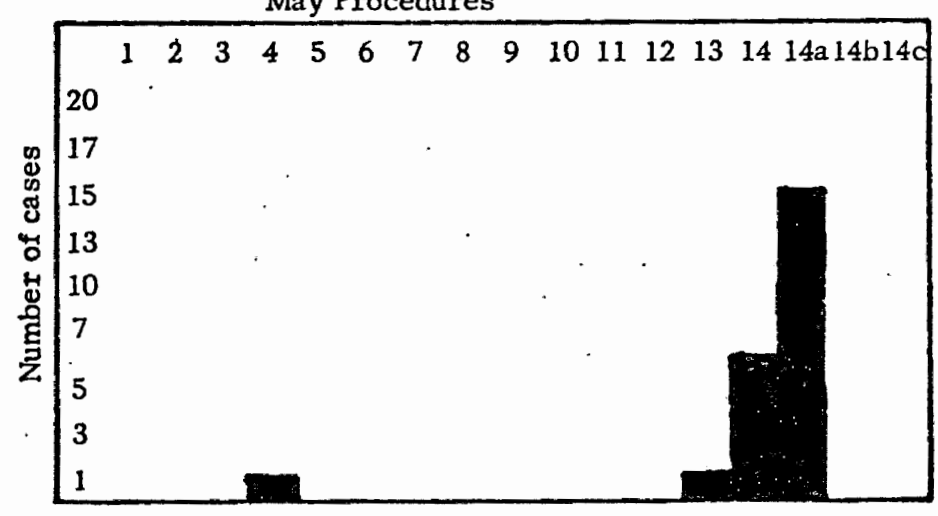

Figure 4. Graphical representation of the development of the process. 
Information from Intervention Plans

The only additional information to be derived from the intervention plans at this time, which is pertinent to the goals and objectives is the assessment of the problem statement. There is no formalized evaluative function now in effect regarding the written problem statement, other than verifying its existence. By reading through all the statements, the evaluator's superficial judgement is that the statements comply with the guideline that children be described from the perspective of current difficulties they are experiencing. There is no evidence of negative labeling in the problem statements on file.

\section{Monitoring Discrepancies}

In counting the frequency of discrepancies which appear on the Monitoring Discrepancy Inventory the following rate of occurrence can be noted.

TABLE III

FREOUENCY OF MONITORING DISCREPANCIES

\begin{tabular}{|c|c|c|}
\hline January & March & May \\
35 & 45 & 4 \\
\hline
\end{tabular}

In the aggregate, monitoring discrepancies were almost all dispelled by the end of the school program year. The discrepancy frequency in January and March require clarification because they reflect two essentially different types of perceptual disparities.

In January, the discrepancies were scattered throughout the 
cases, that is, all of the relationships reflected lack of clarity about the terminology and the development of procedural steps. of the thirty three identified cases in January, twenty four cases exhibited at least one area of discrepancy. In nine cases there was agreement between teacher and Community Team member about the stage and outcome of the decision-making process. Discrepancies centered around two functions, the gathering of additional information and the decision to write an intervention plan. This indicates that most plans were in the early period of negotiation and the procedure was relatively new to both the Community Team member and the teacher.

In March, although the frequency of discrepancy was higher, the discrepancies clustered in a very different pattern. Of the forty five discrepancies counted in March, thirty seven of the discrepancies appeared in four of the identified cases. This can be explained due to a primary lack of agreement as to the existence of a plan. When a teacher, for exampie, reported that an intervention plan had not been written and the Community Team member reported that the plan had not only been written, but reported several procedures had been completed, all of these procedures reported by the Community Team member and disclaimed by the teacher, appear as discrepancies on the Monitoring Discrepancy Inventory. Therefore, in March, in addition to the four cases which account for the majority of that month's discrepancies there were only eight other discrepancies counted.

The following table illustrates the frequency of discrepancies by procedure. The only procedures which exhibit a clustering, which would indicate program difficulties are, as previously noted, early in the program implementation. The confusion in large part can 
probably be explained by the newness of the system, especially since the problem does not reoccur.

Although the information just presented was not available to the Community Team in periodic reports, the monftoring function appeared to have a noticeable influence on the process development. Knowing that monitoring interviews were being scheduled and were being conducted periodically gave Community Team members a sense of deadlines and functioned as a catalyst for program operation.

The introduction of the program evaluation to the teachers and the experience of the monitoring interviews provided the Community Team with another means of explaining and reinforcing their proposed model of service delivery through an additional resource, which was external to the collaboration relationship. Teachers were provided with an additional opportunity to question the Community Team procedure, clarify terminology and express opinions.

\section{Collaboration Discrepancies}

The information which was collected and submitted to the Community Team in the form of periodic reports was data compiled on the collaboration Discrepancy Inventory. The information was collected and reported to Community Team members on an individual basis because the information about perceptual disparities was intended to be useful in enhancing particular collaboration relationships.

The frequency of collaboration discrepancies illustrated in Table $\mathrm{V}$ shows that at the beginning of the monitoring the disparities were fairly evenly spread among the functions selected for reporting. Over time discrepancies gradually decrease and all but disappear in 
TABLE IV

FREQUENCY OF MONITORING DISCREPANCIES

BY PROCEDURE

1: Make observations.

2: Meet with teacher.

3: Gather additional imformation.

4: Decision to write plan.

5: Write problem statement.

6: Write statement with teacher.

7: Develop plan.

8: Use problem statement as base for plan development.

9: Develop plan with teacher.

10 a: State objectives in the plan.

b: State methods in the plan.

c: State benchmark in the plan.

d: State delineated responsibility in the plan.

11: Provide services to children.

12: Provision of sexvice by Community Team.

13: Provision of services by teacher.

14: Meet with teacher ta eqaluate plan.

14 a: Revtew benchmarks with teacher.

b: Establish new benchmarks.

c: Establish new benchmarks with the teacher

TOTAL

Number of Cases Involved

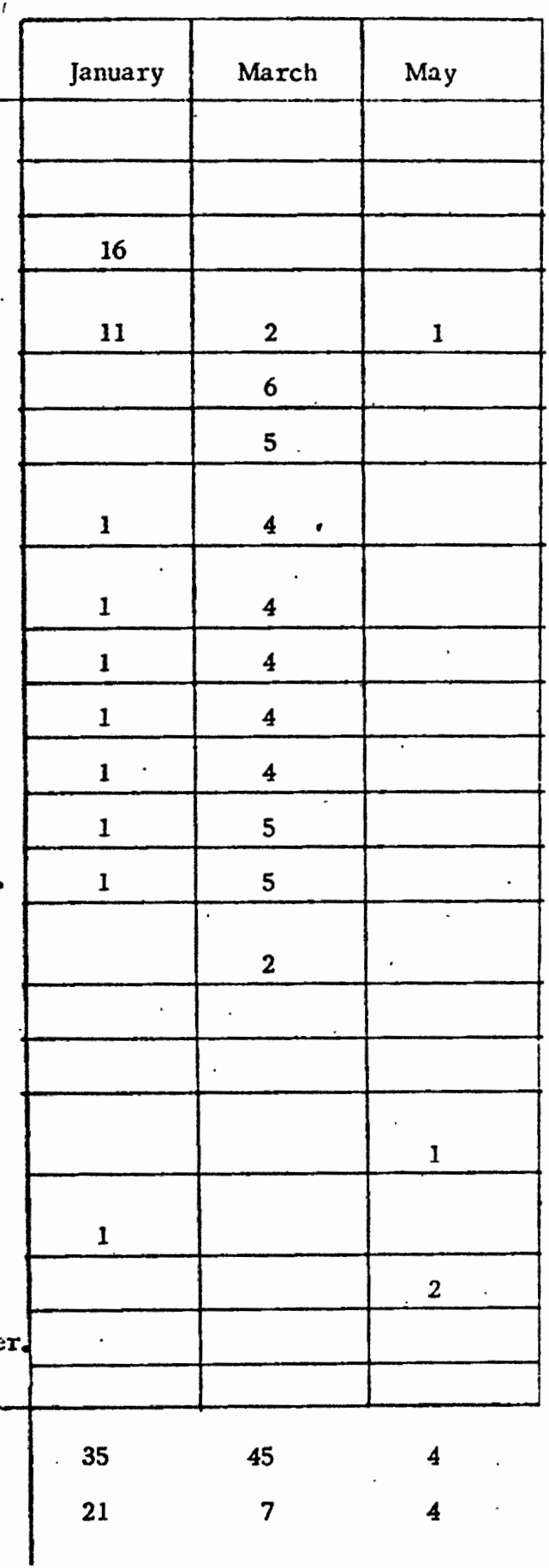


the Goal III objectives of technique sharing and milieu discussion. Discrepancy frequency in the area of service provision does not show any decrease, however these discrepancies were characterized by very slight variations in the description of the services provided.

\section{TABLE V}

FREQUENCY OF COLLABORATION DISCREPANCIES

Service Provision
Sharing Techniques
Physical Milieu
Social Milieu

Total

\begin{tabular}{|c|c|c|} 
Jamuary & Maxch & May \\
\hline 4 & 10 & 10 \\
\hline 2 & & \\
\hline 2 & 1 & \\
\hline 2 & 3 & 1 \\
\hline
\end{tabular}

10
11

One possible explanation for collaboration discrepancies which emerged during one of the reports made to the Community Team was that Community Team members were under-estimating their provision of the collaboratives functions described in the objectives in relation to service provision reported by teacher. In order to check the extent of this under reporting, a frequency table was compiled comparing the number of instances that Community Team members under reported services, over-reported or were uncertain. Under reporting was counted when a Community Team member stated that he or she had not provided the collaborative service while their respective teacher-partner reported that they had. Over-reporting was counted when the Community Team member responded that he or she had provided the services and the teacher reported that the Community Team member had not. The 
incidence of the Community Team member being uncertain was taken from the number of times the Community Team member responded "Don't Know" to the monitoring question.

As noted in Table VI the frequency in all areas decreased over time.

TABLE VI

FREQUENCY OF COMMUNITY TEAM MEMBER UNDER-REPORTING

PROVISION OF COLLABORATIVE SERVICES

Community Team Member Under-reporting

Community Team Member Over-reporting

Community Team Member Not Sure

Different Services Reported

Total

\begin{tabular}{|c|c|c|}
\hline January & March & May \\
\hline 5 & 8 & 2 \\
\hline 4 & 1 & \\
\hline 1 & 1 & \\
\hline 10 & 4 & 9 \\
\hline
\end{tabular}

The incidence of Community Team under reporting in January accounts for five out of ten recorded discrepancies for that month. In March, over reporting accounted for eight out of fourteen reports and in May, only two out of eleven.

The effect and usefulness of the collaboration discrepancy information is difficult to discuss since it deals with an essentially personal and subjective realm of interpersonal communication between two individual professionals. That Community Team members utilized. the discrepancy information periodically reported to them can be inferred from the evidence of decreased discrepancies in certain areas. This possibility is only a supposition and cannot be stated conclusively. 
During Community Team meetings, when the collaboration discrepancy information was reported there were a couple of instances when the information instigated adiscussion of possible restructuring and renegotiating of expectations, within particular collaboration relationships. There was at least one instance where attitudinal differences between Community Team member and teacher were clarified and although neither member of the collaboration changed their fundamental views, they did not feel that this was required for them to continue to work together effectively. In addition to providing Community Team members with a perception check, this redefinition of divergent expectations is an important way that collaboration discrepancy information can be used in the development of collaborative interaction.

\section{Logistical Difficulties}

Allusion has been made throughout the monitoring narrative to the difficulties encountered by the time lag between the monitoring interview of the teacher and that of the respective Community Team member. Every attempt was made to schedule corresponding interviews as closely together as possible but sometimes, as much time as a full week would separate the two interviews. The amount of information shared between teacher and Community Team member during this interval could greatly alter the frequency of discrepancies reported at any fixed point in time.

This time lapse is almost unavoidable but the information should be scanned and interpreted with an awareness of this situation. 


\section{PEER INTERACTION INVENTORY}

The observational technique was developed for the purpose of collecting information in relation to the Community Team's prioritized objective of encouraging and promoting cooperative activities among children. The Community Team members wanted to learn if there would be an increase in cooperative behavior among children in classrooms over a period of time. The Peer Interaction Inventory was not intended to provide a pre-test post-test measure but offers information about the relative frequency and nature of peer interactions. Compilations of frequency counts indicate that in the three classrooms used in the sample, non interaction among children is consistently the most common behavior. Relative to the high incidence of non interaction, cooperation, as defined for purposes of coding, did not occur very often.

\section{Agreement Rate}

In assessing the findings of the Peer Interaction Inventory the rate of agreement between the two observers must be considered. In tallying the overall number of behaviors observed and agreed upon, the rate of agreement was 79.5 per cent. This percentage was based on tallying all of the behavior categories.

A second agreement rate was calculated, eliminating the category of Non Interactive behavior because of the disproportionately high frequency of this behavior and the relative ease in recognizing and recording non interaction. The rate of agreement among the other behavior categories, discounting Non Interactive, was 26.4 per cent.

This low agreement between two observers raises serious questions 
about the usefulness of this instrument to precisely measure specific behaviors in the classroom. However, the instrument does provide some interesting indicators of the nature of classroom peer interaction.

\section{Frequency Rates}

In viewing basic frequency counts, the most common behavior which occurred was in the Non Interactive category, that is, children engaged in an independent or isolated activity, not interacting with either a peer or an authority in the classroom. The incidence of non interactive behavior was much higher than the incidence of any other single behavior category in all classrooms observed. The difference between frequency in the non interactive category and the second most common behavior varied among classrooms. (See Table VII.).

TABLE VII

FREQUENCY OF OBSERVED INTERACTIONS

\begin{tabular}{|l|r|r|r|}
\hline \multicolumn{2}{|c|}{ Classroom 1 } & Classroom 2 & Classroom 3 \\
\hline VERBAL 1 & 3 & 2 & 1 \\
PHYSICAL 1 & 2 & 1 & 5 \\
VERBAL 2 & 0 & 0 & 4 \\
PHYSICAL 2 & 2 & 0 & 0 \\
COOPERATIVE & 50 & 33 & 76 \\
DOMINANT & 3 & 0 & 3 \\
SUBMISSIVE & 3 & 0 & 1 \\
NO RESPONSE & 2 & 0 & 2 \\
COMPETING RESPONSE & 5 & 0 & 1 \\
INTERACTIVE. & 42 & 107 & 27 \\
NON INTERACTIVE & 358 & 336 & 360 \\
\hline \multicolumn{2}{|c|}{ TOTAL OBSERVATIONS: } \\
TOTAL INTERACTIONS: & 240 & 478 & 478 \\
\hline
\end{tabular}


The number of non interactive occurrences was relatively the same in all classrooms. Although the Non Interactive frequency rate was slightly down in Classroom 2, compared to the other classrooms, the difference between the highest frequency of Non Interactive behavior in a classroom, which was in Classroom 3, and the lowest frequency of Non Interactive behavior, which was in Classroom 2, was only twenty four behavior counts out of 478 total possible observed behaviors. Regardless of variations which naturally characterize different classroom environments and which appear in the Cooperative and Interactive categories, peer non interaction remained consistently high.

The second and third most common behaviors fell into two categories which are the same for all three classrooms: Cooperative and Interactive. Cooperative behavior was defined, for the purposes of the Peer Interaction Inventory, as equal participation in activity or conservation. Interactive behavior was determined to be an additional peer interaction; additional to those specified in the Peer Interaction Inventory categories, and was also to include interactions between child and an authority.

In Classroom 1, the second most common behavior observed was Cooperative and the third most common behavior was Interactive. Also, in Classroom 3, Cooperative was the second, and Interactive the third most common behavior. Although Classroom 1 and 3 were similar in that Cooperative ranked second and Interactive third in both of their frequency counts, Classroom 3 had a much wider difference between frequency of Cooperative behavior, the more common behavior of the two, and Interactive behavior. 
Classroom 2, however represents a reversal in the frequency of these two behavior categories. In Classroom 2, Interactive was the second most common behavior recorded, and the Cooperative category was the third most common interaction.

\section{$\underline{\text { Percentages }}$}

In reporting percentages, only the three major categories of behavior observed, Cooperative, Interactive and Non Interactive, are presented.

\section{TABLE VIII}

PERCENTAGES OF OBSERVED INTERACTIONS

\begin{tabular}{l|r|r|r|}
\multicolumn{1}{c}{ Classroom I } & \multicolumn{1}{c}{ Classroom 2 } & Classroom 3 \\
\cline { 2 - 4 } COOPERATIVE & 10.4 & 6.9 & 15.9 \\
INTERACTIVE & 8.8 & 22.4 & 5.7 \\
NON INTERACTIVE & 74.6 & 70.3 & 75.3 \\
ALL OTHER INTERACTIONS & 6.2 & .4 & 3.1 \\
\multicolumn{1}{c}{ TOTAL } & $100 \%$ & $100 \%$ & $100 \%$
\end{tabular}

These percentages are based on the tallied frequencies of total possible observed interactions. The total possible observations, as noted under Table I differ slightly between the three classrooms. In both classroom 2 and 3, an interaction was missed because the observer's view was blocked or the child left the room. This fact tends to slightly skew the percentage reported.

\section{$\underline{\text { Ratios }}$}

To facilitate the Community Team's stated interest in comparing the amount of cooperative behavior amongst children in the classroom 
with other types of interaction, ratios were established based on the three major behavior categories. All ratios were calculated based on total possible observed interactions.

The first set of ratios combines the two interactive categories of Cooperative and Interactive and compares them, as a unit, to the Non Interactive category. The ratios of interactive (Cooperative/ Interactive) behavior to non interactive behavior, by classroom are stated in the following table:

\section{TABLE IX}

\section{RATIO OF INTERACTIVE: NON INTERACTIVE BEHAVIORS}

\begin{tabular}{|c|c|c|}
\multicolumn{1}{c|}{ Classroom 1. Classroom 2 } & Classroom 3 \\
\hline $1: 3.9$ & $1: 2.4$ & $1: 3.5$ \\
\hline
\end{tabular}

In Classroom 1, for every interactive behavior there were almost four non-interactive behaviors, in Classroom 2, the ratio was the lowest, one to about two and a half and in Classroom 3, the ratio was one to three and a half.

The second set of ratios singles out the Cooperative category since this was the primary focus of the Community Team's request for information about the nature of classroom peer interaction. The comparison reflected by the ratios in Table VII is between Cooperative and Non Interactive. Again, listed by classroom, the ratios are recorded as follows: 
TABLE X

RATIO OF COOPERATIVE: NON INTERACTIVE BEHAVIORS

\begin{tabular}{|c|c|c|}
\hline Classroom 1 & Classroom 2 & Classroom 3 \\
\hline $1: 7.2$ & $1: 10.2$ & $1: 4.7$ \\
\hline
\end{tabular}

In Classroom 1, for every cooperative interaction among children there were over seven non interactive intervals. In Classroom 2, the ratio was the highest; for every cooperative behavior there were over ten non interactive counts. In Classroom 3, where the ratio was the lowest for every cooperative interaction approximately four and a half non interactive intervals.

The ratios illustrate the low incidence of cooperative activities among children in their classrooms, especially as compared to the amount of time they spend in either independent or isolated activity.

\section{Discussion of the Instrument}

Before drawing any conclusions from the report of the classroom observations, it is necessary to briefly ennumerate the logistical obstacles and conceptual difficulties encountered in the attempt to provide reliable and valid information about cooperation in the classroom. An explanation of these obstacles will be helpful in evaluating the findings and in clarifying the reasons for a low agreement rate.

Logistical Obstacles: The synchronizing of the two separate tape recorders used during the observation was a difficulty early in the observation period. At certain points, in the middle of a ten minute observation of a particular child, the tapes were one to two seconds off. This amount of time becomes critical during a fifteen 
second interval and can, in part, account for the low agreement rate. Another logistical difficulty encountered was the impossibility of the observers' to hear many of the verbal exchanges between children. This was due to the tape recorder earphones, the observers' inability to move freely and easily around the room and the level of distracting sounds in a normal classroom atmosphere. Although the coding instructions stressed behavioral determinations, the ability to hear conversations would have aided the observers in their attempt to make a judgement about the nature of the interaction observed. Had the observers been able to hear more of what the children were saying, the variety of action recorded would probably have been greater. This is an unfortunate loss of important information but the requirements of this particular observation technique and observations in general make the problem of hearing very complicated.

One Community Team member expressed disappointment at the inability to hear verbal exchanges between children, feeling certain, based on experiences with children in the classroom that a greater variety of action was occurring than was reflected by the Peer Interaction Inventory. This may very well be true but the observational instrument was designed to count behaviors and another technique would be used if verbal interactions are of prime importance. While hearing difficulty was a problem in terms of information loss, seeing all interactions was also occasionally awkward. The child being tracked would move behind a group of children and be temporarily blocked from the observers' view. In a couple of instances, a child actually left the room either to go to the restroom or to a special activity period held outside of the classroom. 
In one of the classrooms, Classroom 2, on the day observations were made, about half of the children were absent due to illness. In this situation the children's awareness of observers' presence was very high. It is impossible to determine, to what extent, if any, the children's awareness of observers effected their behavior. For. the most part, children in this classroom sat at their desks, in isolated, non-interaction with peers, staring at the observers.

There was some awareness of observers' presence in the other classrooms but not to any degree of interference. Children in the other two classrooms made note of the observers and after a few seconds returned to their normal activity.

Another major obstacle existed within the Interactive category where no distinction was made between "other" peer interactions and the interactions between a child and the teacher. From the observations it is known that a large proportion of the behaviors recorded under Interactive were interactions with the teacher but this is only based on the experience of the observation and not documented evidence. Since the instrument was purposefully designed without a separate distinction for child/authority exchanges, no conclusive information was collected regarding the amount or the nature of the interaction between child and teacher.

The over-riding logistical obstacle, which has been noted on the description of the Peer Interaction Inventory development process, was the time required in selecting and revising an observational instrument. The reasons for this time consumption are many and varied but the resulting delay of the initial observation, finally made in February, excluded the possibility of a pre and post test measure. 
In order to provide the Community Team with some indication of increase or decrease in the frequency of peer cooperation over time, the initial observation should have been made early in the school year, even before the Community Team entered their assigned classrooms. The lack of posttest measure further limits the validity of the information.

Conceptual Difficulties: In addition to the purely practical difficulties of seeing, hearing and timing, there were some obstacles that were particular to this observation instrument and to the values and beliefs of the Community Team staff for whom the instrument was tailored.

The instrument was researched and developed within the guidelines of the Community Team's goals and objectives. The observers were very conscious of the Community Team's values, perhaps to the extent of being overly cautious when making a judgement about the nature of an interaction.

This caution could have been partially related to, and intensified by, the imprecise definitions developed for coding behaviors. The definitions reflect the Community Team members belief in the avoidance of labels for children and a liberal consideration of a term such as aggression. The Community Team was very clear that an aggressive behavior could be considered either positively or negatively, depending on the context and could cite examples of aggressive behavior which were appropriate and those which were inappropriate. Their criteria for assessment seemed to be a sense of fairness, which was naturally subjective and situational. Being unable to decide on a definition of fairness, the Community Team left coding determinations up to the subjective judgements of the observers. Using such intangible elements as a basis for measurement and attempting to reflect a clearly articu- 
lated, but difficult to operationalize belief system, made the problem of precise coding a double edged sword for the observers.

Perhaps the greatest difficulty encountered in the development of the Peer Interaction Inventory was the difficulty of defining and operationalizing terms. During the prioritizing of objectives, when the Community Team selected cooperation as their major interest regarding peer behavior within the milieu of the classroom, there was no objective definition of cooperation utilized by the staff. At that particular stage of the process, the staff viewed cooperation as a symbolic term, somehow encompassing their overall purpose and intent. They were not thinking of cooperation in behavioral or operational terms, but in a larger sense, reflective of their goal. Later, when cooperation was defined and operationalized as "equal participation in activity", the process of operationalizing cooperation essentially changed the conceptual definition, which was the one the Community Team had selected as their priority.

The Community Team never actually prioritized cooperation as defined in the Peer Interaction Inventory definitions. They prioritized a broader conceptual definition of cooperation. The findings of the observation, in being reported to the Community Team and in being utilized, to whatever extent possible, in future program planning must be considered with an awareness of two definitions of the term cooperation.

Coding Difficulties: Another major variable to be considered in evaluating the instrument and the findings was the confusion surrounding the coding instructions. The confusion centered around two of the instructions. The first one, number.3, deals with a situation 
involving doubt about whether or not the child is interacting.

Number 3. Unless the child manifests a behavioral reaction, such as asking a question or following a specific instruction, score listening to teacher as Non Interactive. If there is some doubt, Non Interactive takes precedence.

Although the emphasis was on a behavioral determinant for non interactive behavior, observer drift and the highly subjective nature of assessing interaction, account for an inconsistent approach to the recording between the Non Interactive and the Interactive category. The intent of the instruction was to clarify coding procedures for the observer. The result was that of creating shades of grey rendering judgement more difficult.

Timing in this instance again, became critical. For example, a child could be sitting still, exhibiting no interactive behavior, assumedly listening to the teacher's instructions for thirteen of the fifteen second interval and at the fourteenth or fifteenth second, make a move which required a decision about whether the child was following instructions, which would be counted as interaction with authority, or merely a behavior which was essentially not an interaction. Although the instructions for coding indicate that any doubt suggests a non interactive count, the basis for doubt varies considerably from one observer to another. Had the training period been more extensive and rigorous, it is conceivable that some degree of precision between observers could have been achieved in this area.

The instruction to give the Non Interactive category precedence in situations involving doubt further complicates the process of analyzing the data collected. There is no way of determining, aside from observer approximation, how much of the behavior recorded under Non 
Interactive can be attributed to doubt situations. This somewhat contaminates the Non Interactive count.

The problem with instruction 7 is related to the confusion involving the timing of a child's behavior.

Number 7. Record the "last scoreable response". ("scoreab1e" is the key word. Record the last completed, understandable behavior.)

The intent of "last scoreable response" was to account for the anticipated problem of a child beginning a behavior at the very end of the fifteen second interval. The instruction indicated that the last complete behavior which could be understood and described, should be the fourteenth or fifteenth second, but had not been completed, should be discounted and the behavior exhibited in the previous seconds should take precedence. Again, timing and lack of trained precision added to the existing confusion inherent in the requirement for split second decision-making.

Training of Observers: One other factor which probably effected the low agreement rate was the shortness of the time the observers had to practice the observation instrument before beginning the actual observations. It is possible that much of the confusion created by the imprecise definitions and the complicated coding instructions could have been lessened had there been a greater opportunity for more extensive training of observers and refining of the technique. Resources to support the observation were, however, limited and the training of observers was very brief. To what extent refinement of the instrument would be possible, given adequate time, is a matter of conjecture. 
TEACHER ATTITUDE QUESTIONNAIRE

The questionnaire provides an indication of how the Community Team program was perceived and accepted by the teachers at Gregory Heights Elementary School. In reporting the responses to the questionnaire, frequency tables, which can be easily read due to the small number of respondents, will be utilized.

\section{Awareness of Methods}

Generally, there seemed to be a full awareness of intervention methodologies utilized by the Community Team at Gregory Heights among non-participating teachers as well as those involved in the program. Every respondent was aware of one to one work with an individual child. Among non-participating teachers there was slightly less awareness of some of the indirect intervention methods, notably work with school administration and collaboration regarding physical milieu of the classroom.

One participating teacher noted an additional method utilized by Community Team not on the list in the questionnaire, the use of video tape in working with children, which the file verifies was used frequent1y.

\section{Most Important Methods}

All respondents were asked to select the four methods they considered most important for the Community Team to continue. They were not limited to the categories listed but could make suggestions and include in their priorities.

Among participating teachers the most frequent methods mentioned 
TABLE XI

\section{AWARENESS OF INTERVENTION METHODS}

One to one work with individual child in class.

One to one work with individual child out of class.

Small group work with chlldren in class.

Small group work with children out of class.

Work with parents.

Work with school administration.

Collaboration with teacher re: child.

Collaboration with teacher re: all children.

Collaboration re: how class structured.

\begin{tabular}{|c|c|c|c|}
\hline $\begin{array}{l}\text { Participating } \\
\text { Teachers }\end{array}$ & $\begin{array}{l}\text { NonParticipating } \\
\text { Teachers }\end{array}$ & Principal & Total \\
\hline 4 & 3 & 1 & 8 \\
\hline 3 & 3 & 1 & 7 \\
\hline 3 & 3 & 1 & 7 \\
\hline 3 & 2 & 1 & 6 \\
\hline 4 & 2 & 1 & 7 \\
\hline 3 & 1 & 1 & 5 \\
\hline 3 & 3 & 1 & 5 \\
\hline 3 & 1 & 1 & 6 \\
\hline & & & 8 \\
\hline
\end{tabular}

were one to one work with individual child in class and work with parents. Non participating teachers favored small group work in the classroom and collaboration with the teacher regarding the social milieu. The principal cited small group work, parent contact and collaboration about some of the children, as most important intervention strategies.

Generally, the respondents views of most important functions to be continued relate to their awareness of methodologies currently utilized by the Community Team.

Respondents were then asked to state why they had prioritized the methods they had. Teachers tended to express concern for expanded opportunities and information for children, parents and teachers and 
TABLE XII

MOST IMPORTANT METHODS TO BE CONTINUED

One to one work with individual child in class.

One to one work with individual child out of class.

Small group in class.

Small group out of class.

* Small group including all children.

*Work with whole class.

Work with parents.

Work with administration.

Collaboration with teacher re: child.

Collaboration with teacher re: class.

*Information and referral

* Magic circle.

* Collaboration: re: some children in the classroom.

\begin{tabular}{|c|c|c|c|}
\hline $\begin{array}{l}\text { Participating } \\
\text { Teachers }\end{array}$ & $\begin{array}{l}\text { NonParticipating } \\
\text { Teacher }\end{array}$ & Principal & Total \\
\hline 3 & 1 & & 4 \\
\hline i & & & 1 \\
\hline 2 & 2 & 1 & 5 \\
\hline 2 & & 1 & 3 \\
\hline 1 & & - & 1 \\
\hline 1 & 1 & & 2 \\
\hline \multirow[t]{2}{*}{3} & 1 & 1 & 5 \\
\hline & 1 & & 1 \\
\hline 1 & & & 1 \\
\hline \multirow[t]{4}{*}{1} & 2 & & 3 \\
\hline & 1 & & 1 \\
\hline & 1 & & 1 \\
\hline & & 1 & 1 \\
\hline
\end{tabular}

*Added categories.

stressed the enrichment aspect of providing some children with special attention, allowing added opportunity for children to work in small groups and emphasizing the teacher's limitations to provide all experiences and support services needed. Both participating and non-participating teachers expressed opinions of this nature.

The principal's stated reason for selecting the methods he had was that, in his view, they have the greatest likelihood of producing the most behavior change for the least amount of time and effort 
extended. With the exception of the administrator's selection of collaboration and the teachers', especially the participating teacher's mention of individual casework, the priorities of teachers and principal are the same. The difference in rationale, however, is noteworthy. Teachers articulated concern was with teacher's limitations, while the administrator supports priority determinations in terms of effectiveness considerations.

\section{Most Effective Community Team Approach}

One final question was asked regarding staff opinion of the most effective Community Team approach. The questionnaire listed a range of four selections and respondents could only check one.

\section{TABLE XIII}

MOST EFFECTIVE APPROACH

One child at a time.

Small group of children outside classroom.

A child or a few within normal routine of classroom.

Work indirectly, assisting teacher's work with children.

*ther: adepends on situation.

*Other; depends on child's needs.

\begin{tabular}{|c|c|c|c|}
\hline $\begin{array}{l}\text { Participating } \\
\text { Teachers }\end{array}$ & $\begin{array}{l}\text { NonParticipating } \\
\text { Teachers }\end{array}$ & Principal & Total \\
\hline & & & \\
\hline 4 & 1 & & 5 \\
\hline & 1 & & 1 \\
\hline & 1 & & 1 \\
\hline & & 1 & 1 \\
\hline
\end{tabular}

* Added categories.

The iresponse of the participating teachers was unanimous and relates to their previously stated priorities regarding direct intervention to children which are one to one work individual child and small 
group work in the classroom. There was no pattern to responses among non-participating teachers.

\section{Conception of Community Team Role}

Two questions were asked with the intent of assessing the staff views of the Communfty Team member's function in the classroom and manner of relating services to and/or through the teacher.

The first question was.designed to deduce perceived function and respondents could only check one in a range of five choices.

TABLE XIV.

PERCEIVED COMMUNITY TEAM FUNCTION IN CLASSROOM

Resource person for the classroom.

An intruder from outside the school.

An assistant to the teacher.

A disruption to class routine.

A friend for the children.

\begin{tabular}{|c|c|c|c|}
\hline $\begin{array}{l}\text { Participating } \\
\text { Teacher }\end{array}$ & $\begin{array}{l}\text { NonParticipating } \\
\text { Teacher }\end{array}$ & Principal & Total \\
\hline 1 & & 1 & 2 \\
\hline & & & \\
\hline 1 & 2 & & 3 \\
\hline & 1 & & 1 \\
\hline 2 & & & 2 \\
\hline
\end{tabular}

Teachers participating in the Community Team program seem to be more impressed with the provision of services to children and the classroom than non-participating teachers who conceive of the Community Team member providing support services to the teacher.

The question regarding the manner in which the Community Team member relates to the teacher (principal) presented a range of three choices and there was no limit on the choices respondents could check. 
TABLE XV

TEACHER PERCEPTION OF ROLE IN RELATION

TO COMMUNITY TEAM

\section{A recipient of special services. \\ Partner/peer. \\ An expert re: children's school difficulties. \\ Other: does not apply.}

\begin{tabular}{|c|c|c|c|}
\hline $\begin{array}{l}\text { Participating } \\
\text { Teachers }\end{array}$ & $\begin{array}{l}\text { NonPa rticipating } \\
\text { Teacher }\end{array}$ & Principal & Total \\
\hline 3 & & & 3 \\
\hline 4 & 1 & 1 & 6 \\
\hline & 1 & & 1 \\
\hline & 1 & & 1 \\
\hline
\end{tabular}

The participating teachers have a strong sense of collaboration and awareness of recelving services, while non-participating teachers express no collective agreement, which could be largely due to lack of exposure. The principal views the program as collaborative.

\section{Probe on Collaborative Process}

Because the method of collaboration is so critical to the Community Team's service strategy, two questions were designed to verify information about staff's feeling of accessibility to Community Team members and of the approach characterizing an equal sharing in decision-making.

In questioning access, respondents were asked if they felt free to share questions and concerns about children's social-emotional characteristics with a Community Team member. The response was unanimously yes. Only one other question in the attitude survey received a unanimous response rate.

The question concerning collaboration was presented as a range and respondents could only select one of the choices. There was total 
agreement among participating teachers, supported by the principal's response but apparent confusion among non-participating teachers, probably due to lack of experience with the program.

\section{TABLE XVI}

BEST DESCRIPTION OF COMMUNITY TEAM APPROACH

Gives directions to teacher.
Persuades teacher to
follow advise.
Collaborates
Operates independently
of teacher.
Other: don't know.

\begin{tabular}{|c|c|c|c|}
\hline $\begin{array}{l}\text { Participating } \\
\text { Teacher }\end{array}$ & $\begin{array}{l}\text { NonParticipating } \\
\text { Teacher }\end{array}$ & Principal & Total \\
\hline & & & \\
\hline 4 & 1 & 1 & 6 \\
\hline & & & \\
\hline & 2 & & 2 \\
\hline
\end{tabular}

\section{Positive Contributions}

When asked, to which relationships and in what ways, staff perceive Community Team as making a positive contribution, what emerged from the response of the participating teachers was an emphasis on the relationships amongst children and teachers and between child and teacher. Specific examples of positive contributions grouped around three concepts, reinforcement for children and for teacher, a resource for both, but primarily for the teacher and reassurance for the teacher and amongst teachers.

Non-participating teachers and the principal tended to stress the view of the Community Team member as a resource person.

Responses from participating teachers and principal included at least one mention in every relationship category, while non-participating teachers checked every relationship except one, between parent and 
teacher, which could be accounted to lack of information and/or experience with the program.

\section{Negative Contributions}

The same categories of relationships were presented to the respondents with the question of what, if any, negative effect was due to Community Team intervention.

The participating teachers, unlike the non-participants, could be specific about their concern that children not identified within the Community Team program felt neglected and do not have equal access to the extra attention offered by the Community Team member. Two of the four participating teachers noted this effect: Another negative effect stated, was that of children sometimes receiving more attention than was appropriate to their need. All teachers who mentioned this drawback had a sense that too much attention had the effect of reinforcing acting-out behavior in children.

Two out of the three non-participating teachers stated that they thought there was a negative effect but couldn't be specific. The principal was not aware of any negative contribution to relationships due to Community Team methods.

\section{Benefits to Children and Teacher}

In an attempt at getting more specific information about staff perceptions of Community Team program contributions, respondents were asked to list particular benefits they felt they and/or the children had received from the Community Team.

Listings in response to this question support information previously acquired. This question is probably redundant and need not be 
included in the questionnaire. Respondents noted such specific benefits as having a positive relationship with a caring adult, increased selfesteem and broadened opportunities for interaction, as benefits for children. For teachers, respondents noted that the Community Team member offered an additional resource and a new perspective into the child's family 1ife.

A question which was asked later but is related to perceived benefits was whether or not teachers felt better prepared to deal with social-emotional difficulties, which arise in the classroom, as a result of their involvement with Community Team program. All participating teachers responded to this question in the affirmative, while all others responded that the question did not apply to their experience.

\section{Time Consumption and Allotment}

Recognizing the perennial problem of constraints on teacher's time respondents were asked to approximate how much additional time they felt was required to work with the Community Team program. Most agreed that slightly more work was required, however one participating teacher felt that a great deal of additional work was required.

TABLE XVII

HOW MUCH MORE WORK REQUIRED BY COMMUNITY TEAM

A great deal more.

Slightly more.

Same a mount.

Other.

Does not apply.

\begin{tabular}{|c|c|c|c|}
\hline $\begin{array}{l}\text { Participating } \\
\text { Teachers }\end{array}$ & $\begin{array}{l}\text { NonParticipating } \\
\text { Teachers }\end{array}$ & Principal & Total. \\
\hline 1 & & & 1 \\
\hline 3 & 1 & 1 & 5 \\
\hline & & & \\
\hline & & & \\
\hline & 2 & & 2 \\
\hline
\end{tabular}


The next question had to do with recommendations for restructuring time among various Community Team program functions. These functions were enumerated and under each listing a range of options were included: should be more extensive, should be less extensive, it is not necessary. If respondents felt that the time alloted to a particular function was appropriate and should be kept at the same level the function was not checked.

Among non-participating teachers there was no area of agreement about changes in time allotment. There were, however, five areas which all non-participating teachers considered should be kept at the current leve1. These areas are: 1) periodic evaluations of child's progress, 2) discussions about how all children in the classroom interact, 3) the implementation of techniques and strategies suggested by Community Team member, 4) monitoring and program evaluation interviews and 5) working with parents regarding things discussed with the Community Team.

Al1 four participating teachers agreed that the implementation of techniques and strategies suggested by the Community Team member should receive the same amount of time in the future. They also agreed on maintaining collaboration time with Community Team in defining difficulties a child is experiencing at the same level.

In these areas, two out of four participating teachers felt there should be time restructuring. The provision of services to children which was required in the intervention plans and the discussion of social milieu were considered to be functions where time spent could be more extensive. One area which two out of the four participating teachers agreed could be less extensive was monitoring and program evaluation interviews. 
In all other categories, only one respondent indicated change was required.

The principal's response was that all functions ideally, could be more extensive and noted that setting aside a particular meeting for the teacher and Community Team member to plan during a regular school schedule was a highly desireable measure.

Concentrating on the response of participating teachers, there is very little guidance for future time redistribution based on the lack of general agreement about extensive change. The strongest indications from participating teachers is that diagnostic collaboration time and the time spent in the implementation of techniques suggested by Community Team should remain the same. Areas to be considered for expansion are service provision and collaboration regarding social milieu. Also, to be considered are ways to cut back on the time required by monitorIng and program evaluation interviews.

\section{Level of Program Continuance}

A general question asked about whether the Community Team program should be expanded, kept at the same level or cut back. No one thought the program should be lessened but there were qualifications to responses that the program be expanded. 
TABLE XVIII

AT WHAT LEVEL SHOULD PROGRAM BE CONTINUED?

Expanded.

Kept at same level.

Cut back.

Other.

\begin{tabular}{|c|c|c|c|}
\hline $\begin{array}{l}\text { Participating } \\
\text { Teachers }\end{array}$ & $\begin{array}{l}\text { NonParticipating } \\
\text { Teachers }\end{array}$ & Principal & Total \\
\hline 2 & 2 & 1 & 5 \\
\hline 2 & 1 & & 3 \\
\hline & & & \\
\hline & & & \\
\hline
\end{tabular}

One non-participating teacher included in her response that the program be expanded, but handled differently.

One participating teacher indicated that the time generally should be expanded, especially the frequency of time spent with the children.

\section{Opinions of Mental Health Strategies}

Three questions were asked concerning mental helath and educational concepts of classroom interventions. The first question related to respondents' views of mainstreaming children who have been identified as requiring social-emotional support, within a typical classroom setting by providing them with additional services, such as those offered by the Community Team. 
TABLE XIX

TO WHAT EXTENT SHOULD CHILDREN REMAIN IN CLASSROOM PROVIDED WITH SPECIAL SUPPORT SERVICES?

Aimost always.

Quite often.

Very infrequently.

Almost never.

Dan't know.

No response,

\begin{tabular}{|c|c|c|c|}
\hline $\begin{array}{l}\text { Participating } \\
\text { Teacher }\end{array}$ & $\begin{array}{l}\text { NonParticipating } \\
\text { Teacher }\end{array}$ & Principal & Total \\
\hline 1 & 1 & & 2 \\
\hline 2 & & 1 & 3 \\
\hline 1 & & & 1 \\
\hline & & & \\
\hline & 1 & & 1 \\
\hline & 1 & & 1 \\
\hline
\end{tabular}

The response, illustrated in Table XIX indicates a tendency, especially among participating teachers and principal, to favor this approach.

The second question dealt with the extent to which staff felt that children who will experience serious social-emotional difficulties in school can be identified in their first three years at school. As reflected in Table XX, respondants feel early identification is highly possible.

TABLE XX

TO WHAT EXTENT IS EARLY IDENTIFICATION POSSIBLE?

Almost always.

Quite often.

Very infrequently.

Almost never.

Don't know.

No response.

\begin{tabular}{|c|c|c|c|}
\hline $\begin{array}{l}\text { Participating } \\
\text { Teacher }\end{array}$ & $\begin{array}{l}\text { NonParticipating } \\
\text { Teacher }\end{array}$ & Principal & Total \\
\hline 3 & 3 & & 6 \\
\hline 1 & & 1 & 2 \\
\hline & & & \\
\hline & & & \\
\hline & & & \\
\hline & & & \\
\hline
\end{tabular}


The third question was about the potential effectiveness of Community Team methodologies as preventive. When asked to what extent they considered the Community Team approach would be able to prevent children from experiencing serious social-emotional difficulties, respondents indicated no pattern of agreement.

\section{TABLE XXI}

TO WHAT EXTENT CAN COMMUNITY TEAM METHODS EFFECT PREVENTION?

Almost always.

Quite often.

, Very infrequently.

Almost never.

Don't know.

No response.

\begin{tabular}{|c|c|c|c|}
\hline $\begin{array}{l}\text { Participating } \\
\text { Teacher }\end{array}$ & $\begin{array}{l}\text { NonParticipating } \\
\text { Teacher }\end{array}$ & Principal & Total \\
\hline 1 & 1 & & 2 \\
\hline & 1 & 1 & 2 \\
\hline 2 & & & 2 \\
\hline & & & \\
\hline 1 (sometimes) & & & 1 \\
\hline & 1 & & 1 \\
\hline
\end{tabular}

In all three questions, a range of cholces was presented and respondents could only check one.

Effect of Discrepancy in Educational Philosophy

Teachers were asked whether or not they thought a teacher and a Community Team member could work together effectively if they had differing philosophies of education. The intent of this question was to acquire guidance in the future attempts of Community Team members to develop successful collaborative relationships with educators. The response, indicated in Table XXII reflects no consensus among respondents. 
TABLE XXII

CAN COMMUNTTY TEAM MEMBER AND TEACHER WITH DIFFERING

PHILOSOPHIES WORK TOGETHER EFFECTIVELY?

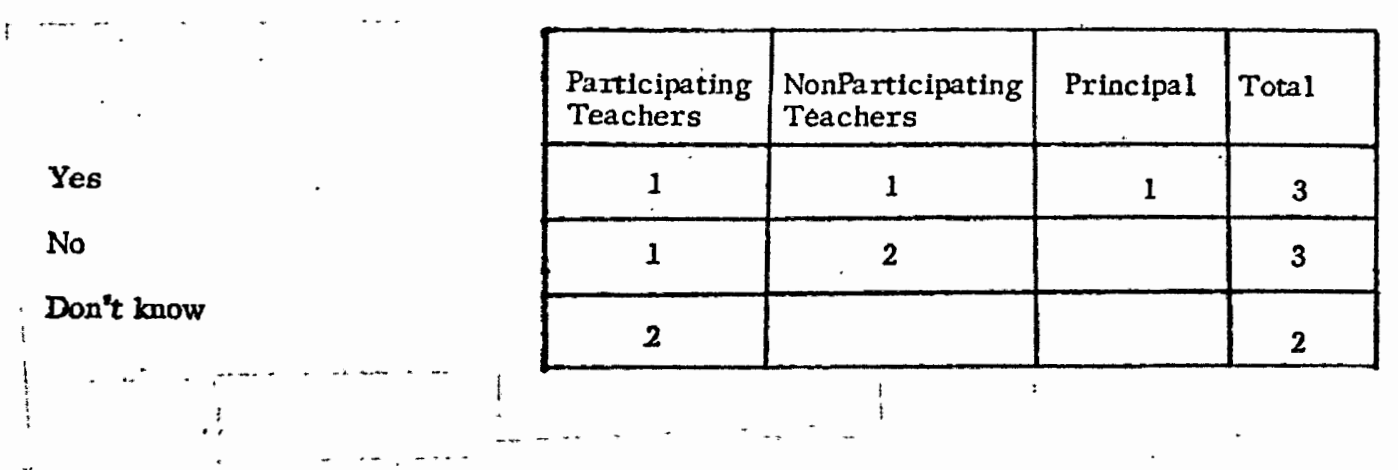

When questioned if, in their opinion, they shared the same philosophy of education as the Community member with whom they worked, all four participating teachers responded affirmatively, although one teacher qualified the affirmative response by adding that in some cases there were discrepancies. The principal clarified his affirmative response by adding that an effective working relationship can only be accomplished if differing opinions are clarified in discussion and included in planning intervention strategies.

\section{School Responsibility for Social-Emotional Support}

The second of only two questions which received a unanimous response was whether or not respondents thought it was the responsibility of the school to be concerned about children's social and emotional experience. All teachers and the principal agreed that it was the school's responsibility.

\section{Curriculum Content}

A series of questions was asked relating to whether or not schools should include social and emotional content within their curricular 
program and what effect this might have on the academic content.

The staff was asked whether or not they thought schools could teach social and emotional development. "Teaching" was not defined in the questionnaire. All but one of the respondents answered "Yes" to the question. One respondent answered "Don't Know". The principal noted that the teaching of social-emotional content should be, at least partially, indirect, as in role modeling.

When asked if social-emotional content should be part of the curriculum, respondents generally tended to favor the idea.

TABLE XXIII

SHOULD SOCIAL-EMOTIONAL CONTENT BE PART OF CURRICULUM?

\begin{tabular}{|c|c|c|c|c|}
\hline & $\begin{array}{l}\text { Participating } \\
\text { Teachers }\end{array}$ & $\begin{array}{l}\text { NonParticipating } \\
\text { Teachers }\end{array}$ & Principal & Total \\
\hline Yes & 3 & 2 & 1 & 6 \\
\hline & 1 & . 1 & & 2 \\
\hline Don't know & & & & \\
\hline
\end{tabular}

When questioned if they thought social-emotional curriculum would have the effect of competing with academic content, all participating teachers responded in the negative. While the principal answered yes, he qualified his response by stating that he did not believe that there was any inherent conflict between academic and social-emotional curriculum but that often teachers would regard them as competitive. 
TABLE XXIV

WOULD SOCIAL-EMOTIONAL CURRICULUM COMPETE WITH ACADEMIC PROGRAM?

Yes

No

Don't know

\begin{tabular}{|c|c|c|c|}
\hline $\begin{array}{l}\text { Participating } \\
\text { Teachers }\end{array}$ & $\begin{array}{l}\text { NonParticipating } \\
\text { Teachers }\end{array}$ & Principal & Total \\
\hline & 2 & 1 & 3 \\
\hline 4 & 1 & & 5 \\
\hline & & & \\
\hline
\end{tabular}

The next question was whether or not the staff thought that socialemotional content would be complementary to the academic curriculum. Generally, respondents tended to think that it would be. The principal stated that this type of curricular structure would not be as desireable as a more integrated approach, where social-emotional issues should be dealt with as they arise and growth in the social-emotional area would make possible and factilitate academic growth.

TABLE XXV

WOULD SOCIAL EMOTIONAL CURRICULUM

COMPLEMENT ACADEMIC PROGRAM?

\begin{tabular}{|c|c|c|c|c|}
\hline & & & & \\
\hline & $\begin{array}{l}\text { Participating } \\
\text { Teachers }\end{array}$ & $\begin{array}{l}\text { NonParticipating } \\
\text { Teachers }\end{array}$ & Principal & Total \\
\hline Yes & 3 & 2 & 1 & 6 \\
\hline No & 1 & . & & 1 \\
\hline Don't know & & 1 & & 1 \\
\hline
\end{tabular}

Finally, respondents were questioned as to their thoughts about an integrated curricular structure, with a social-emotional approach accomplished as an on-going continuum incorporated into the academic program. The response to this question was generally one of supporting the concept 
of integration.

TABLE XXVI

WOULD SOCIAL-EMOTIONAL CURRICULUM BE INTEGRATED WITH ACADEMIC PROGRAM?

Yes

No

Don't know

\begin{tabular}{|c|c|c|c|}
\hline $\begin{array}{l}\text { Participating } \\
\text { Teachers }\end{array}$ & $\begin{array}{l}\text { NonParticipating } \\
\text { Teachers }\end{array}$ & Principai & Total \\
\hline 3 & 2 & 1 & 6 \\
\hline 1 & 1 & & 1 \\
\hline & & & 1 \\
\hline
\end{tabular}

Continuance of Program

The final question was asked directly, if in the opinion of the respondent the Community Team program should be continued. A1I but one of the staff said that the program should continue. One non-participating teacher was uncertain.

\section{IDENTIFIED CHILDREN RATINGS}

The purpose of collecting information on how participating teachers rated identified children was to ascertain if there was any change in ratings at the end of the program year. If this information is systemically collected for children at Gregory Heights Elementary School for the next four years, it can provide one indicator of the effect of early intervention to children requiring therapeutic approaches in the classroom.

At the end of the school year there were twenty two identified children remaining with the Community Team program. Ratings for these children were compiled and a comparison was made between their ratings 
in October and June. Community Team members were interested in finding out if there had been any change in how identified children were rated by their classroom teachers.

The categories stated in the frequency table below indicate whether or not there was an increase or decrease in the child's rating. An increase in rating would signify that there was an extension of identified difficulties which the child was experiencing in the classroom. For example, if the child was rated as 3 (likely to experience future learning difficulties) in October and rated as 3D (1ikely to experience future learning difficulties, disruptive) in June, the rating change would be counted as an increase, with the exception of a 4 rating which designated that the child was talented or gifted. If the child was rated as a 3 in October and as a 2 (teacher uncertain about child's academic future) in June, this change would be scored as a decrease. If there was a change in rating but the change did not indicate an increase or decrease; for example, the child was rated $3 D$ in October and $3 W$ (1ikely to experience future learning difficulties, withdrawn) in June, the rating would be scored simply as a change.

\section{TABLE XXVII}

FREQUENCY AND NATURE OF IDENTIFIED CHILDREN RATING CHANGES DURING ONE YEAR

\begin{tabular}{|c|c|c|c|}
\hline Change & No Change & Rating Increase & Rating Decrcase \\
\hline 1 & 9 & 8 & 4 \\
\hline
\end{tabular}


As noted in the table above, four out of the twenty two identified children remaining in the Community Team program exhibited ratings which signify improvement. The eight identified children scored under Rating Decrease reflect an expanded definition of difficulties experienced in the classroom, as measured by this rating program. 
CHAPTER VI

CONCLUSIONS AND RECOMMENDATIONS

This chapter indicates the conclusions which can be drawn from the evaluative study and presents recommendations for further investigation and program modifications. The conclusions relate directly to the reported results of the evaluation instruments and correspond to the Community Team's Goals and Objectives.

\section{MONITORING}

The objective of the monitoring procedure was to provide formative information about the Community Team's delivery system. With minor exceptions the program was produced at the quality level sought, services were delivered and used. The exceptions noted in the findings point out program areas which need some improvement. Areas requiring improvement center around record-keeping, case reviews and policy development.

Improved record-keeping developed partially to fulfill requirements of the program evaluation. This area of programming should continue for there are still gaps in the program files. Accountability for the existence of an intervention plan in written form should be formalized, as should some assessment of the written problem statement. Currently there is no documentation to record the time and the reason a child becomes non-identified.

Since there is no recorded incidence of reestablishing benchmarks, periodic review of program cases should be contemplated. Case reviews could be conducted by clinical personnel of the Children's Psychiatric 
Day Treatment Center in cooperation with representatives from the school. One question which should be addressed by Community Team program staff is whether children should receive services before, or in the absence of, an intervention plan. This practice occurred within the program operation and there is no program policy to explain this practice.

\section{PEER INTERACTION INVENTORY}

Based on the obstacles cited in the discussion in Chapter $V$ and the difficulties encountered in the operationalizing of the value system of the Community Team, the Peer Interaction Inventory cannot be considered a reliable nor a valid measurement of cooperation in the classroom. No conclusions can be stated except that there is a very high degree of non interaction -- 70 to 75 percent of all actions counted -- among children in the classrooms observed and as measured by this instrument. This high frequency is not weighted as being desireable or undesireable. Within the context of a school morning academic program, the incidence of non-interactive behavior is considered appropriate behavior and in a very broad sense, therefore, cooperative.

As a systematic approach to collecting information, the Peer Interaction Inventory Report does provide indicators and raises questions which should be considered in future programming decisions.

Due to concerns the Community Team expressed about measuring teacher performance and the caution exercised in selecting an instrument which did not violate the values of the Community Team program, the observational technique was developed within critical. 1imitations which seriously impair its eventual effectiveness. Logistical obstacles encountered during the administration of the instrument, in addition to 
limited time and resources in development and implementation further complicated the data collection. Now that these limitations have been illustrated in the process of providing classroom interaction information, future planning can reconsider methodologies in an effort to design a more effective manner of collecting data in the classroom.

Further evaluative investigation needs to center around strong outcome measures. The Peer Interaction Inventory is not likely to provide what is required. Many instruments found in the classroom observational literature do provide useful techniques, however most of them include a measurement of teacher performance. A program decision must be made regarding the outcome measure selected in the future. Any technique utilized which does not assess the teacher's impact on the milieu will contain critical limitations. Although program evaluation is concerned with the assessment of Community Team program effectiveness, the impact a teacher makes on a classroom environment suggests that the teacher needs to be designated as a critical intervening variable in any classroom measurement.

To distinguish teacher behavior from other classroom interactions does not imply judgement but merely more precise categories of data collection. If the teacher's influence on classroom behavior is included in future observation designs, careful attention would need to be given to the uses of the information gathered.

TEACHER ATTITUDE QUESTIONNAIRE

The general conclusions, which can be drawn from the response to the questionnaire are supportive of the Community Team's collaborative approach and suggest no major changes in the current structure of the 
Community Team delivery system. Some interesting factors emerged however, which should be considered in programming.

Probably the most important indicator for change considerations came from the open-ended question about negative effects due to Community Team intervention, especially since this was new Information.

Teachers' concern regarding unequal access to Community Team amongst a11 the chlldren in the classroom and the feelings of exclusion from special attention on the part of some children, not identified by the Community Team program, reflect teacher sensitivity to the social milieu of the classroom. This sensitivity for social milieu corresponds to the second goal of the Community Team's program, to program optimal social and emotional growth for all children in the classroom. It would appear that while teachers and Community. Team members share the same goal, in this regard the teacher has extended information because of the greater exposure to the classroom.

As evidenced in the response to questions regarding methodologies and levels of intervention, there is high visability of Community Team program in the school and among primary grade level teachers there is at least awareness, if not articulation of interielated levels of service delivery. Accessibility to Community Team amongst staff is excellent; all respondents felt free to share their questions and concerns with a Community Team member.

Teachers appear to be highly receptive and appreciative of the collaborative style utilized by the Community Team. Their frequent mention of the contributions of reinforcement, reassurance and additional resource are reflective of the collaborative relationship. All respondents who had an opinion of how to best describe the Community Team 
approach described it as collaborative; equal sharing with teacher in important decision-making matters.

No aggreement about restructuring time allotments emerged from the questionnaire, which could reflect a generalized satisfaction with program structure or, could indicate that respondents had no clear ideas about how to change the structuxe.

In support of the concern about time restrictions, there are indicators of teachers' feelings of 1imitations in their response to questions about priorities for the Community Team to continue. Teachers tend to feel that the Community Team provides services to children, parents and teachers which are needed, but which teachers do not have the time and other resources to provide adequately without additional support.

The response to questions about including social-emotional content in the school curriculum is non-conclusive although there is a slight tendency towards favoring inclusion, that it would not compete with, but complement the academic program and that it could be accomplished as an integrative process.

This technique proved very beneficial in providing information and should be considered as an integral part of the evaluation design. It. is time-consuming to administer in an interview format however, and alternative methods of administration may need to be contemplated.

One consideration which should be discussed is the idea of setting aside a particular meeting time for teacher and Community Team member to plan during the school day. This time could be partially utilized by the evaluator and could have the effect of minimizing time required to conduct monitoring procedures. As noted, in the findings the principal considered this idea to be highly desireable. 
The Community Team should also consider the reported negative effect of unequal attention towards particular children and discuss possible redistribution of time within the classroom milieu.

Time did not allow for administering the questionnaire to Community Team members. This strategy is advisable and the information gathered could be utilized in a number of ways including orientation of new Community Team members, generating discussion of program philosophy and goals and as a comparison to responses from the educational counterpart of the program collaboration.

\section{IDENTIFIED CHILDREN RATINGS}

No conclusions can be drawn from the results of these ratings nor were any expected. .This data is intended for longitudinal study and provides one very minimal indicator of change in children identified early in their academic careers as requiring therapeutic approaches to social and emotional development. It represents one small step toward a methodology for the evaluation of prevention.

In the future administration of this program evaluation, time needs to be spent at the beginning of the school year, in discussing the collection and recording mechanics of identified children ratings: The forms developed by the evaluator during this study may prove useful to school personnel who are required to gather this information. 
Abramson, Anne. "On Their Turf: Helping Troubled Kids at School," Involvement, January-February, 1974.

Adams, Robert and Howard Weinick. "Consultation: An In-Service Training Program for the Schoo1," Journal of the American Academy of Psychiatry, 5 (3): 479-489, 1966.

Aiken, Lewis R. Psychological and Educatlonal Testing, Boston, A11yn and Bacon, Inc., 1971.

Alderson, John H. "The Challenge for Change in School Social Work," Social Casework, 3-10, January, 1971.

Alderson, John J. "The School Social Worker on the Pupil Personnel Staff," Social Work in the Schools: Patterns and Perspectives, John J. Alderson editor, Illinois: Whitehall Co., 1969.

Alkin, Marvin C. "Evaluation Theory Development," Evaluation Comment, 2 (1): 2-7, October, 1969.

Allinsmith, Wesley and George Goethals. The Role of Schools in Mental Health, New York: Basic Books, 1962.

Beatty, Walcott H., Ed. Improving Educational Assessment and an Inventory of Measures of Affective Behavior, Washington, D.C.: Association for Supervision and Curriculum Development, 1969.

Berlin, Irving N. "Mental Health Consultation in Schools as a Means of Communicating Mental Health Principles," Journal of the American Academy of Child Psychiatry, 1 (4): $671-678,1962$.

- "Preventive Aspects of Mental Health Consultation to Schools," Mental Hygiene, 51 (I): 34-40, January, 1967.

- "The School Social Worker as Mental Health Consultant," Lecture given at Northwest Regional Conference of School Social Workers, The Quay, Vancouver, Washington, October 22, 1966. - "Mental Health Consultation in the Schools: Who Can Do It and Why," Community Mental Health Journal, Vol. 1, 1965.

Bernard, Harold W. Mental Health in the Classroom, New York: McGrawHill Book Co., 1970.

Bessel, H. and U. Palomares. Methods in Human Development. E1 Cajon, California: Human Development Training Institute, 1972. 
Biber, B. "Integration of Mental Health Principles in the School Setting," in Prevention of Mental Disorders in Children, Gerald Caplan editor, New York: Basic Books, 1961.

Bloom, Bernard L. "Community Mental Health: A Historical and Critical Analysis," General Learning Press, Morristown, New Jersey, 1973.

Bloom, B. "The Evaluation of Primary Prevention Programs," in Comprehensive Mental Health, Robert N. Greenfield and M. Miller editors, Madison: University of Wisconsin Press, 1968.

Bragg, R. and W. Freeman. "Principles of Mental Health Consultation to a School System," American Journal of Orthopsychiatry, Digest of Papers, 39 (2), March, 1959.

Brody, S. "Preventive Intervention in Current Problems in Early Childhood," in Prevention of Mental Disorders in Children, Gerald Caplan editor, New York: Basic Books, 1961.

Broskowski, Anthony and Brank Baker. "Professional, Organizational and Social Barriers to Primary Prevention," American Journal of Orthopsychiatry, Vol. 44, 1974.

Caplan, Gerald. "Concepts of Mental Health and Consultation," excerpt, Children's Bureau, Department of Health, Education and Welfare, Washigton, D.C., 1959.

- The Theory and Practice of Mental Health Consultation, New York: Basic Books, 1970.

Clairborn, W.L. and R. Cohen, Eds. "School Intervention," Behavior Publications, Vol. 1, 1973.

Costin, Lela. "Adaptations in the Delivery of School Social Work Services," Social Casework, 53 (6), 348-354, June, 1972.

Costin; Lela B. "A Historical Review of School Social Work," Social Casework, October, 1969.

Cowen, E.L. "A Preventive Mental Health Program in the School Setting: Description and Evaluation," Journal of Psychology, 56: 307-356, 1963.

Cowen, E.L., E.A. Gardner and M. Zax. Emergent Approaches to Mental Health Problems, New York: Appleton-Century-Crofts, 1967.

Escalone, Sibyle L. "Mental Health, the Educational Process and the Schools," Mental Hygiene, 51 (1): 34-40, January, 1967.

Flanders, Ned A. "Teacher-Pupil Contracts and Mental Hygiene," Journal of Social Issues, 13 (1): 30-39, 1959. 
Gaup, Peter G. "Authority, Influence and Control in Consultation," Community Menta1 Health Journal, Vol. 2, No. 3, Fal1, 1966.

Gottlieb, B.H. and I.J. Gottlieb. "An Expanded Role for the School Social Worker," Social Work, 16 (4): 12-21, 1971.

Granlch, Belle. "Teachers and School Social Workers," Mental Hygiene, $51(1): 41-8,1967$.

Hoepfner, Ralph, Ed. CSE-RBS Test Evaluations: Tests of Higher Order Cognitive, Affective and Interpersonal Skills, Evaluation Technologies Program, Center for the Study of Evaluation HumanIzIng Learning Program Research for Better Schools; Inc., 1972.

Hollister, W111iam G. "Current Trends in Mental Health Programing In the Classroom," Journal of Social Issues, 15 (1): 50-58, 1959.

Iscoe, Ira, John Pierve-Jones, Thomas S. Friendman, Joyce McCearty. "Some Strategies in Mental Health Consultation," in Emergent Approaches to Mental Health Problems, Cowen, Gardner and Zax, editors, New York: Appleton-Century-Crofts, 1967.

Kahn, Alfred. Theory and Practice of Social Planning, New York: Russell Sage Foundation, 1969.

Katz, F.E. "The School as a Complex Social Organization," Harvard Educational Review, 34 (3): 428-55, 1964.

Kennedy, John F. Message From the President of the United States Relative to Mental IIlness and Mental Retardation, 88th Congress, First Session, U.S. House of Representatives Document No. 58. U.S. Government Printing Office, 1963.

Kling, Jacquelyn and Anita Lohman. Milieu Treatment for Children, Portland, Oregon: Children's Psychiatric Day Treatment Center, University of Oregon Health Sciences Center, 1976.

Koroloff, Nancy, Quentin D. Clarkson and Wayne F. Neuburger, "Program Evaluation Project," Portland, Oregon: Program Evaluation Project, Portland State University, 1974.

Kuhn, Thomas S. The Structure of Scientific Revolutions, Chicago: The University of Chicago Press, 1970.

Lippitt, Ronald and Martin Gold." "Classroom Structure as a Mental Health Problem," Journa1 of Social Issues, 15 (1): 40-49, 1959.

MacLennan, Beryce W., Robert D. Quinn and Dorothy Schroeder. "The Scope of Community Mental Health Consultation," in The Practice of Mental Health Consultation, Fortune V. Mannine, Beryce W. MacLennan and Milton F. Shore, editors, Adelphi, Maryland: National Institute of Mental Health, 1975. 
Rhodes, W.C. "The Disturbing Child: A Problem of Ecological Management," Exceptional Children, 33 (7): 449-445, 1967.

Scriven, Michael. "The Methodology of Evaluation," in Perspectives of Curriculum Evaluation, Chicago: Rand-McNally and Co., 1967.

Simon, Anita and Gil B. Boyer, Eds. Mirrors for Behavior II, Vol. B. An Anthology of Observation Instruments, Philadelphia: Research for Better Schools, Inc., 1970.

Suchman, Edward. Evaluative Research, New York: Russell Sage Foundation, 1967.

Trost, Mary Ann. "The Preventive Role of Social Work in a Schoo1 Setting," Child Welfare, 47 (7): 397-404, 425, July, 1968.

Weiss, Carol H. Evaluating Action Programs, Boston: Allyn and Bacon, Inc., 1972.

Williams, R.B. "School Compatibility and Social Work Role," Social Service Review, 44 (2): 169-176, 1970a.

Williams, R.B. "The Helping Professions: Problems Only?," Journal of School Health, 40 (1): 24-27, January, $1970 \mathrm{~b}$. 


\section{GOALS AND OBJECTIVES FOR IN-SCHOOL PROGRAM OF COMMUNITY TEAM}

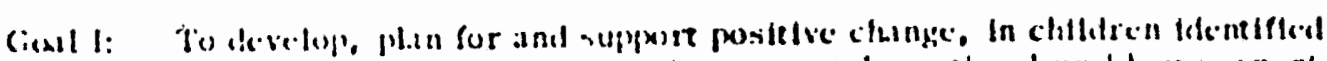

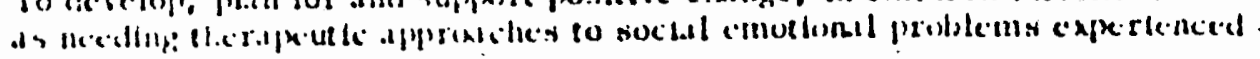
In the: cles inserusthe

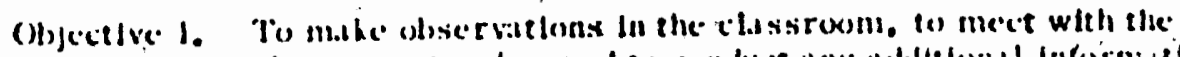

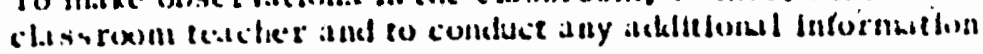
frithering actlvitles.

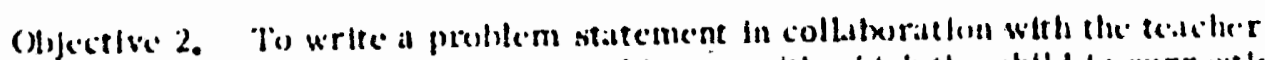
from the pereperctive of issuces with whidch the chlld is currently desling.

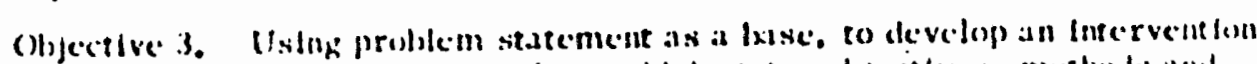

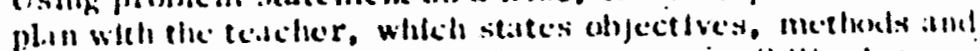

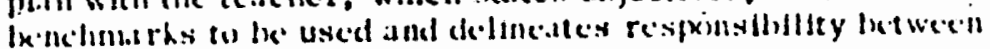
Communtey reatm me-miner and the tescher.

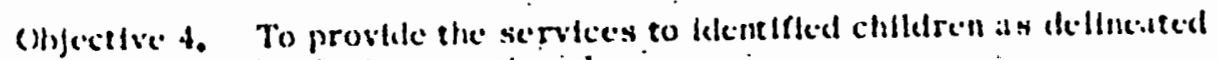
by the intervention plas..

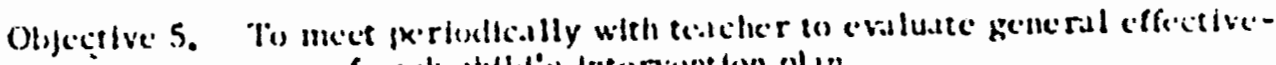
iness of celch chlld's Interventon pline.

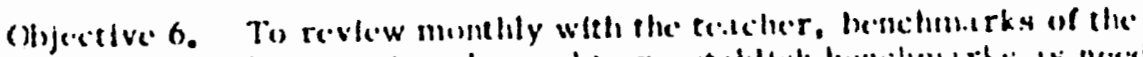

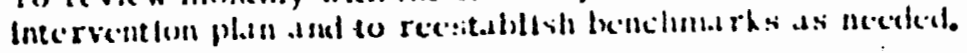

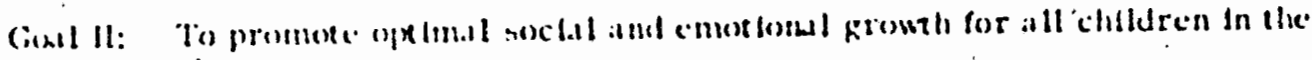
(l.1.4r(x)ll1.

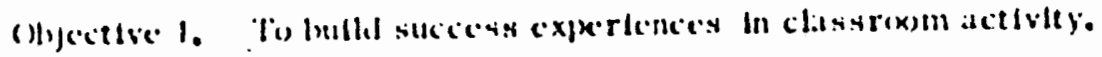

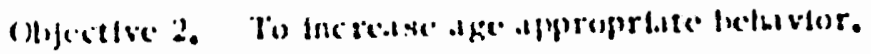

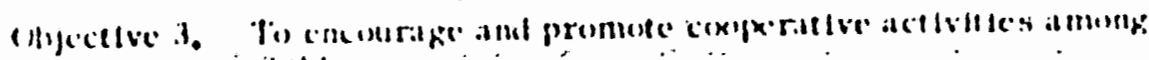
ahlilren.

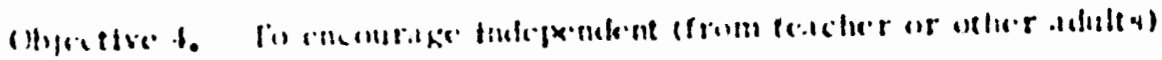
listifly.

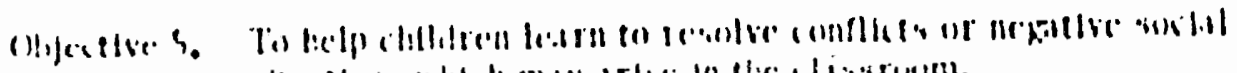

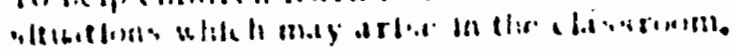

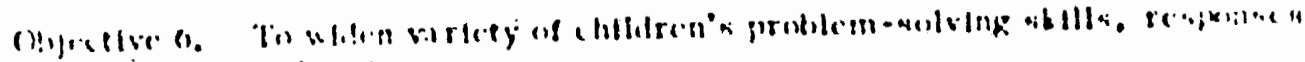
and inelunis.

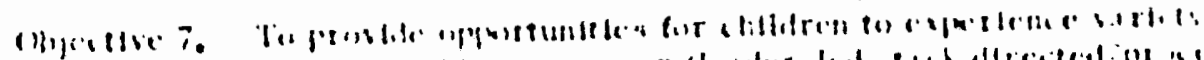

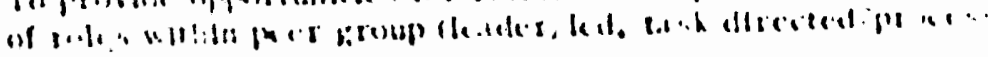
urlenterl, che.). 


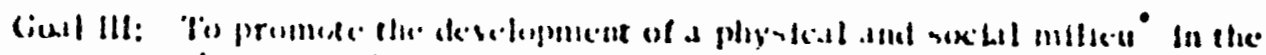

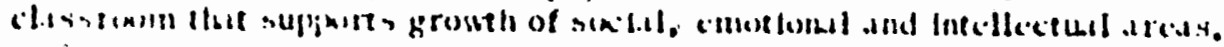

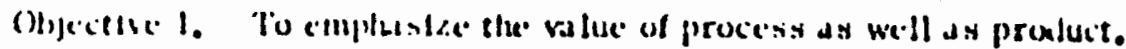

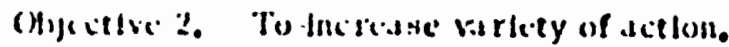

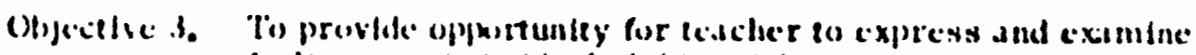

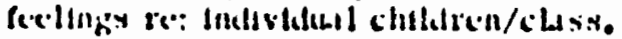

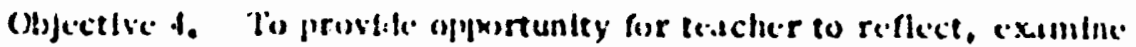

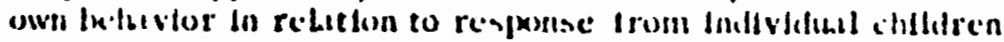
and class.

(H)ectlve 5, To lncrease expresiton of fecllngs.

Objectlve b. To ahtre whth teocher methols and technleques for de.llinf:

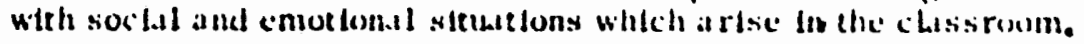

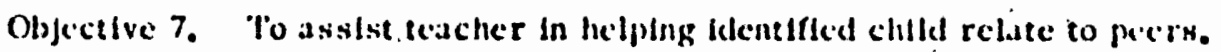

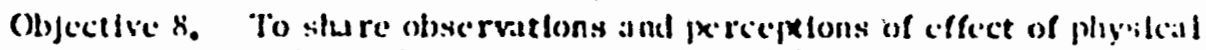
and socidl mblleu on ladenelited chlldren and classroum.

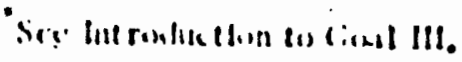




\section{NTRODUCTUN TO GOAL III}

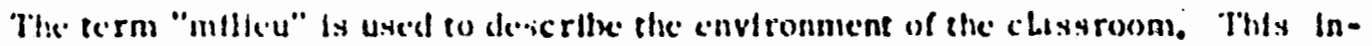

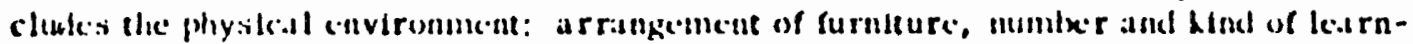

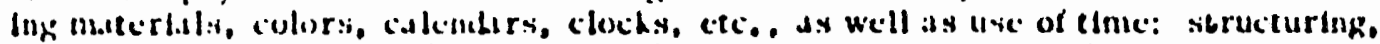

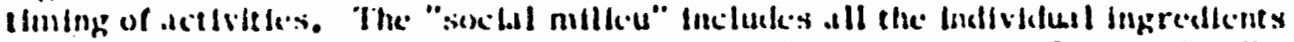

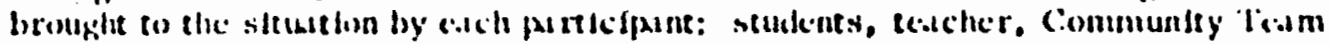

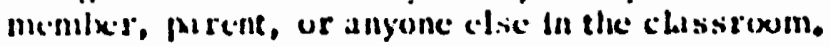

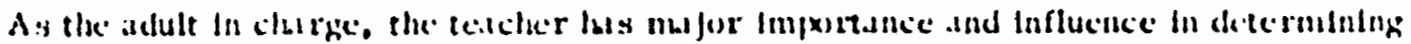

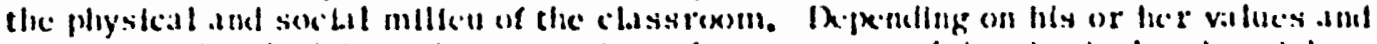

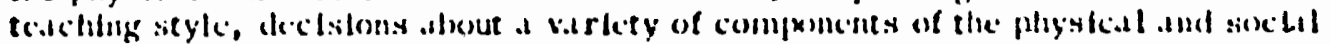

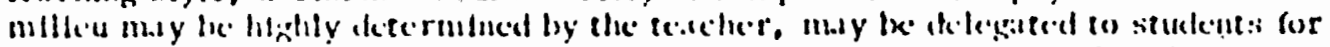

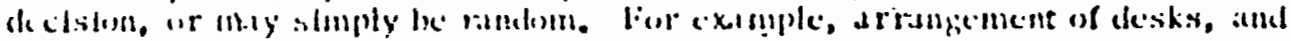

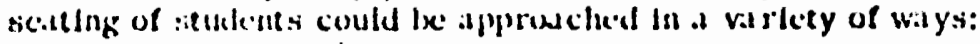

-alphilxetlcally

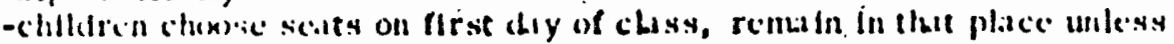
megither whth toucher

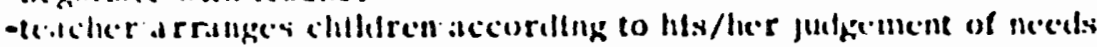
-chlldien mily irade scolts at will.

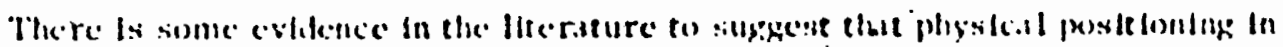

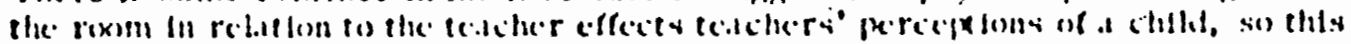

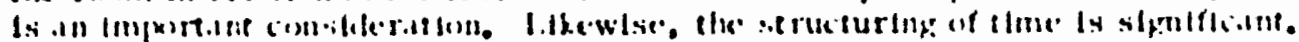

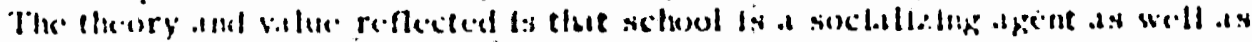

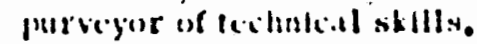


APPENDIX B

INTERVENTION PLAN

Identified child

Ditc

Tedcher

Commusity Tlam Member

Observations of child:

Information githering activities conducted:

Activity

Datc

1.

2.

3.

4.

Problem Statement: 


\section{Dile (H) enctives \\ 1. \\ 2. \\ 3. \\ 4 \\ 5. \\ 6.}

Mcellendes

$1:$

2.

3.

t.

5.

(1. 
APPENDIX C

MONITORING INSTRUMENT

Identified Child

Date

Teacher (i)

Community Team Member (B)

Yes No In The Don't File know

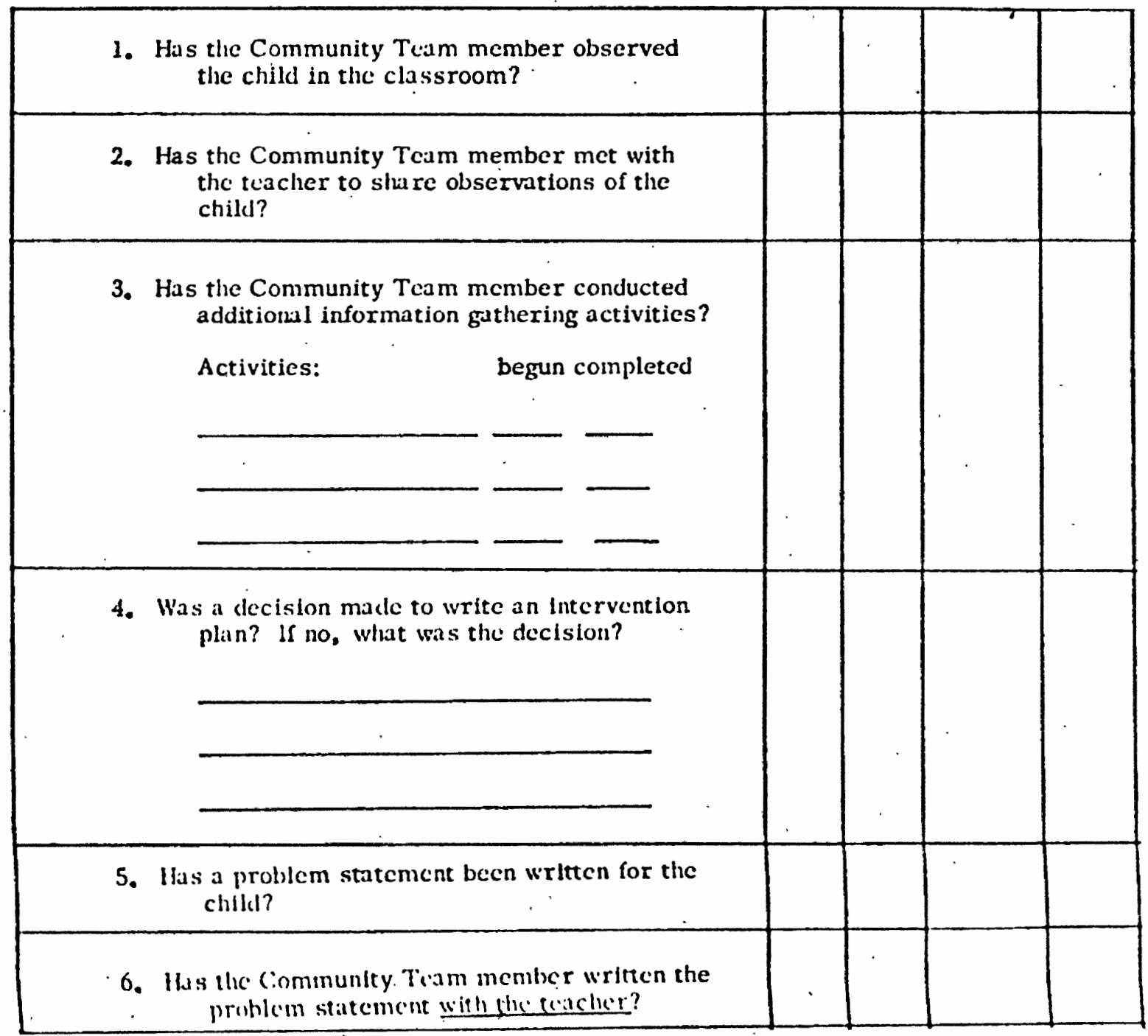




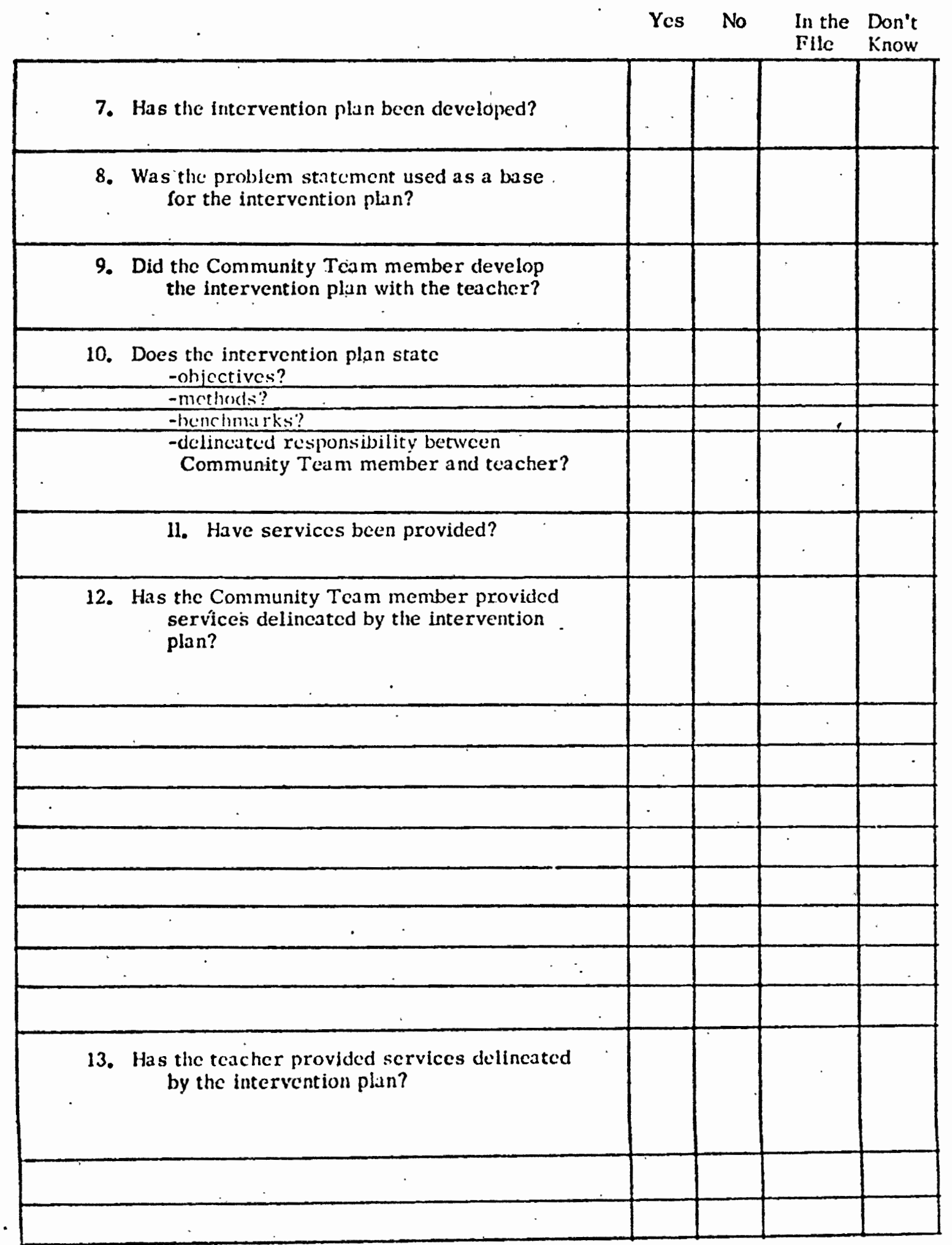




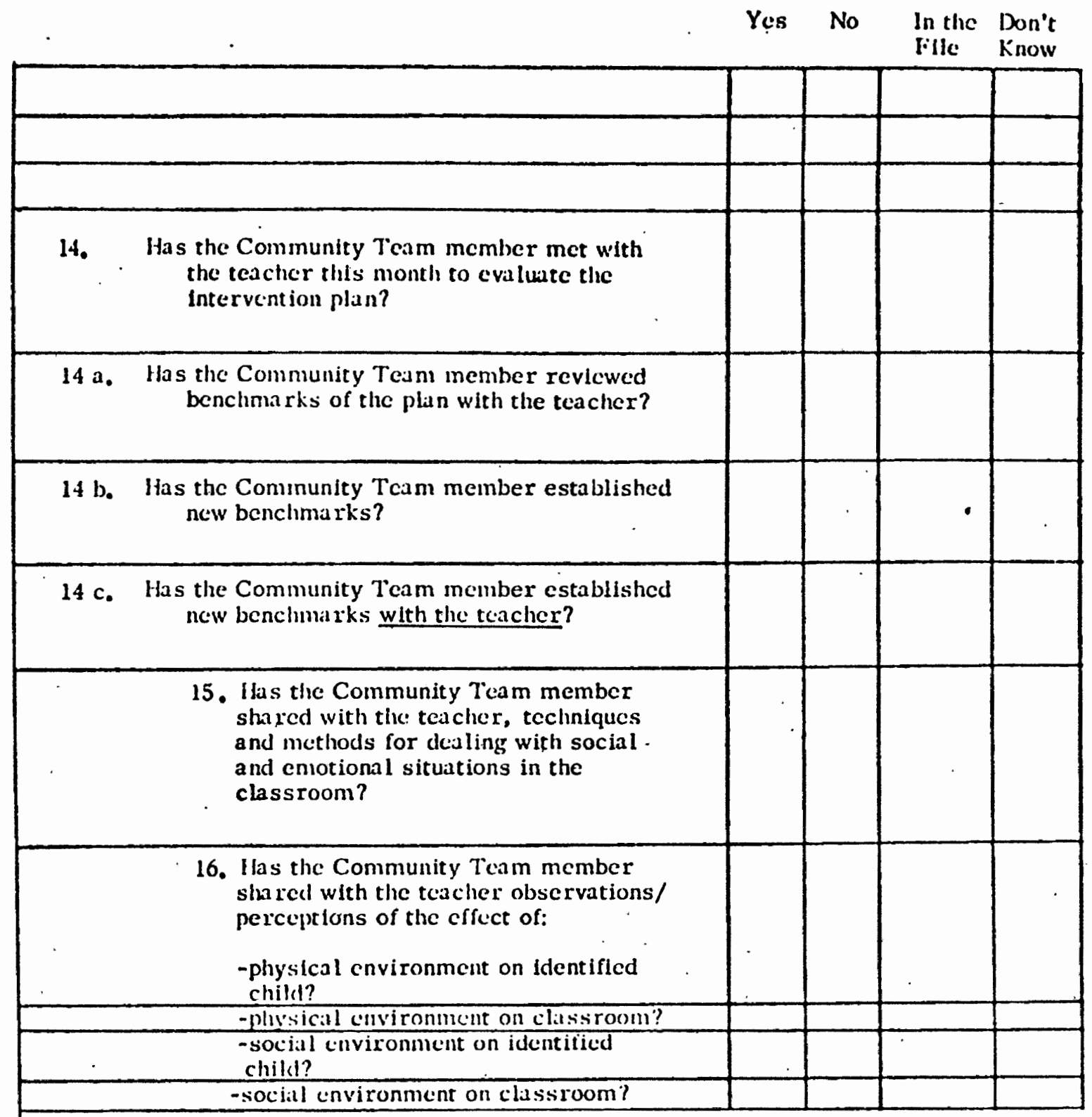


APPENDIX D

MONITORING DISCREPANCY INVENTORY

Teacher (A):

Date:

Community Team Member (B):

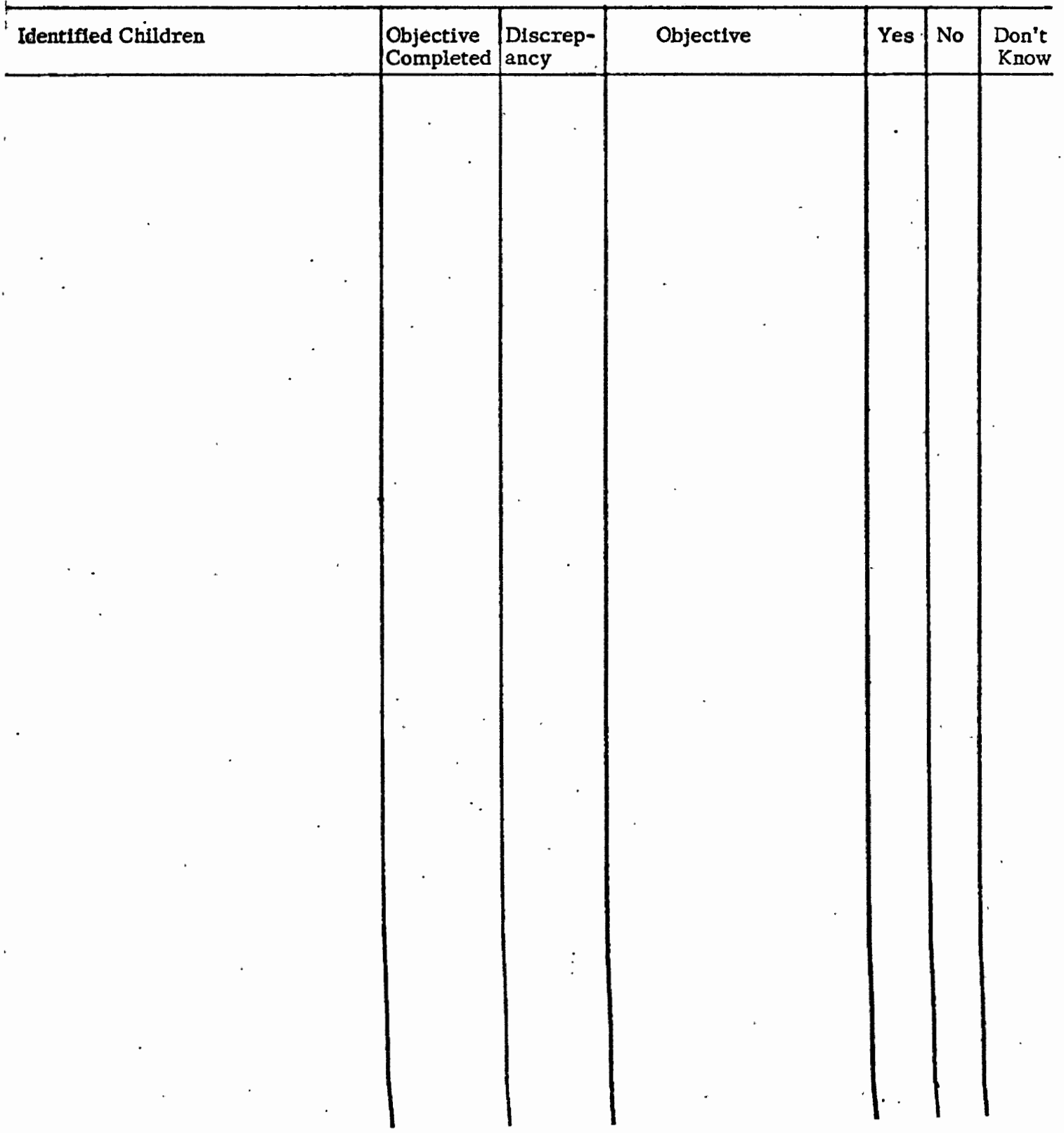


APPENDIX E

COLLABORATION DISCREPANCY INVENTORY

Teacher (A):

$\therefore \quad$ Community Team Member (B):
Date:

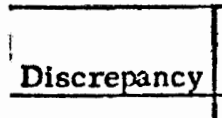

Sharing Techniques

Classroom Milieu

Physical
Social

Physical
Social

Services Provided to

Identified Children

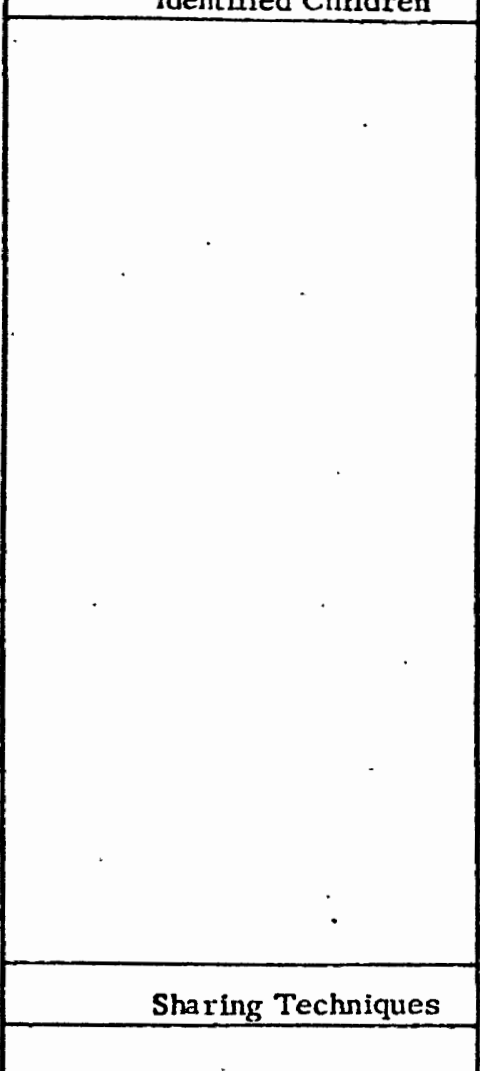

Description 
APPENDIX F

PROCESS DEVELOPMENT SCALE

\begin{tabular}{|c|c|c|c|c|}
\hline $\begin{array}{l}\text { Process } \\
\text { Objective }\end{array}$ & Corresponding Procedures & Date: & Date: & Date: \\
\hline 1 & $\begin{array}{l}\text { 1: Make observations, } \\
\text { 2: Meet with teacher. } \\
\text { 3: Gather additional information. }\end{array}$ & $\rightarrow$ & & \\
\hline 2 & $\begin{array}{l}\text { 4: Decision to write plan. } \\
\text { 5: Write problem statement. } \\
\text { 6: Write statement with teacher. }\end{array}$ & & 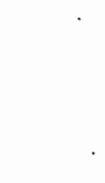 & \\
\hline 3 & $\begin{array}{l}\text { 7: Develop plan. } \\
\text { 8: Use problem statement as base for plan } \\
\text { development. } \\
\text { 9: Develop plan with teacher. } \\
\text { 10 a: State objectives in the plan. } \\
\text { b: State methods in the plan. } \\
\text { c: State benchmark in the plan. } \\
\text { d: State delineated responsibility in the plan. }\end{array}$ & . & : & 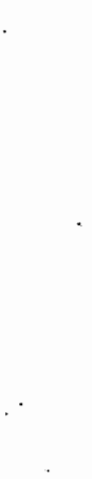 \\
\hline 4 & $\begin{array}{l}\text { 11: Provide services to children. } \\
\text { 12: Provision of service by Community Team. } \\
\text { 13: Provision of services by teacher. }\end{array}$ & . & $\therefore$ & \\
\hline 5 & 14: Meet with teacher to evaluate plan. & & & \\
\hline 6 & $\begin{array}{l}14 \text { a: Review benchmarks with teacher. } \\
\text { b: Establish new benchmarks. } \\
\text { c: Establish new benchmarks with the teacher. }\end{array}$ & & & \\
\hline
\end{tabular}


APPENDIX G

INSTRUCTIONS FOR CODING

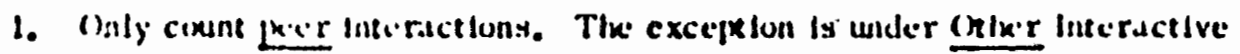
whlch incluik.: any linteraction whth the tedacker or other adult.

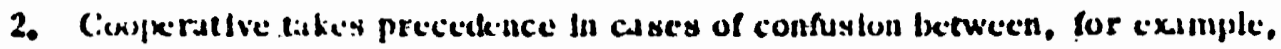

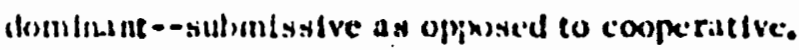

3. Unless the chlld munlfests a beluvforsl reaction, such as asking a quentlon, or following a sifeciftc Instruction, score listcinlng to teaclecr as .ion Interactlve. If there is sone doulx, Non Interactive takes precentence.

4. Score at 15 second Intervals, puuse for 5 seconds. (The tape is recorded at these Internals.)

5. Record activity and clinute under which the obsicrvation takes place.

6. Alike notes of any unusual occurences whlch thectere with oliservatlon.

7. Record the "hist scorcable response." "Scoreable" to the key word. Record the last completed, understanchble beluvior. 
APPENDIX $\mathrm{H}$

PEER INTERACTION INVENTORY

Name of Child

Date

Name of Coder

Time

Description of Setting

Aggressive - Positive

\begin{tabular}{|l|l|}
\hline Verbal 1 & Physical 1 \\
& \\
\hline
\end{tabular}

Aggressive - Negative

Verbal 2

P'hysical 2

\section{Cooperative}

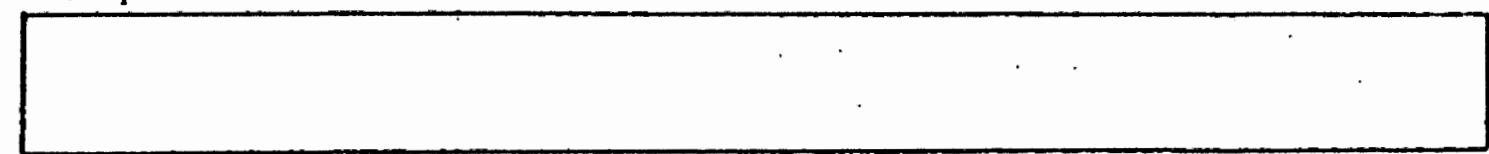

Dominant

Submissive

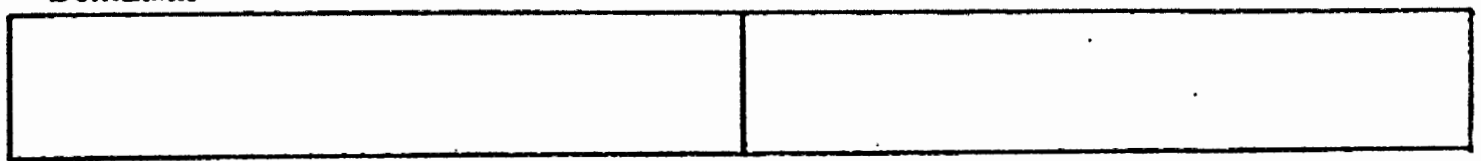

No Response

Competing Response

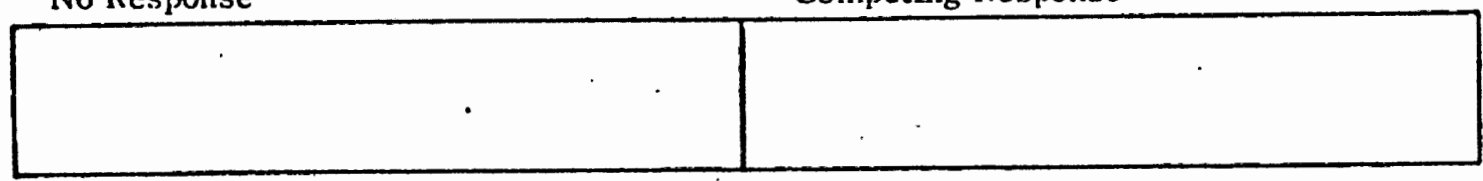

Other

\begin{tabular}{|l|l|}
\hline Interactive & Non-Interactive \\
\hline
\end{tabular}

Comments: 


\section{APPENDIX I}

\section{PEER INTERACTION INVENTORY DEFINITIONS}

\section{Aggressive-Pusltive}

Verbal 1 appropriate expression of anger, assertiveness, confronting a nother with a legitimate opinion or response

Physlcal 1 appropriate physical response in asserting position, playing. defending self, non-ciest ructive or hostile roughhousing appropriate to setting and interaction

Aggressive-Negative

Vcribal 2 threats, insults, accusations expressed in hostile tone, destructive intent toward another

Physical 2 kicking, hitting, spitting, fighting with hostlle intent, imppropriate to setting or interaçtion

Cooperative equal participation in activity or conversation

Dominant gives commands (verbal and non verbal - pointing, gesturing)

Submissive follows commands (verbal and non verbal)

No Response failure to respond to command or question while not engaging in other activitics

Competing Response failure to respond to command or question engaging in other activities

\section{OTIIER}

Interactive

Non intcractive additional peer interaction or Interaction with authority

independent or isolation activity "docs not apply" to peer or authority interaction 


\section{APPENDIX $J$ \\ TEACHER ATTITUDE QUESTIONNAIRE}

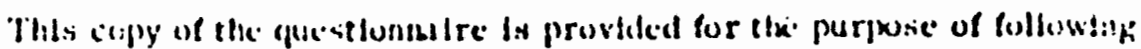

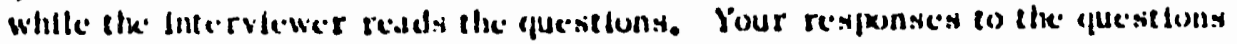

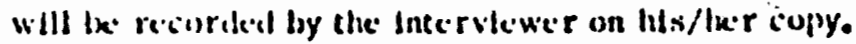

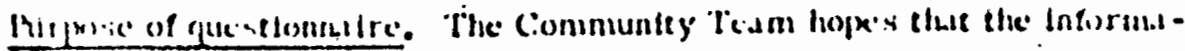

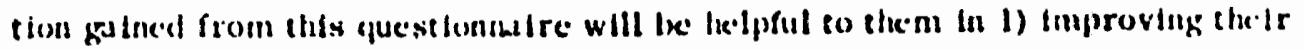
dellvery of servlees to your schex)l, 2) restructuring and revisting the/f frogram In the future, ind 3) assiesslng whtt Impact, If any, the Communtty liedm program lus had on the staft of your school.

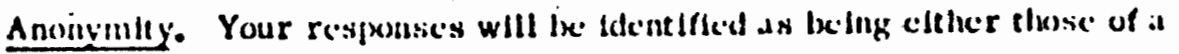
teaclice who this or bas not worhed with a Communtey Tcam mentere durlng the

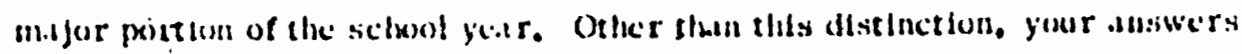
will le: kept strletly conflekentast.

The Interview. The interviewer will read tle questions. if you diu net

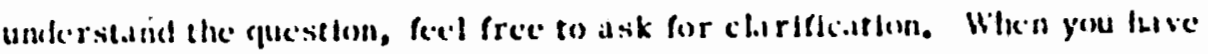

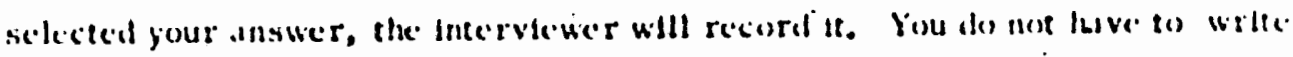

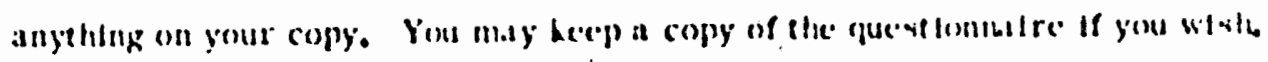

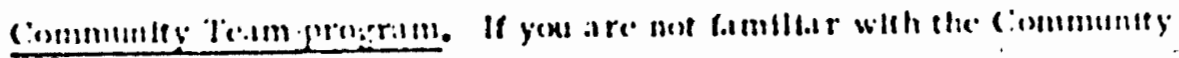

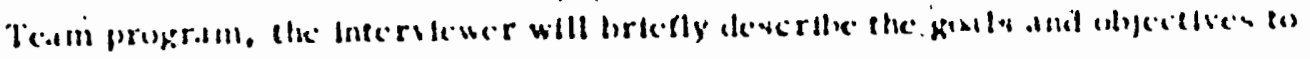

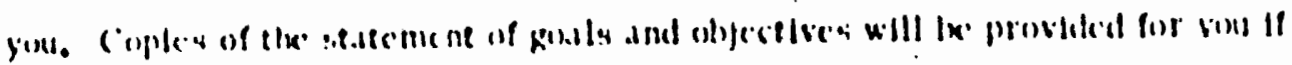
Fint would lihe to the once.

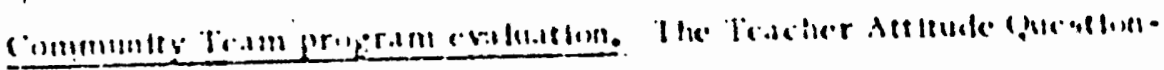

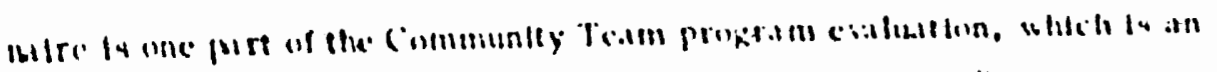




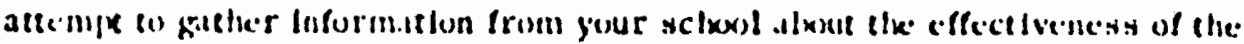

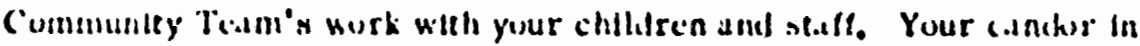

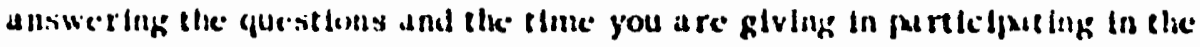
progitan covaluaten lx very much apprectuted. 


\section{Communey Team Program livaluation gaestfonalie}

llave wobled mull communsty Tram In clasisucem for mest of ilke program

- Have not worked with Communaty $y \cdot a r$ Team in clasistonm for most of lle progruin jear

Exceple wien stupulated. check all categuries which you think are approprlate.

1. Prom what you lave learne d or expertenced concerning the Communtly Tiam's work

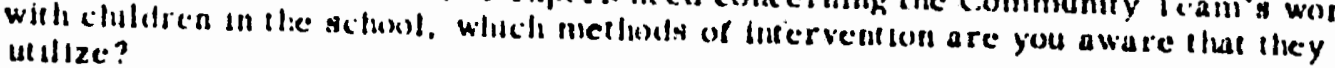

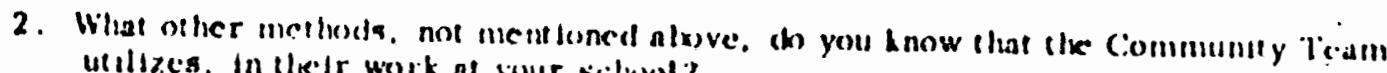

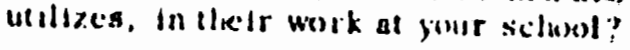

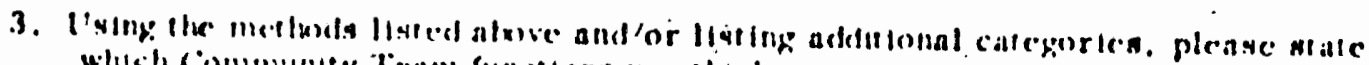

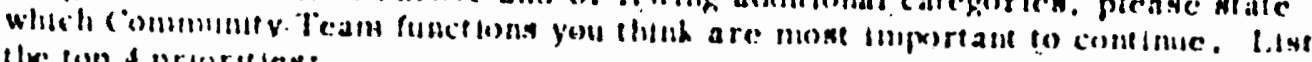
the ropl 4 pronrutes:

1.

2.

3.

4. 


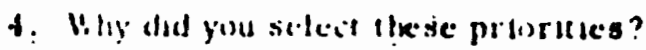

1.

2.

3 .

4.

5. In which of the: approaches linted leclow (k) you think that the Communtty Tcam memler is able to norh mont effectively? (cleck ofle.)

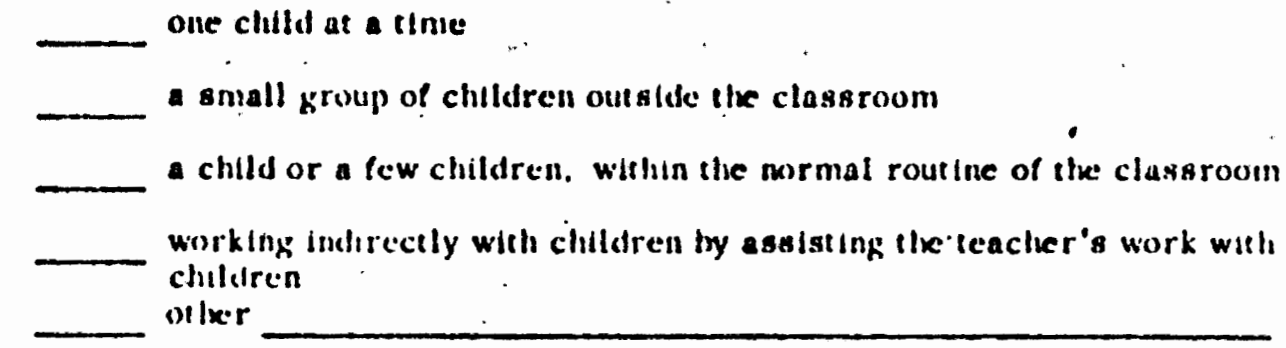

6. In wheh of the relattonships listed below do you think that the Community Team memixer mahes a postlive conerilution?

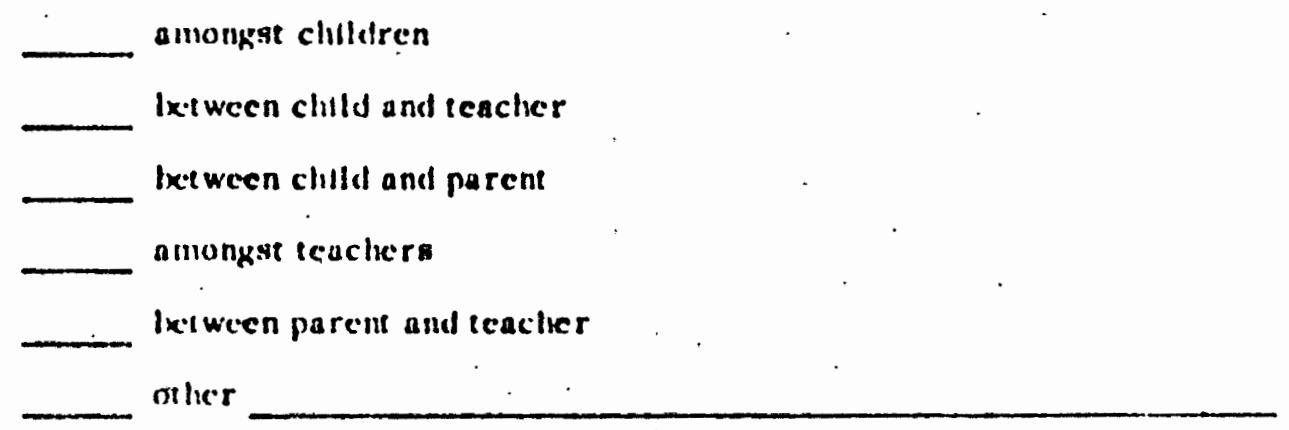

7. If you cheided any of the relat fonshins livted in number a what are flec Commumby

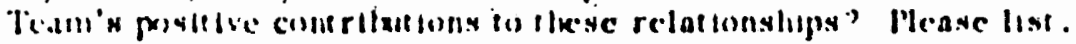

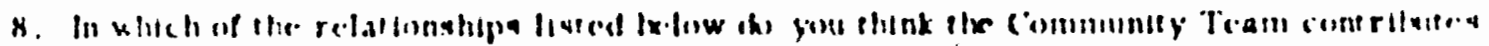
merivively"

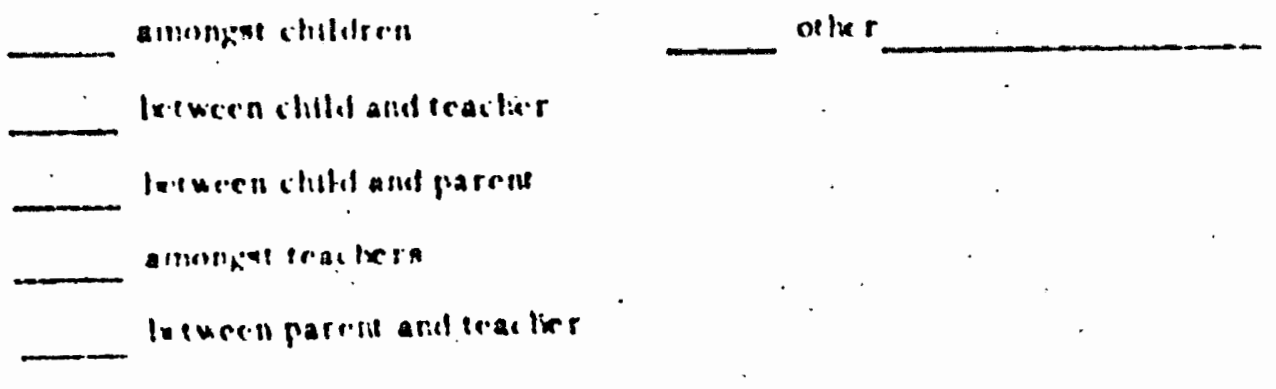




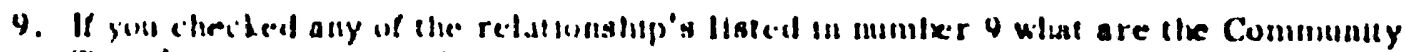

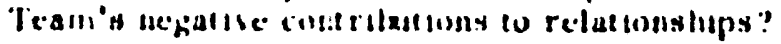

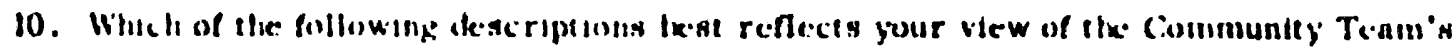
presence in the classroom? (ciliech one.)

and

e resuurce person for the classroum an int nuder frum outslde the sclkol an assistiant to like leacluer - dis rupetion to class routinc. a friend for llke clilldren. other

11. When working with the Communty liem member. (k) you feel:

like a recipient of spectal servilecs

a partiner and a peer
an expert regarding chlldren's achionl difficulties
ollker

12. Do you fecl free to shatre questions/concerns alxut cluldrens soctal ecmothonal charactertstics wsth a Community Team nemlere?

$$
\text { Yera No_ No_ Coes not upply }
$$

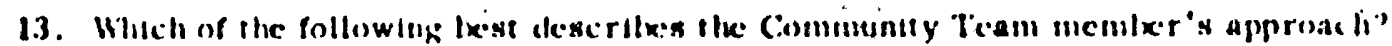
(cleck one.)

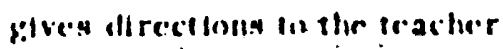
peramackes teachere to follow line lwer advice

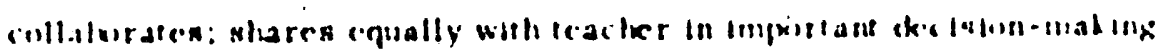
maticin.

"ikerairs inckponikntly of the teacter inler 


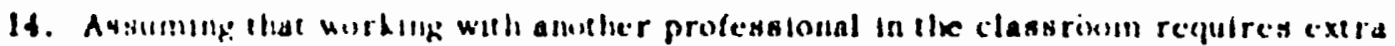

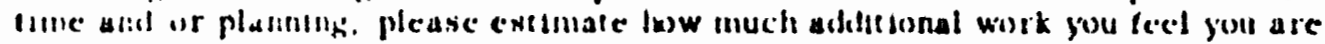
(hulig. (clech nike.)

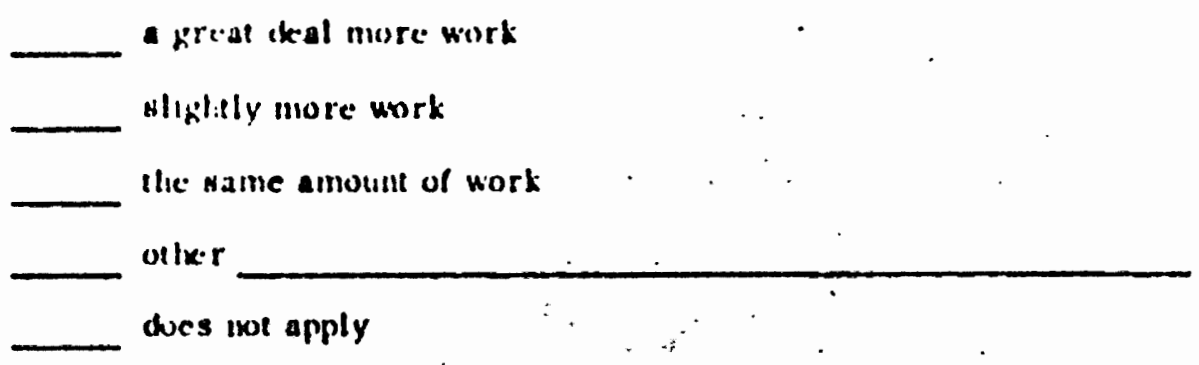

15. Please clectk arcas in which you feel the ilme allotnent could te reseructured in worhtilg with the communty l'eam:

$$
\text { a. }
$$
collahoratlon with Conmuntty Tcum in defining difflculties a cluld is cexperiencing could le more extenslive could tre less extensive not incesssary

b. ckveloplng intervention pluns with Community Ticam nicmixes coutrine more extensive could be less extensive met mecesisary

c. providing wervices to chlldren whith intervent ion plan requileser countix: more extentwe could la lese cextchstive

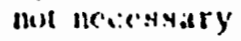

d. perlodic evaluallons of child's progress countre mure cxenaive could be less cexiensive nuteceratary c. discussions abjit luw all chlldect in clasaroum interace. coultine imore extenative could tie lena exicnsive nos mecesarary

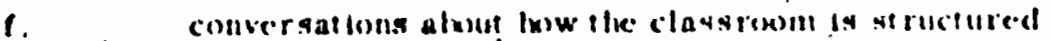
conformentere cxtensive could Ix la.sa coxiconsive mose mecomitist

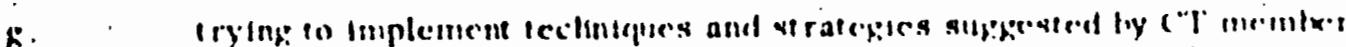

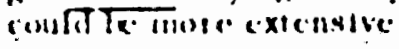
inulal ix leven cextenstice ment neiventiry

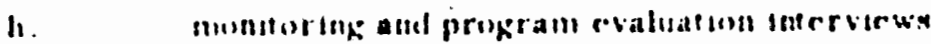

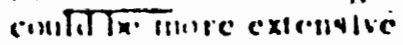

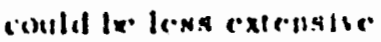

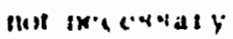

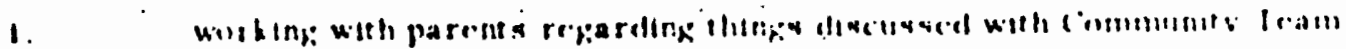

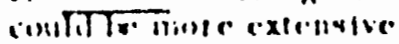

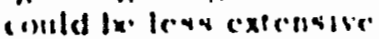
nue inemary

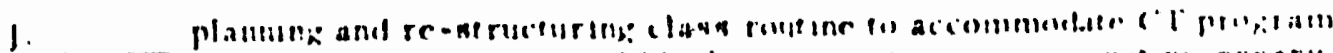

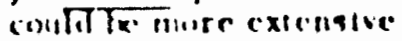
conlal in tran cxichalice mini lie.eranats

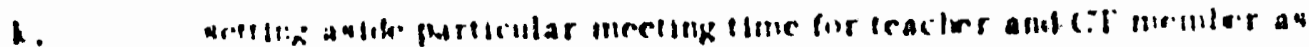
part cinlal la miste ratenabe could le less csicnuive init inesuaty

1. ifier 


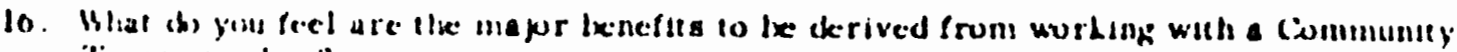
leosm meminer?

lior the clinldren:

For the teacher:

mo Ixisetsts lo le terived

17. Ae what level stusuld, in your oplaton, the Communty Team program at your sctusol Ixe contunucd? (Clixck onc.)

expancled

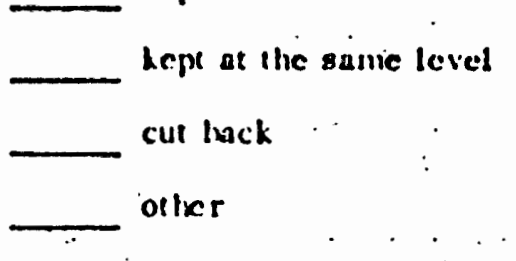

18. To what extent is you think that chlldren who are experlencing soclat -emotional difficullic:s slmuld remain in the class room, supporeced wah special services, like He (ummunlly Team? (Cleech one.)
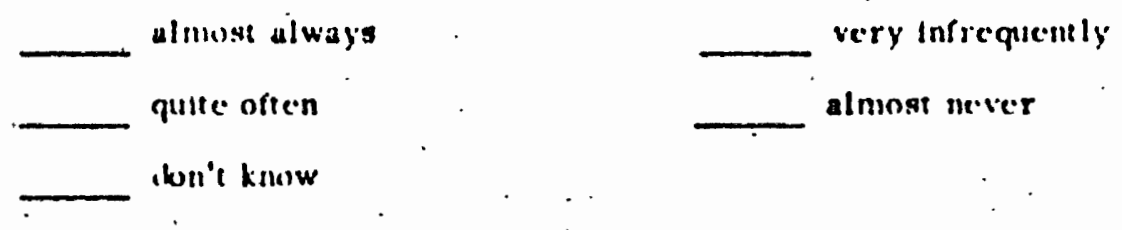

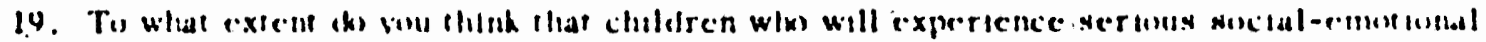

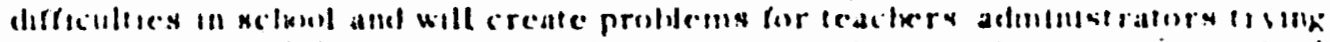

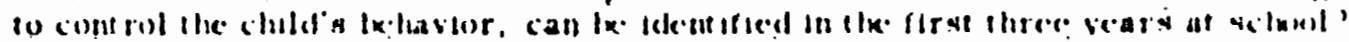
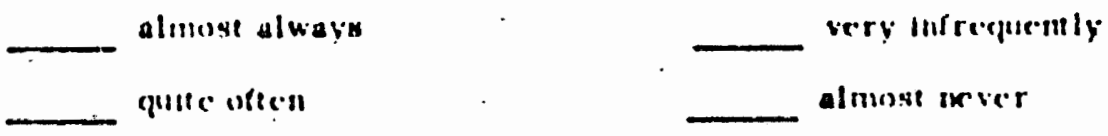

(k)II' hin)w

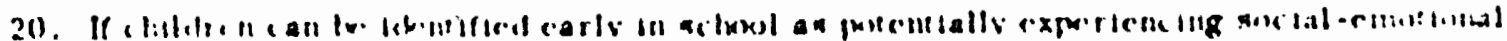

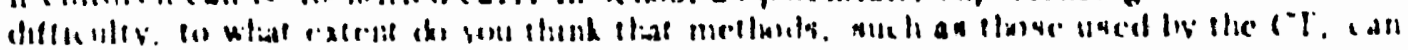

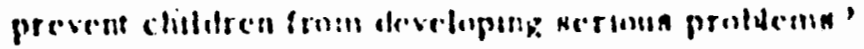

$$
\text { almenat always }
$$

qustc uften very infregurntly

aninge sxier 
21. If a teacher and a CT member have differing philosophies of education. can they work logether effectively, in the classroom?

Yes No Don't know

22. Do you perceive that you and the CT member with whom you work, share the same philosophy of education?
Y Yes
No
Does not apply

23. As a result of your involvement with a CT member, do you feel that you will be better prepared to deal with children experiencing social-emotional difficulties in the classroom?

Yes

No

Does not apply

24. Do you think it's the responsibility of the school to be concerned about childrens' social and emotional experience?
Yes
No
Don't know

25. Can schools teach social and emotional development to and for children?

Yes

No

Don't know

26. If you think schools should and can teach social and emotional growth, do you think these areás should be part of the curriculum?
Yes
No
Don't know

a. Do you think that including a social-emotional approach with the curriculum would have the effect of competing with the academic content of the curriculum?

Yes.

Don't know

b. Do you think that including a social emotional approach within the curriculum would be unrelated to, but provide a complementary support for the academic content of the curriculum?
Yes
No
Don't know

c. Do you think that including a social emotional approach within the curriculum would be accomplished as an on-going continuum, integrated within the academic program?
Yes
No
Dont' know

27. In your opinton, should the Community Team program be continued?

Yes

No

Don't know 


\section{APPENDIX $\mathrm{K}$}

\section{GUIDANCE/EXTRA SERVICES SCREENING}

Co duwn a colly of your cla's llst. Based on yn:ar exix-rience with children and your prolicisionis! judgement, rate casch chlld:

1. The chlld will not tave problems diring hls/her academic career. .

2. You are not ccrtaln alxoul the student's academic future.

3. The chlld t:s having or will thave furure leariling difflculties:

$3 A$ - Atrenclance is a problem. Misses an atverage of $1 / 2$ day a weck or more.

30 - Child llkcly to be dismuxive.

$3 w$ - Child !ikely to be withdrawn.

3L - Chlld likely to hive leaming difflculty.

4. The child is tolented or glited in:

4. 1 Math/science.

4. 2 Visual arts (painting, ccramics, drawing, lllustration, handicrafts, industrtal arts, hone economics, ctc.).

4. 3 Socinl Leacership cant and does nurkedly infuence the behavior of others,

4.4 Lallighage Arts/soctal studics/communication skills.

\subsection{Athletics.}

-5. Stucients rated 3 who are getting remedial or supportive services that are effective :should be marked l'w (= a plan is working). It would thelp if you would indicate what the plan is:

Roturn checked llst to the principal

$$
\begin{aligned}
& \text { SNC = Special Necels Center } \\
& \text { Sp = Speech with therapist } \\
& \text { N = Munterey Reading } \\
& \boldsymbol{T}=\text { Tutoring to build skill or } \\
& \text { self-concept. } \\
& \mathrm{C}=\text { Changed clasises } \\
& T-B=\text { Teacher Stuclent Bela vior } \\
& \text { Contract } \\
& \text { C. } \boldsymbol{T}=\text { Community } \mathrm{T} \times \mathrm{am} \\
& \text { C. T. : Diugnusitlc Tuaclicer }
\end{aligned}
$$


APPENDIX L

IDENTIFIED CHILDREN RATING CHART

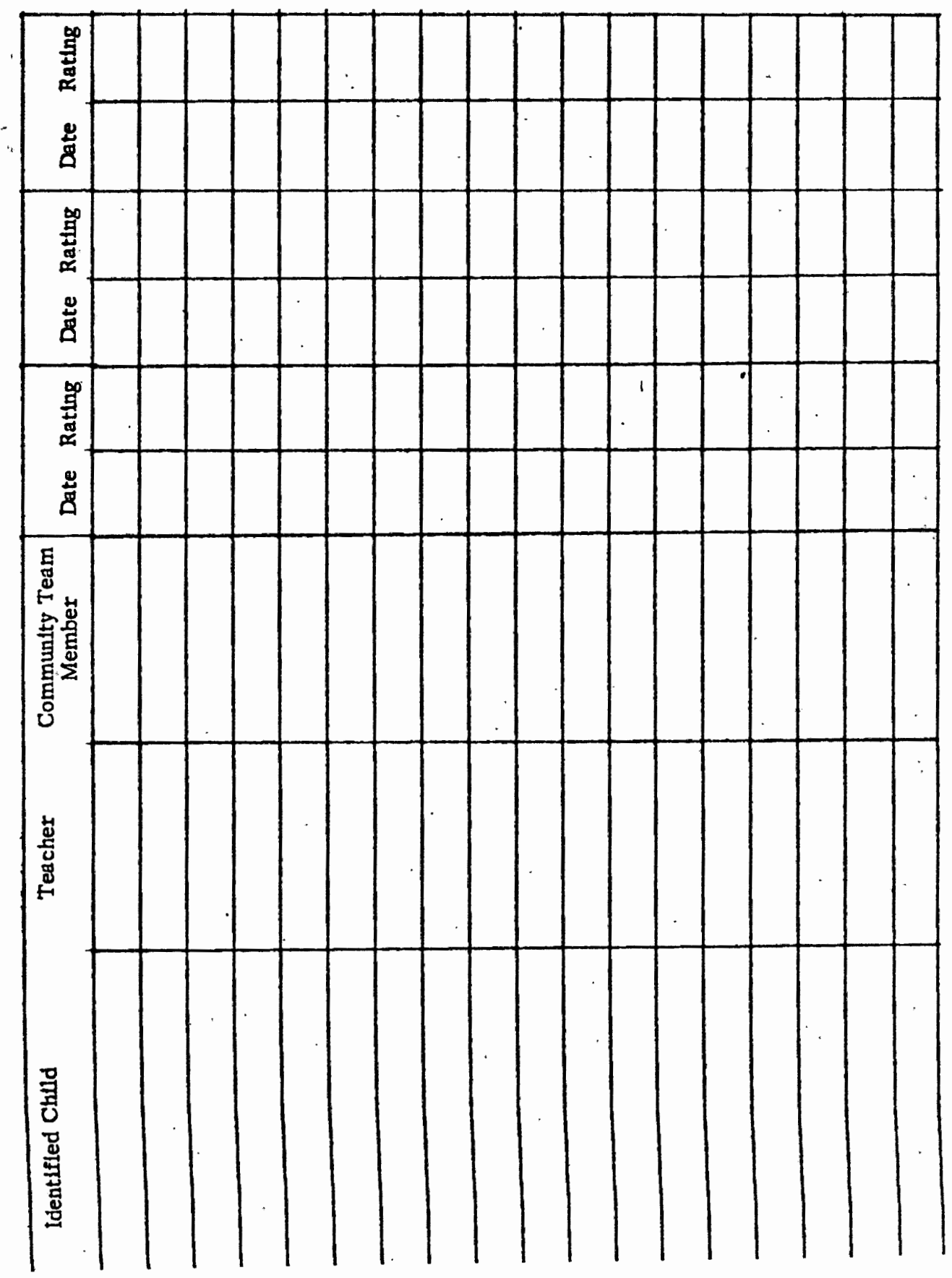

